Materials Science \& Technology Division

CRADA Final Report

For CRADA Number ORNL02-0632

\title{
Development of Stronger and More Reliable Cast Austenitic Stainless Steels (H-Series) Based on Scientific Design Methodology*
}

\author{
G. Muralidharan and V. K. Sikka \\ Oak Ridge National Laboratory \\ R. I. Pankiw \\ Duraloy Technologies, Inc. \\ Date Published - April 2006 \\ Prepared by the \\ OAK RIDGE NATIONAL LABORATORY \\ Oak Ridge, Tennessee 37831 \\ Managed by \\ UT-BATTELLE, LLC \\ For the \\ U.S. Department of Energy \\ Under Contract DE-AC05-000R22725 \\ APPROVED FOR PUBLIC RELEASE \\ UNLIMITED DISTRIBUTION
}

* This work was supported through a CRADA with Duraloy Technologies, Inc., sponsored by the U.S. Department of Energy, Office of Energy Efficiency and Renewable Energy, Industrial Technologies Program, under contract DE-AC05-00OR22725 with UT-Battelle, LLC.

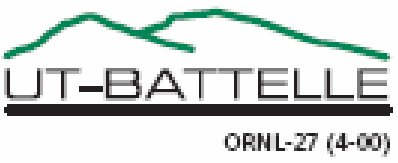




\section{DOCUHEHT AMALABLITY}

Reports produced arter Janury 1, 106, are gonoraly waslabie freo wa to U.S. Copatment of Energy (DCE) Information Eridge.

Whb sibe htpolimwaslgowtrige

Reports produced tefore hrusy 1, 19: ma be purchased ty mambers of the pubils from the followhy woure.

Hutbond Tectrical Information Service

5285 Fort Foys Roud

Springthold, va 22181

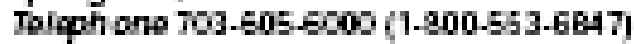

T00 $\mathrm{700}-4 \mathrm{~B} 7-46 \%$

For 702-60-6000

E-misin intosnke rotworligo

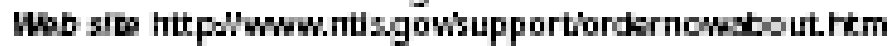

Feports are walable to DoE employes, DCE contrattors, Erergy Tohmology Data Exhange (ETEE) roprosentatiss, and

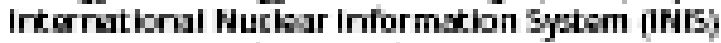

ropresentaws from the following surce.

Grine of Scientilk and Techricaliriommtion

P.O. Eos 62

Oak fidge, TH 37031

Toliph ane 65.5T68401

For $665.576 .5 \mathrm{T2}$

E-moil refortsugdont.osti.goy

Whb sio htpollwwaslgowtorsat.htm

This report wa prepared as an aoount of work aporeored ty an agency of the Untod States Gowrnment. Hather the United state Gowrnmert nor ary agency thereof, nor ary of their emplopes, make ary wiranty oxpes or impled or sosmes ary legal iability or reponsibily for the accuracy, completenes, or ugfures of ary infombton, affuratus, product, or prosess deciosed or represents that its we woud ret hifing privitely owned rights. Fer'orence herein to ary sedift commer dal podut, prooss, or service ty trade name, tademark, manufacture, or otherwse, dow not recosarily constitute or Imply ts andersment, roommentstion, or foworing by the Lhtod state Gowmment or any ageng theroof. The viwe and opinbon of sutors oprosod herdin do not nocesurly state or rerket tose of the United sates cowernment or ary syency thereof. 
C/ORNL02-0632

Materials Science and Technology Division

CRADA Final Report

For CRADA Number ORNL02-0632

\title{
Development of Stronger and More Reliable Cast Austenitic Stainless Steels (H-Series) Based on Scientific Design Methodology*
}

\author{
G. Muralidharan and V. K. Sikka \\ Oak Ridge National Laboratory \\ R. I. Pankiw \\ Duraloy Technologies, Inc. \\ Date Published - April 2006 \\ Prepared by the \\ OAK RIDGE NATIONAL LABORATORY \\ Oak Ridge, Tennessee 37831 \\ Managed by \\ UT-BATTELLE, LLC \\ For the \\ U.S. Department of Energy \\ Under Contract DE-AC05-000R22725 \\ APPROVED FOR PUBLIC RELEASE \\ UNLIMITED DISTRIBUTION
}

* This work was supported through a CRADA with Duraloy Technologies, Inc., sponsored by the U.S. Department of Energy, Office of Energy Efficiency and Renewable Energy, Industrial Technologies Program, under contract DE-AC05-00OR22725 with UT-Battelle, LLC. 


\section{Abstract}

The goal of this program was to increase the high-temperature strength of the H-Series of cast austenitic stainless steels by $50 \%$ and upper use temperature by 86 to $140^{\circ} \mathrm{F}$ (30 to $60^{\circ} \mathrm{C}$ ). Meeting this goal is expected to result in energy savings of 38 trillion Btu/year by 2020 and energy cost savings of $\$ 185$ million/year.

The higher strength H-Series of cast stainless steels (HK and HP type) have applications for the production of ethylene in the chemical industry, for radiant burner tubes and transfer rolls for secondary processing of steel in the steel industry, and for many applications in the heat-treating industry.

The project was led by Duraloy Technologies, Inc. with research participation by the Oak Ridge National Laboratory (ORNL) and industrial participation by a diverse group of companies. Energy Industries of Ohio (EIO) was also a partner in this project. Each team partner had welldefined roles. Duraloy Technologies led the team by identifying the base alloys that were to be improved from this research. Duraloy Technologies also provided an extensive creep data base on current alloys, provided creep-tested specimens of certain commercial alloys, and carried out centrifugal casting and component fabrication of newly designed alloys. Nucor Steel was the first partner company that installed the radiant burner tube assembly in their heat-treating furnace. Other steel companies participated in project review meetings and are currently working with Duraloy Technologies to obtain components of the new alloys. EIO is promoting the enhanced performance of the newly designed alloys to Ohio-based companies. The Timken Company is one of the Ohio companies being promoted by EIO. The project management and coordination plan is shown in Fig. 1.1. A related project at University of Texas-Arlington (UT-A) is described in Development of Semi-Stochastic Algorithm for Optimizing Alloy Composition of HighTemperature Austenitic Stainless Steels (H-Series) for Desired Mechanical and Corrosion Properties (ORNL/TM-2005/81/R1). The final report on another related project at the University of Tennessee by George Pharr, Easo George, and Michael Santella has been published as Development of Combinatorial Methods for Alloy Design and Optimization (ORNL/TM-2005133).

The goal of the project was to increase the high-temperature strength by $50 \%$ and upper use temperature by 86 to $140^{\circ} \mathrm{F}$ ( 30 to $60^{\circ} \mathrm{C}$ ) of H-Series of cast austenitic stainless steels. Meeting such a goal is expected to result in energy savings of 38 trillion Btu/year by 2020 and energy cost savings of \$185 million/year.

The goal of the project was achieved by using the alloy design methods developed at ORNL, based on precise microcharacterization and identification of critical microstructure/properties relationships and combining them with the modern computational science-based tools that calculate phases, phase fractions, and phase compositions based on alloy compositions. The combined approach of microcharacterization of phases and computational phase prediction would permit rapid improvement of the current alloy composition of an alloy and provide the long-term benefit of customizing alloys within grades for specific applications. 


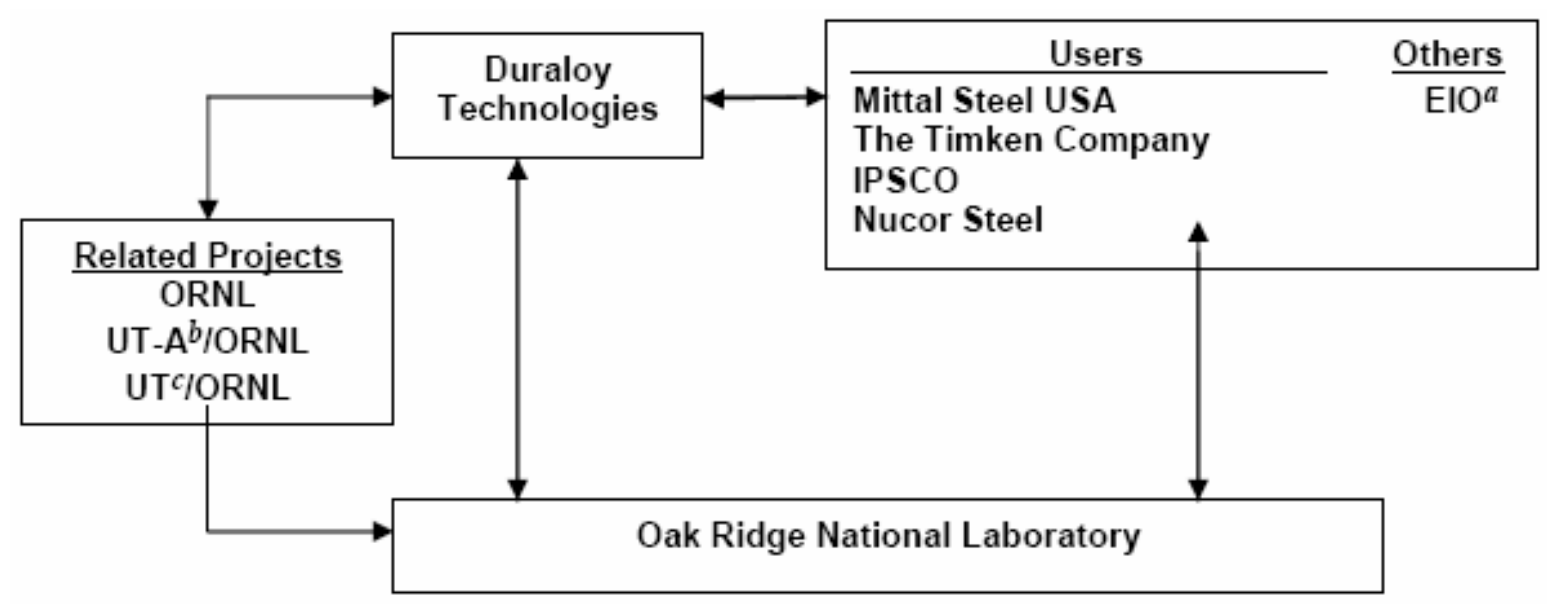

${ }^{a}$ Represents Energy Industries of Ohio's steel, chemical, and heat-treating industries.

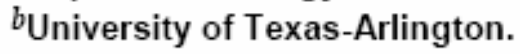

cUniversity of Tennessee.

Figure 1.1: Organization plan for project coordination and management.

The project was appropriate for the domestic industry because the current H-Series alloys have reached their limits both in high-temperature-strength properties and in upper use temperature. The desire of Duraloy's industrial customers to improve process efficiency, while reducing cost, requires that the current alloys be taken to the next level of strength and that the upper use temperature limit be increased.

This project addressed a specific topic from the subject call: to develop materials for manufacturing processes that will increase high-temperature strength, fatigue resistance, corrosion, and wear resistance. The outcome of the project would benefit manufacturing processes in the chemical, steel, and heat-treating industries.

\section{Statement of Objectives}

The goal of this program was to increase the high-temperature strength of the H-Series of cast austenitic stainless steels by $50 \%$ and upper use temperature by 86 to $140^{\circ} \mathrm{F}$ ( 30 to $60^{\circ} \mathrm{C}$ ). Meeting this goal is expected to result in energy savings of 38 trillion Btu/year by 2020 and energy cost savings of $\$ 185$ million/year.

The project goals were achieved through a unique approach consisting of the following steps:

1. Conduct computational thermodynamic and kinetic modeling to identify the phases in cast compositions of $\mathrm{HK}$ and $\mathrm{HP}$ (Fe-25Cr-25Ni and $\mathrm{Fe}-25-35 \mathrm{Ni}$ ) steels as a function of temperature.

2. Conduct microstructural characterization of phases present in HK and HP steels and compare results with calculated values to radiate the output of computational models.

3. Develop correlations between creep properties and weight percentage of phases in commercially used compositions of HK and HP steels. 
4. Based on correlation of creep properties, identify weight percentage of phases required to meet the project objective.

5. Use computational thermodynamic modeling to identify new compositions of HK and HP steels that are expected to meet the creep strength requirements.

6. Produce experimental size heats of newly identified compositions of HK and HP steels.

7. Conduct creep tests on new compositions to validate the predicted creep properties.

8. Produce radiant burner tubes of newly identified compositions of HP alloy and test their performance in production furnace environments.

\section{Benefits to the Funding DOE Office's Mission}

The mission of the Department of Energy (DOE) - Industrial Technologies Program (ITP) program is to identify the manufacturing industry that uses and wastes most energy. Among the industries identified by DOE-ITP are aluminum, steel, chemical, petrochemical, metal casting, heat treating, and forging. In most cases, energy is wasted because of a lack of continued longterm availability of manufacturing equipment. In some cases, water-cooled components are needed to carry out a process. There are some operations where efficiency can be approved if the operations can be carried out at higher temperatures. The lack of materials that perform under commercial production conditions is a major source of energy inefficiencies that result from either not being able to run long production campaigns or require using water cooling. This project addressed the very important need of developing materials that resulted in nearly double the creep strength of current material and increase their maximum operating temperature by 86 to $140^{\circ} \mathrm{F}\left(30\right.$ to $\left.60^{\circ} \mathrm{C}\right)$.

\section{Technical Discussion of Work Performed by All Parties}

There has been some Japanese and European effort to better understand the behavior of existing cast austenitic stainless alloys and develop improved alloys in the late 1980s and through the 1990s, but there is not great penetration of such experimental alloys into the commercial markets. In the late 1990s, the Japanese (mainly through NRIM) and European (mainly the COST programs) governments have initiated large research efforts aimed at helping industry improve existing metals and alloys. The Japanese in particular are devoting large efforts to provide data bases on extremely long-term aging or service exposure $(>100,000 \mathrm{~h})$ of stainless steels and alloys and nickel-based superalloys to enable computational science (thermodynamic or microstructural modeling) to provide a more scientific basis for designing new alloys.

Alloy development of complex engineering alloys based on single or multiple alloying element additions or changes over wide ranges can often be very labor intensive, time-consuming, and costly. Usually such traditional brute-force efforts produce only modest incremental improvements, and then such improvements must be further verified by testing relevant to realtime component service. Therefore, most applications engineers attempt to redesign components or to solve their materials problems by selecting alternate materials, and they only turn to traditional alloy development as a last resort. In the mid-1980s, a far more scientific and yet practical method of precise microstructural analysis and identification of the degradation/failure mechanisms was devised at ORNL to improve the creep-resistance of 300-series austenitic stainless steels at 1300 to $1470^{\circ} \mathrm{F}\left(700\right.$ to $\left.800^{\circ} \mathrm{C}\right)$ [1,2]. This method provided a framework for 
translating various single or combined alloying element effects directly into their effects on precipitation behavior or stability of the parent matrix phase (austenite).

The native microstructure established in fully-austenitic HK-40 and HP alloys consists of dendritic structures of austenite matrix with finer dispersions of carbides (Cr-rich $\mathrm{M}_{23} \mathrm{C}_{6}$ or Nbrich $\mathrm{MC}$, depending on the alloy) and heavier clusters of $\mathrm{NbC}$ in the interdendritic regions (last liquid to solidify) and dispersions of $\mathrm{M}_{23} \mathrm{C}_{6}$ along the seams between colonies of dendrites (dendrite cores in a given colony are all parallel to $<100>$ ). Aging effects can vary, with little deleterious effects above 1740 to $1830^{\circ} \mathrm{F}\left(950\right.$ to $\left.1000^{\circ} \mathrm{C}\right)$, particularly in the modified HP alloys, but with potential embrittlement (severe ductility loss at ambient temperatures) due to $\mathrm{M}_{23} \mathrm{C}_{6}$ films and/or sigma phase formation during prolonged exposure below $1650^{\circ} \mathrm{F}\left(900^{\circ} \mathrm{C}\right)$, mainly in the HK-40 type alloy. Additions of cobalt are made mainly to strengthen and stabilize the austenite matrix phase, while additions of tungsten promote solid solution strengthening as well as WC formation. Figure 4.1 shows the rupture strengths of these various alloys as a function of temperature typical of applications as tubing in ethylene pyrolysis furnaces. Ethylene cracking and radiant furnace tubes generally involve prolonged exposure at relatively steady temperatures, where creep-resistance and oxidation/corrosion resistance are the life-defining properties. However, materials processing applications of such alloys (mainly HK-40), including coiling drums of Steckel Mills and retorts for calcining, involve more than just creep-strength and must also include thermal fatigue resistance to prevent surface cracking (critical for coiling drums) or catastrophic through-section fracture (for retorts). While one can possibly use the more expensive chemical/petrochemical premium alloys for such materials processing equipment applications, the materials processing industries would probably be better served by improving the strength and aging resistance of the standard HK-40 grade steel to provide a more costeffective solution.

When this scientific knowledge of how to stabilize desirable phases and reduce or eliminate undesirable phases was coupled with a thorough knowledge of microstructure/properties relationships and failure mechanism, precise microstructures were designed that produced outstanding long-term creep-resistance the first time those modified stainless steels and alloys were made [3,4]. The alloying addition effects were classified as: (a) direct reactant effects (i.e., $\mathrm{Nb}+\mathrm{C}=\mathrm{NbC}$ ); (b) catalytic effects (i.e., solutes that enhance the formation of a phase even though they are not direct reactants, like silicon enhancing the formation of Fe2Mo Laves phase or boron enhancing the formation of $\mathrm{TiC}$ or $\mathrm{M}_{23} \mathrm{C}_{6}$ carbides); (c) inhibitor effects (i.e., solutes that retard or prevent the formation of particular precipitate phases, like $\mathrm{C}, \mathrm{B}$, and $\mathrm{P}$ retarding or preventing the formation of intermetallic phases like sigma, chi, or Laves); and (d) interference effects (i.e., two or more phases competing for the same element to decouple or simplify phase behavior and control in complex alloys). 


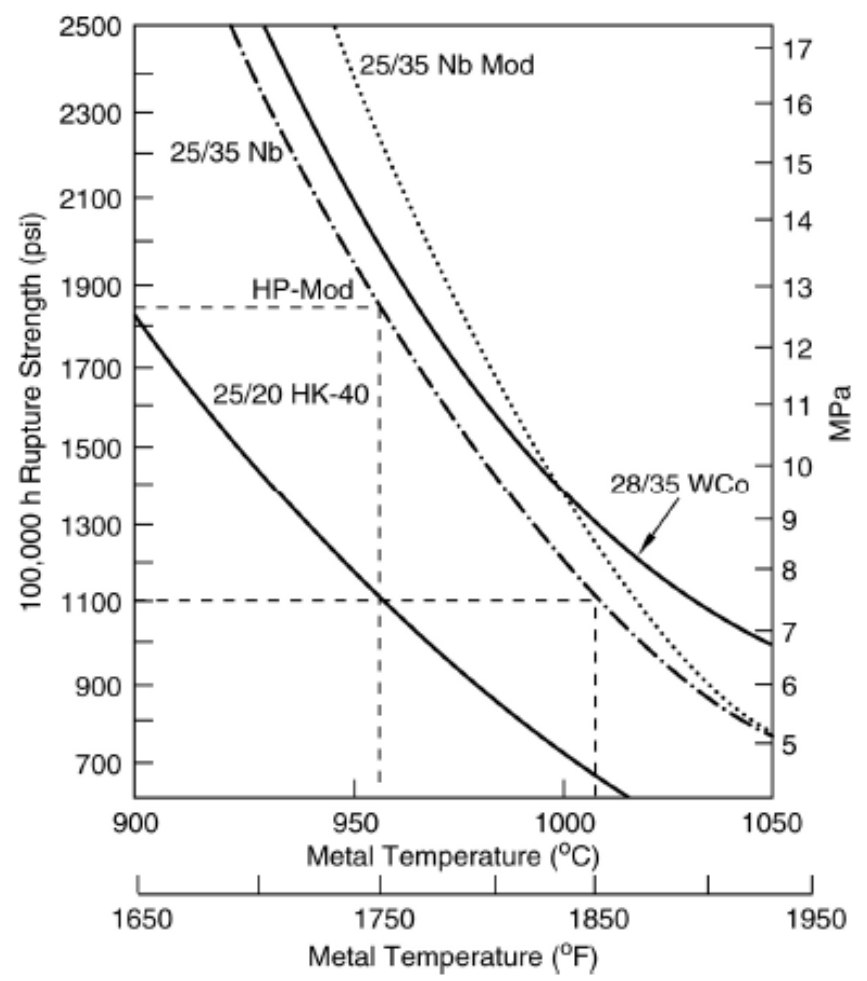

Figure 4.1: Rupture strength of various $\mathrm{H}$-Series steel modifications as a function of temperature.

Some of the microstructural effects controlled to create extremely long-term creep-rupture resistance include: (a) eliminate creep voids, (b) promote fine dispersions of MC carbides, (c) prevent dissolution or coarsening of fine MC carbides, (d) delay or prevent the formation of embrittling grain-boundary intermetallic phases, and (e) prevent dislocation recovery or recrystallization (mainly for wrought alloys).

This alloy design methodology produced improved modified type 316 austenitic stainless steels and modified $800 \mathrm{H}$ austenitic stainless alloys for heat-exchanger tubing applications in fossil power plants that clearly outperformed the best commercially available comparable alloys today [5]. This alloy design method was recently adapted to producing a modified 803 austenitic stainless alloy with improved creep-rupture resistance at $1500^{\circ} \mathrm{F}\left(816^{\circ} \mathrm{C}\right)$ [5].

Finally, this alloy development method was recently applied to developing cast austenitic stainless steels with improved creep-resistance at 1300 to $1650^{\circ} \mathrm{F}$ (700 to $900^{\circ} \mathrm{C}$ ) for critical exhaust component applications (manifolds and turbocharger casings) in advanced diesel engines [6]. Figure 4.2 shows the enhanced creep performance for new alloys as compared to the commercial cast alloy CF8C. The project was funded at ORNL by Caterpillar. This last example clearly demonstrates that focused, meaningful alloy development can be accomplished in 1.5 to 2.5 years, in contrast to the traditional methods, and formed the background and basis for this proposal. 


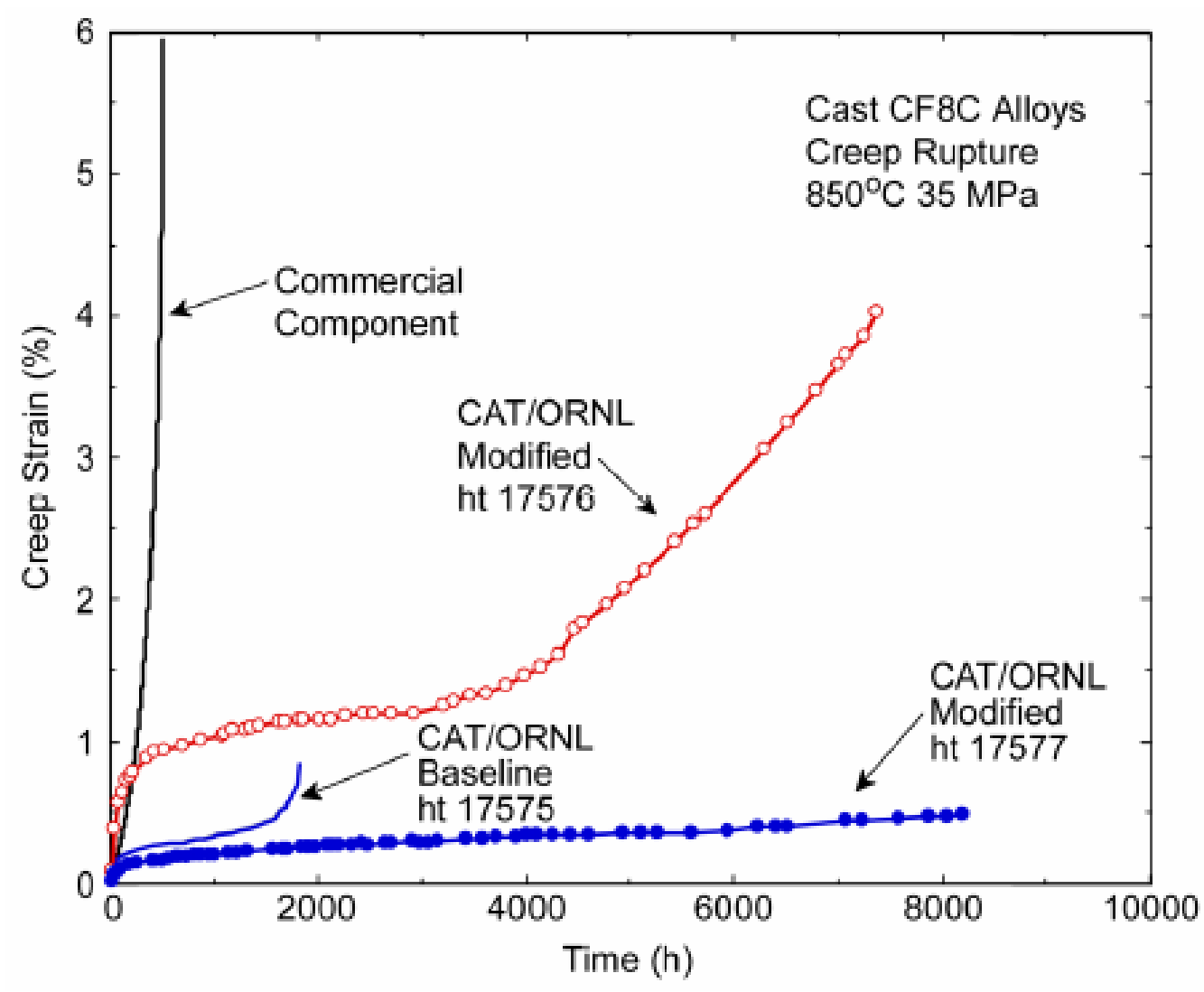

Figure 4.2: Comparison of creep strain versus time for standard commercial and modified cast CF8C (Fe-19Cr-12Ni-Nb,C) austenitic stainless steel by the proposed concept. Nearly an order of magnitude improvement in creep strength was achieved.

In the current project, the above-described approach was complimented by the computational capability of identifying the microstructural evolution at operating temperature as a function of time.

This project was aimed at meeting the above identified needs. More specifically, the project goal was to increase the high-temperature strength by $50 \%$ and the upper use temperature by 86 to $140^{\circ} \mathrm{F}\left(30\right.$ to $60^{\circ} \mathrm{C}$ ) of $\mathrm{H}$-Series of cast austenitic steel by using computational alloy design and microstructural characterization.

The goals of the project were met by the following approach:

The overall project approach can be summarized using the diagram shown in Fig. 4.3. In the first phase of the project, results on phase stability and volume fraction of phases obtained through thermodynamic and kinetic modeling were compared with the actual microstructure observed through microstructural characterization of selected existing H-Series alloys [7-11]. Alloys selected for this study represented a wide range in creep properties. Correlations between the microstructure and creep properties were established in this phase. Using these correlations, microstructures that would be needed to achieve alloys with improved properties were identified, and criteria for such microstructures were established. 


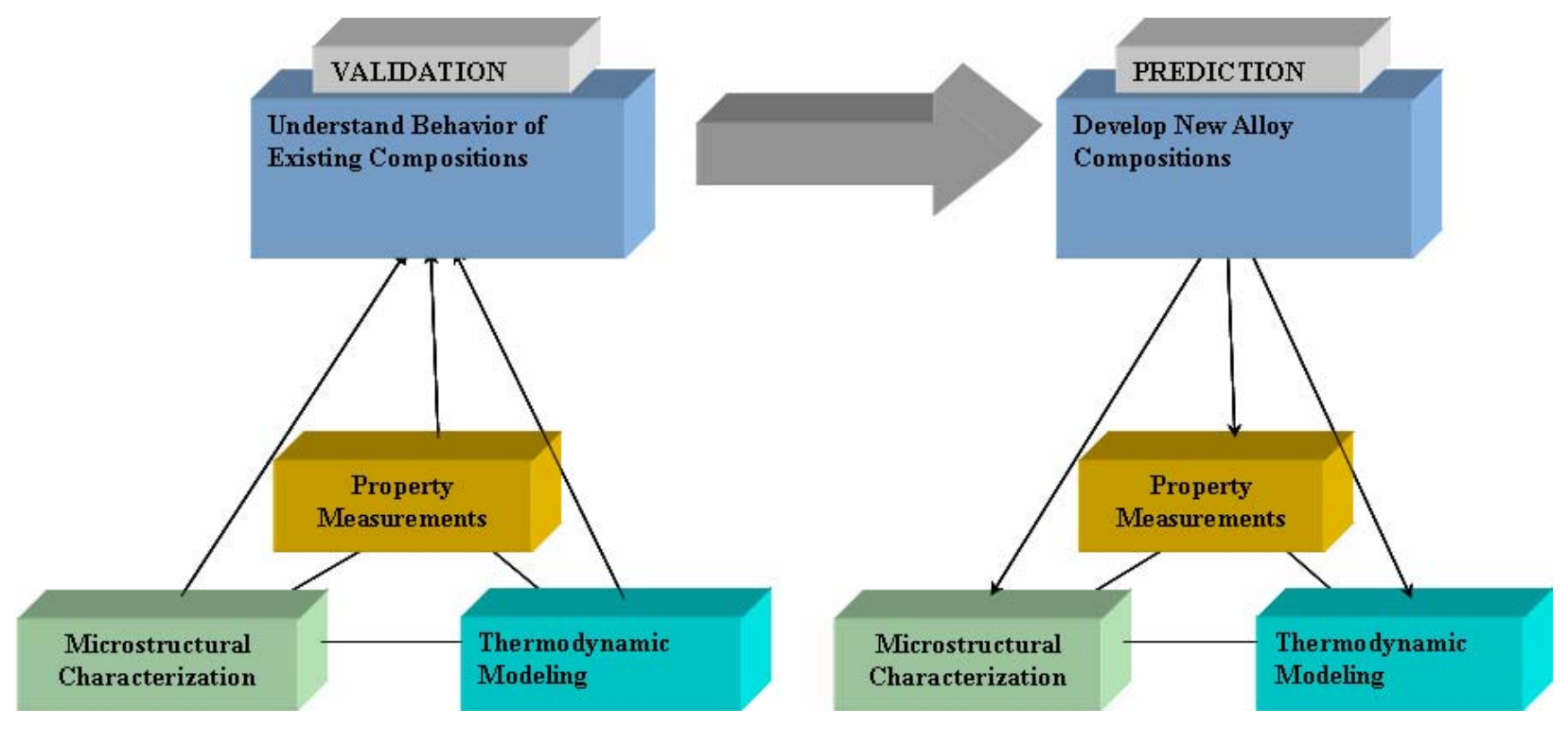

Figure 4.3: Schematic of the overall approach adopted in the project with Duraloy Technologies, Inc.

In the second phase of the work, thermodynamic calculations were used to sample composition space and identify alloy compositions that would satisfy the desired microstructure criteria. Alloys of compositions that could potentially have improved properties were prepared on laboratory scale, and their creep properties were measured. Information obtained from the microstructure-property correlation was used to refine the existing relationships, and a new generation of alloys was identified. Alloy compositions with improved properties were identified in this work and are outlined later in the report.

The following tasks were performed to accomplish the objectives of this project:

Task 1. Computational Thermodynamic Analysis of Various Phases in HK and HP Modified $\underline{\text { Steel }}$

Subtask 1.1. ThermoCalc ${ }^{\mathrm{TM}}$ analysis of phases for current HK and HP modified compositions in the cast, aged, and removed from service conditions

Subtask 1.2. ThermoCalc ${ }^{\mathrm{TM}}$ analysis of newly identified modifications of HK and HP modified compositions in the cast and aged conditions

Subtask 1.3. Refining the ThermoCalc ${ }^{\mathrm{TM}}$ analysis to incorporate the cooling rates observed during the centrifugal and static castings

Task 2. Microcharacterization of Specimens of HK and HP Modified for Verification of Computational Models and Correlation with Mechanical Properties

Subtask 2.1. Microcharacterization analysis for current HK and HP modified compositions in the cast, aged, and removed from service conditions 
Subtask 2.2. Correlate the microstructural analysis with mechanical properties

Subtask 2.3. Identify new compositions of improved strength and thermal stability based on verified computational analysis and microstructural/mechanical property correlation

Task 3. Cast Experimental Size Heats of New Compositions Developed Based on Tasks 1 and 2 and Determine Their Mechanical Properties

Subtask 3.1. Melt 20-lb heats and cast into 1- × 4- × 6-in. slabs

Subtask 3.2. Conduct stress relaxation tests on cast compositions

Subtask 3.3. Conduct detailed mechanical properties testing of selected compositions

Subtask 3.4. Correlate mechanical properties with microstructure

Task 4. Centrifugal and Static Casting of Selected Compositions

Subtask 4.1. Melt 500-lb heats and make centrifugal and static castings

Subtask 4.2. Conduct mechanical properties on centrifugal and static castings poured from 500-lb heats

Task 5. Develop an Alloy Property/Composition Predicting Software Tool for Commercial Applications

Subtask 5.1. Develop all correlation of properties with microstructural features and the alloy compositions

Subtask 5.2. Develop user-friendly software that captures the property/composition correlation for $\mathrm{H}$-Series stainless steels with predicting capabilities

\section{Task 6. Fabricate Prototype Components}

Subtask 6.1. Cast tubes and other accessories needed to fabricate prototype components

Subtask 6.2. Fabricate prototype components through machining and welding operations

Subtask 6.3. Complete installation of the prototype components in various production applications

Task 7. Meetings and Technical Reports

Subtask 7.1. Hold at least two technical meetings per year

Subtask 7.2. Complete final report 


\subsection{Potential Applications and Impacts Target Industries and Magnitude of Potential Energy Savings}

All of the applications where HK and HP grades are currently used can be replaced by the higher strength versions of the same grades developed during this project. The newly developed HP grade can also replace Supertherm ${ }^{\mathrm{TM}}$, a commercial higher strength version of HP grade that contains expensive elements such as cobalt and nickel up to $15 \%$ by weight.

The most significant applications of the newly developed HK and HP grades are expected in the following three areas:

1. Chemical Industry: Furnace tubes for hydrogen reforming applications. Based on input from Air Products [12], an increase in $40^{\circ} \mathrm{F}\left(4^{\circ} \mathrm{C}\right)$ of hydrogen reforming furnace tubes results in a $3 \mathrm{Btu} / \mathrm{scf}$ of hydrogen produced. The United States uses [13] $9 \times 10^{6}$ tons of hydrogen/year that is produced by steam reforming process. The $9 \times 10^{6}$ tons of hydrogen converts to $3.23 \times$ $10^{12} \mathrm{scf}$ of hydrogen. Thus, by using a savings of $3 \mathrm{Btu} / \mathrm{scf}$ of hydrogen, a total savings of 9.7 trillion Btu/year is projected for use of HP grade of newly developed steels in the hydrogen reforming process furnaces.

2. Steel Industry - Steel Reheating Furnaces: The high-strength HP grade has the potential for replacing water-cooled transfer rolls that are currently used for reheating thin slab casting for in-line hot-rolling. The thin slab casting and its on-line hot rolling requires that the slab exiting from the continuous caster be reheated to desired temperatures at rates corresponding to the rates at which the slab is moving. To achieve such rates, reheating or tunnel furnaces are designed to deliver high heat fluxes by operating at very high temperatures. Inside of the furnaces consist typically of 100 rolls that support the slab while it moves through the furnace. Because of lack of availability of high-strength materials, the furnace rolls are water cooled, which requires a complex roll design. For the water-cooled rolls, there is a constant need for heat (more gas consumption) to off-set the natural furnace cooling created by the watercooled design (made even worse as refractory fails). The uncooled rolls on the other hand stabilize at furnace temperature. Nucor Steel, Crawfordsville, documented a 25\% decrease in gas consumption upon installation of the first 60 uncooled rolls that replaced water-cooled (from 0.5 million Btu/ton of steel to 0.375 million Btu/ton of steel) (private communication with Dan Miller of Duraloy Technologies-email report dated September 26, 2005 entitled "Dry Tunnel Furnace Rolls"). Furnace operating temperatures for certain regions of the furnace are so high that even newly designed higher strength alloys will not be capable of operating in the uncooled condition. Assuming that the rolls from the high-strength H-Series steel composition developed, based on computational alloy design, will permit the replacement of 80 of the 100 rolls in a steel reheating furnace; the energy use for the uncooled rolls will be $0.5-(0.5-0.375) * 80 / 60=0.333$ million Btu/ton of steel. This results in an energy savings of 0.5 to $0.333=0.167$ million Btu/ton of steel. Table 4.1 lists all of the steel mills in the United States that have tunnel furnaces with water-cooled rolls. This table also shows the steel tonnage that each of the steel mills produces and the number of furnaces (lines) that each mill has. Based on this, it is estimated that energy savings would total 14.75 million tons/year $\times 0.167$ million Btu/ton $=2.46$ trillion Btu/year. 
Table 4.1. Steel Plants that use Tunnel Furnace with Water-Cooled Rolls

\begin{tabular}{|l|l|c|c|}
\hline \multicolumn{1}{|c|}{ Steel Plant } & \multicolumn{1}{c|}{ Location } & Number of Lines & Capacity (million tons) \\
\hline ACME & Chicago, Illinois & 1 & 1.6 \\
\hline BHP - Northstar & Delta, Ohio & 1 & 1.5 \\
\hline Gallatin & Ghent, Kentucky & 2 & 2.0 \\
\hline Nucor-Berkeley & Huger, South Carolina & 2 & 2.0 \\
\hline Nucor-Crawfordsville & Crawfordsville, Indiana & 2 & 2.0 \\
\hline Nucor-Decatur & Decatur, Alabama & 2 & 2.0 \\
\hline Nucor-Hickman & Armorel, Arkansas & 2 & 2.0 \\
\hline Steel Dynamics & Fort Wayne, Indiana & 2 & $\mathbf{1 4 . 8}$ \\
\hline Total Tonnage & & & \\
\hline
\end{tabular}

In addition to energy savings listed above, there is a possibility of significant savings in electric energy that is used to deliver the water for cooling of rolls. The energy savings will come from the elimination of pumps, motors, valves, heat exchangers or cooling towers.

3. Heat-Treating Industry: The major applications of the newly developed HP steels in the heattreating industry are for radiant burner tubes. The higher strength of the HP steel from this project will allow higher operating temperature of the radiant burner tubes with increased heat flux and thereby higher heating efficiency. Heat-treating facilities [14] in the United States operate roughly 55,000 furnaces, $66 \%$ of which are gas-fired and 33\% are electrically heated. These furnaces use a total of 458 trillion Btu of energy per year, of which 337 trillion Btu are natural gas, and 121 trillion Btu is electric.

The higher strength radiant burner tube increases the energy savings in two ways: (1) higher operating temperature will increase heat flux and thus heating efficiency, and (2) longer life of the radiant burner tubes because of their higher creep strength. A $1 \%$ savings in energy by the use of radiant burner tubes of the new HP steels would result in a natural gas energy savings of $1 \%$ of 337 trillion Btu/year or 3.37 trillion Btu/year.

The energy savings are also anticipated through the following:

1. Use of higher strength HP grade in ethylene furnace application with possibility for higher operating temperature. Note that to minimize coking, the tube's inner surface will need to be lined with anti-coking material such as ORNL-developed alloy 4 or a weld overlay with aluminum.

2. Use of HK and HP grades for plate transfer rolls in certain steel austenitizing furnaces.

3. Use of higher strength HP grade for trays and fixtures for carburizing furnaces.

Based on the above discussion, a total energy savings of 15.6 trillion Btu/year is expected to be easily achievable between 2015 and 2020. The balance of the energy savings will result as new alloys find applications in the heat-treating and chemical industries. 


\subsection{Domestic Technology Status Including Emerging Technologies}

To our knowledge, there is no similar effort underway in the United States in using computational modeling in the design of H-Series stainless steels.

\subsection{Results and Discussion}

The most important result from this project was the development of a computational method for designing a high-strength low-cost version of cast austenitic stainless steels of standard grades known as HK and HP steels. The computational models were validated in three ways: (1) microstructural phase analysis, (2) creep testing, and (3) production and testing of radiant burner tubes in production furnace environments.

The results of the study are present in three major sections:

1. Study of existing commercial H-Series alloys,

2. Study of a new generation of ORNL alloys, and

3. Development of new advanced alloys.

\subsubsection{Study of Existing Commercial H-Series Alloys}

Although a wide range of $\mathrm{H}$-Series alloys are commercially available, this study focused primarily on HP (Fe-25Cr-35Ni) and HK (Fe-25Cr-25Ni) series alloys. As a part of this study, it was necessary to evaluate the ability of existing thermodynamic databases to predict the microstructure of the alloys and to assess the role of microstructure in determining the creep properties of the alloys. Detailed microstructural characterization was performed on selected $\mathrm{H}$ Series alloys, and the ability of thermodynamic calculations to predict the observed microstructure was evaluated using qualitative and quantitative comparisons $[15,16]$. Results of this work showed that there was a good qualitative agreement between the microstructures of commercial alloys and thermodynamic calculations. Although some discrepancies were observed between quantitative assessments of microstructure and thermodynamic calculations, the overall agreement was reasonable considering the approximations used in performing these comparisons. In the following pages, we present the details of the analyses.

4.3.1.1 Down-selection of Existing Commercial H-Series Alloys: Figure 4.4 shows the creep rupture life of selected commercially available H-Series alloys at $1800^{\circ} \mathrm{F}\left(982^{\circ} \mathrm{C}\right)$ and stresses of 3 and $4 \mathrm{ksi}$ as measured in this project. Note that the creep rupture life varies over a wide range (from less than 100 to $1800 \mathrm{~h}$ ) depending on the composition of the alloys. To understand the role of microstructure in the creep properties of these alloys, it was decided that two alloys with widely different creep properties would be selected and the microstructure of these alloys would be examined. Alloy 3 has the lowest creep rupture life, while alloy 2 has the highest creep rupture life amongst the alloys shown in Fig. 4.4. It was envisaged that the study of these two alloys with widely different properties would reveal significant differences in microstructure and outline desirable and undesirable microstructures. Alloys 2 and 3 were thus selected for detailed study of the relationship between the microstructure and creep properties at $1800^{\circ} \mathrm{F}\left(982^{\circ} \mathrm{C}\right)$. 


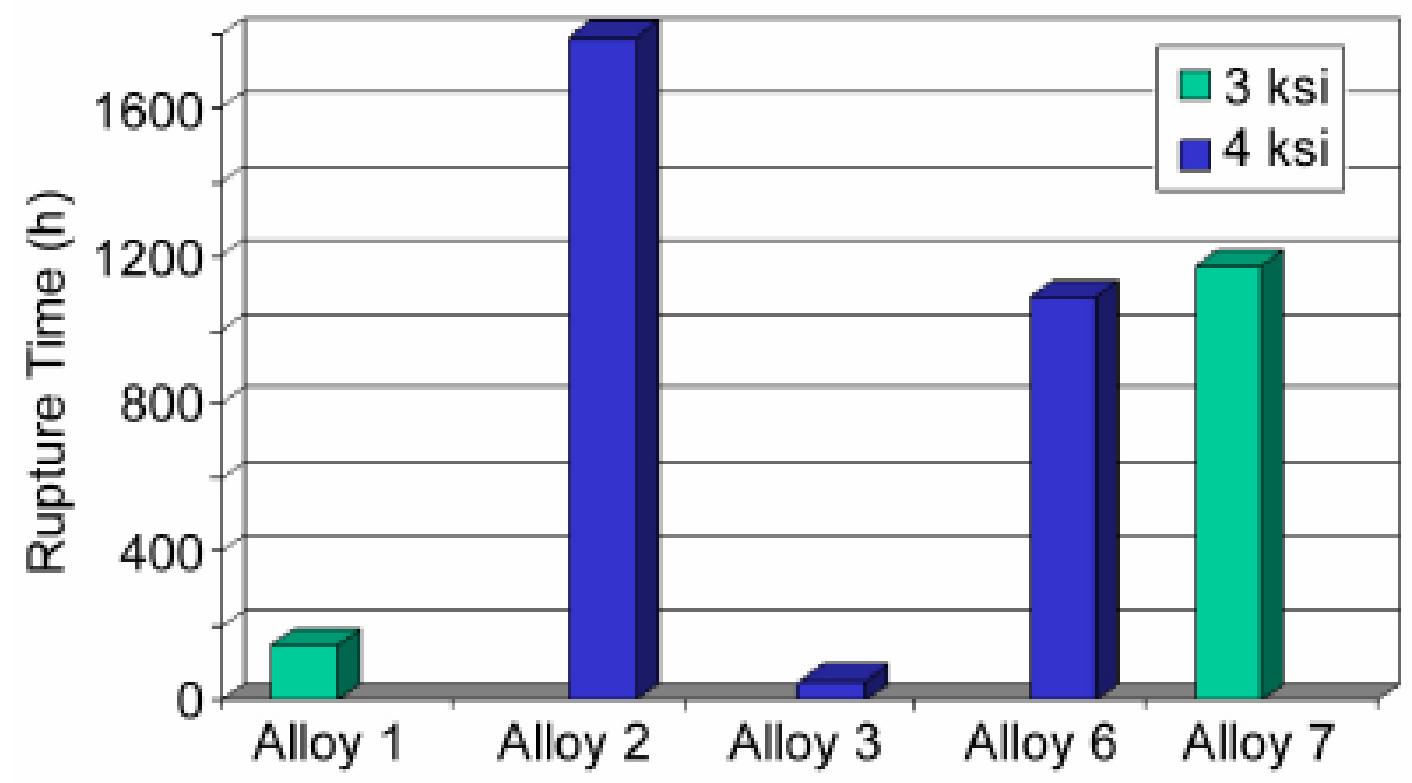

Figure 4.4: Creep rupture life of six selected commercial $\mathrm{H}$-Series alloys at $1800^{\circ} \mathrm{F}\left(982^{\circ} \mathrm{C}\right)$.

4.3.1.2 Thermodynamic Calculations of $\mathbf{H}$-Series Alloys 2 and 3: Figure 4.5 shows results of thermodynamic calculations of the two selected alloys obtained using JMatPro. Figures 4.5(a) and (b) show the stability of various phases as a function of temperature in these alloys. In addition to the austenitic matrix, calculations show that three types of carbides- $\mathrm{M}_{23} \mathrm{C}_{6}, \mathrm{M}_{7} \mathrm{C}_{3}$, and MC can be stable in alloy 2. However in alloy 3 only M7C3and MC-type carbides are predicted to be stable with no $\mathrm{M}_{23} \mathrm{C}_{6}$-type carbides being present in the alloy at any temperature. Detailed microstructural characterization was necessary to verify the results of these thermodynamic calculations and the results are presented below.
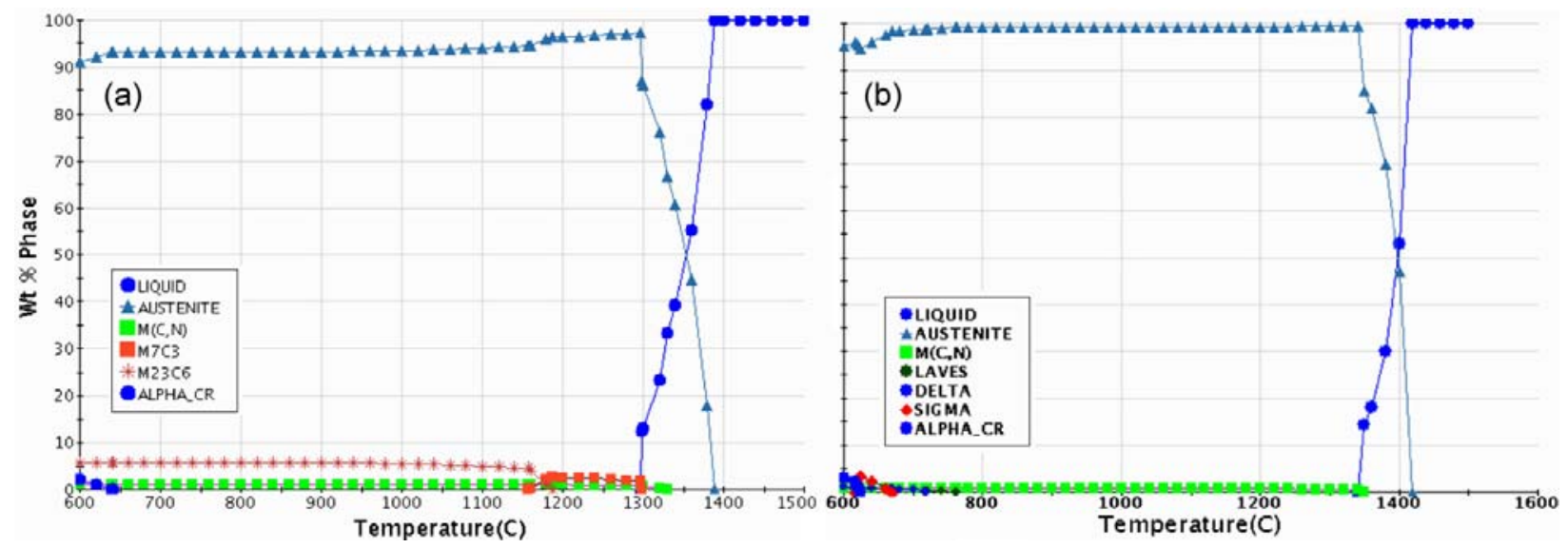

Figure 4.5: Thermodynamic calculations using JMatPro predict differences in carbide precipitation between (a) alloy 2 and (b) alloy 3. 
4.3.1.3 Microstructural Characterization of Alloys 2 and 3 and Validation of Thermodynamic Modeling: Figure 4.6 shows optical microscope images of specimens from alloys 2 and 3 . The specimens were obtained from creep specimens exposed to $1800^{\circ} \mathrm{F}\left(982^{\circ} \mathrm{C}\right)$ but away from the region of failure. Note that specimens obtained from alloy 2 show a higher density of precipitates when compared to alloy 3 , which is the first major difference observed in the microstructure of the two alloys with widely different properties.

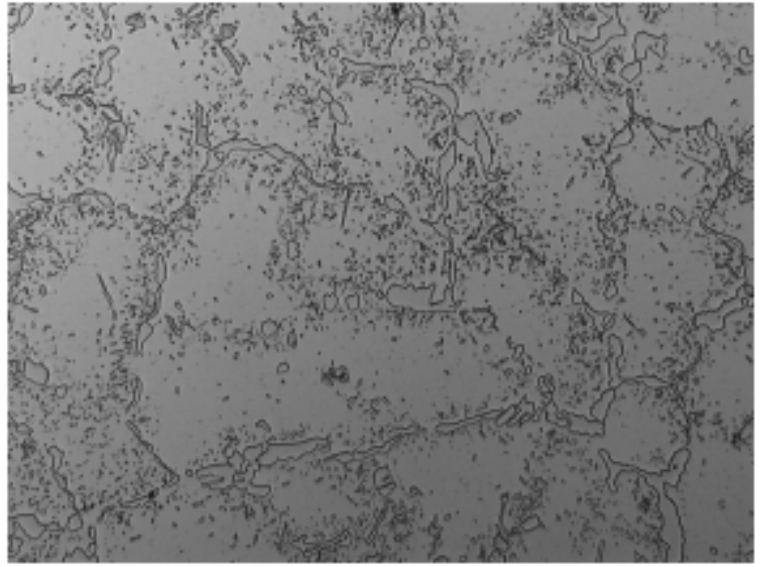

(a)

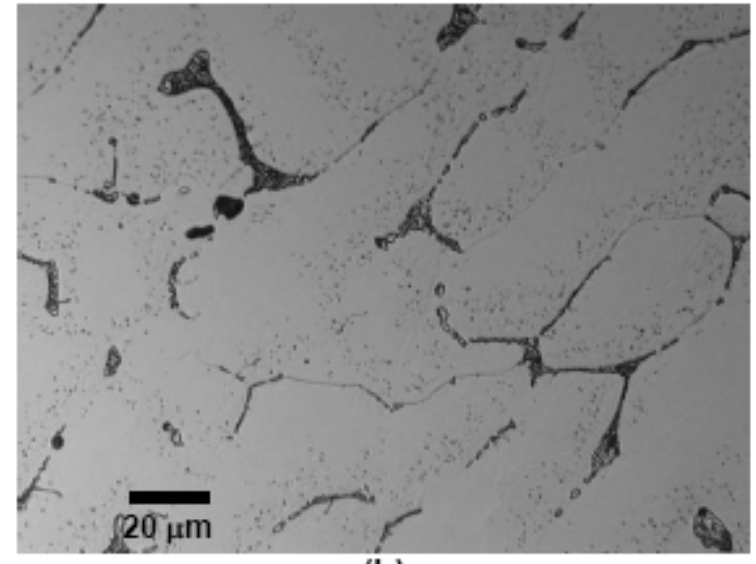

(b)

Figure 4.6: Optical microscopy images of (a) alloy 2 and (b) alloy 3 after creep testing at $1^{1800^{\circ}} \mathrm{F}\left(982^{\circ} \mathrm{C}\right)$ showing more precipitation in alloy 2 than in alloy 3.

Figure 4.7 shows a comparison between the optical microscope image and a back-scattered scanning electron microscope (SEM) image from alloy 2. Note that at least two different types of phases with different contrasts can be observed in these samples in addition to the austenitic matrix. Detailed energy dispersive $\mathrm{x}$-ray analysis (Fig. 4.8) shows that the darker phase is $\mathrm{M}_{23} \mathrm{C}_{6^{-}}$ type carbide, while the brighter phase is MC-type carbide rich in niobium.

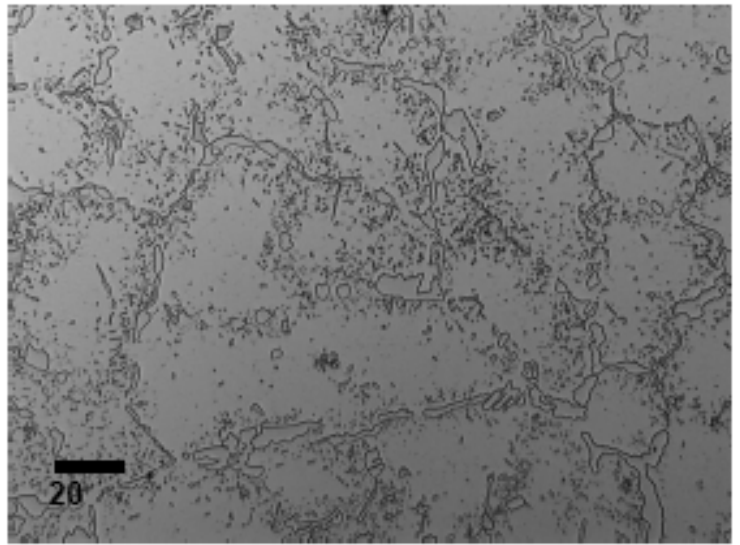

(a)

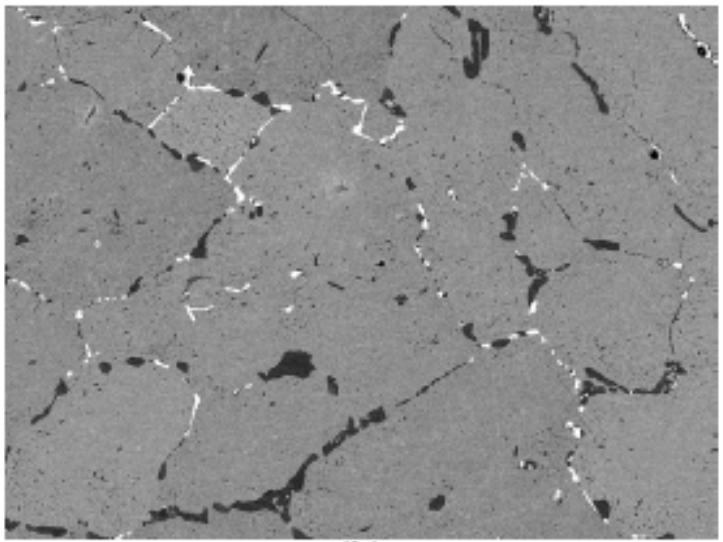

(b)

Figure 4.7: (a) Optical and (b) back-scattered scanning electron microscope image of alloy 2 showing the presence of at least two types of phases in alloy 2. 


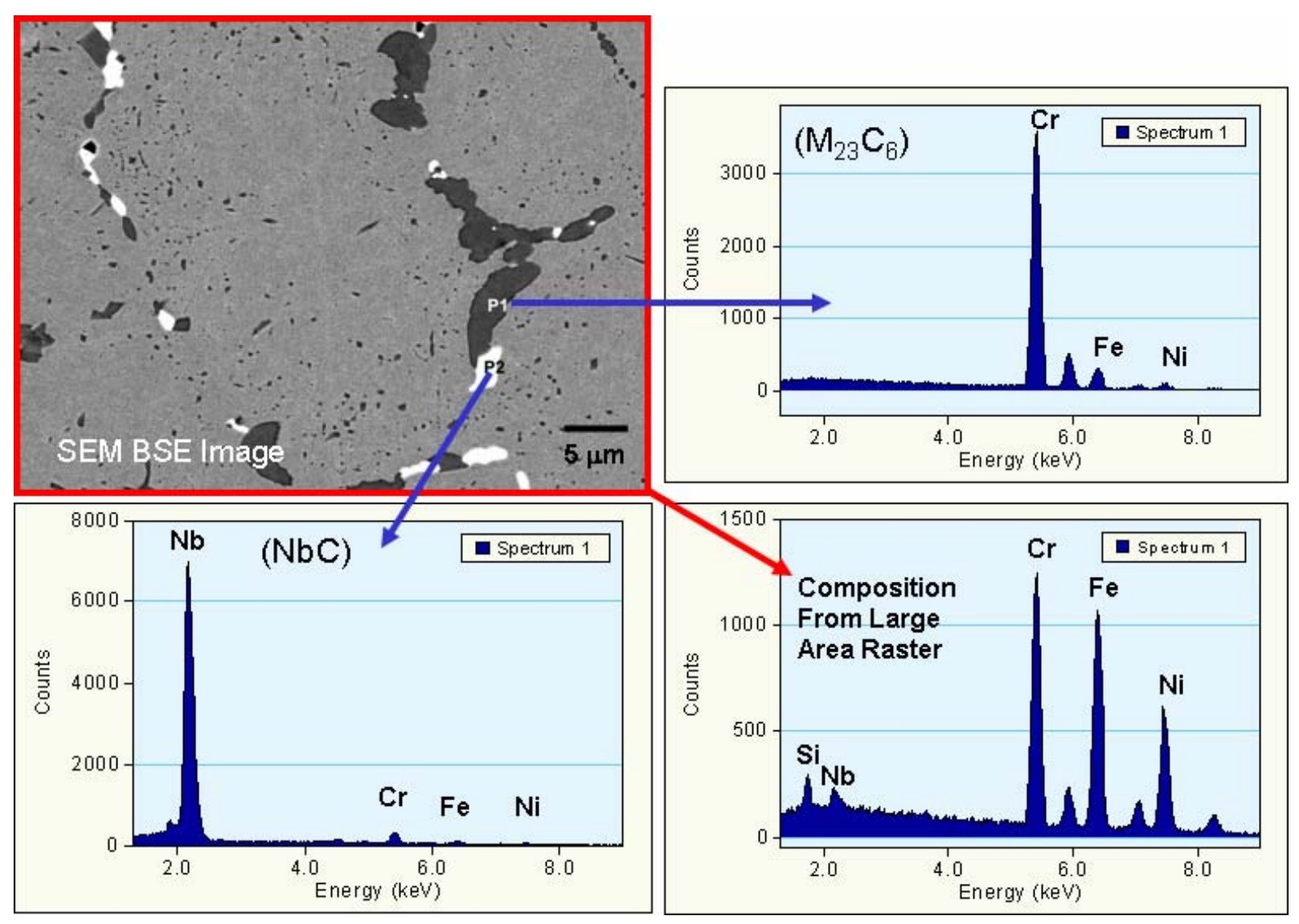

Figure 4.8: Energy dispersive $\mathrm{X}$-ray analyses in the scanning electron microscope reveal phases in alloy 2 as $M_{23} C_{6}$ and $M C$.

Figure 4.9 shows a comparison between the back-scattered electron image obtained from specimens of alloys 2 and 3. Note that the microstructure clearly shows the lack of a darker phase, $\mathrm{M}_{23} \mathrm{C}_{6}$, which is present in alloy 2. As can be seen from the figure, only NbC is prominently present in alloy 3.

Most of the results on microstructure presented above are on a coarse scale. It is well understood that the fine-scale microstructure has a significant effect on creep properties. Figures 4.10 and 4.11 show a scanning and a transmission microscope image of alloy 2 which shows the presence of both $\mathrm{M}_{23} \mathrm{C}_{6}$ and $\mathrm{MC}$ near the grain boundaries and within the grain. In contrast, transmission electron microscopy reveals some precipitation of MC only near the grain boundaries in alloy 3 with very little precipitation within the grains (see Figs. 4.12 and 4.13). Two major differences have been observed in the microstructure of alloys 2 and 3.

1. There was significantly more precipitation in alloy 2, which had better creep properties, when compared to alloy 3.

2. $\mathrm{M}_{23} \mathrm{C}_{6}$ precipitates were absent in alloy 3 , the alloy with inferior creep properties, which is also consistent with the predictions of thermodynamic calculations. 


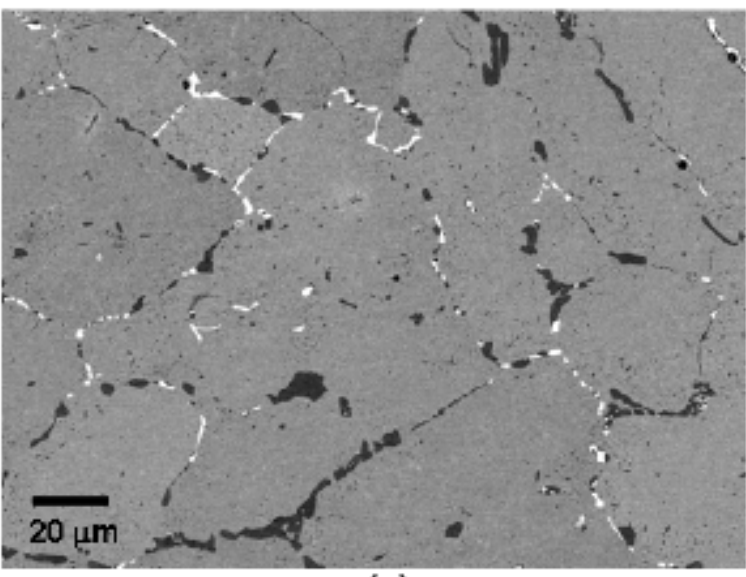

(a)

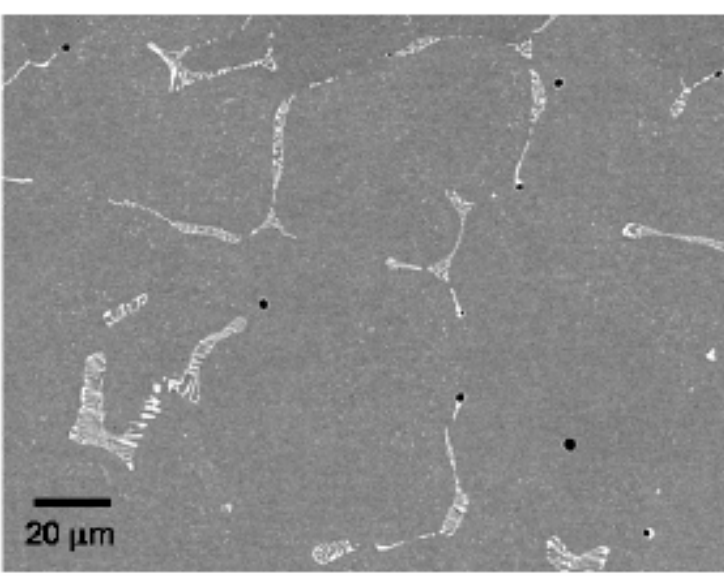

(b)

Figure 9: Backscattered electron imaging of (a) alloy 2 and (b) alloy 3 reveals the presence of only interdendritic and matrix NbC (bright regions) in alloy 3.

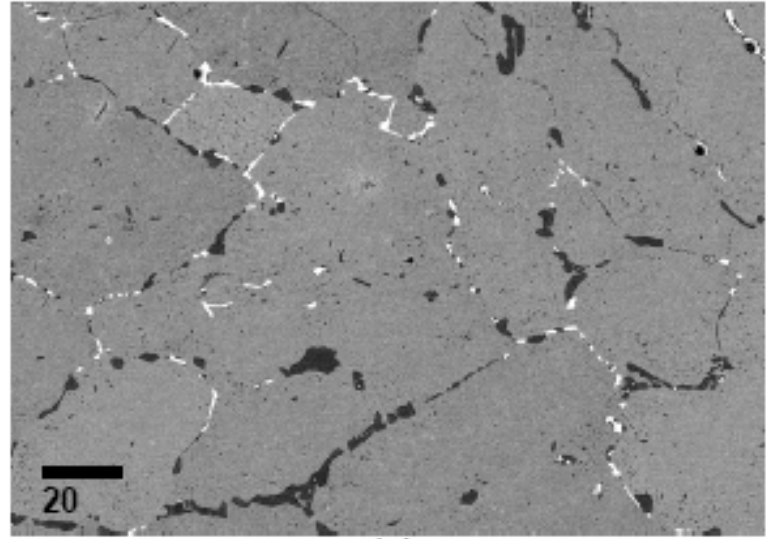

(a)

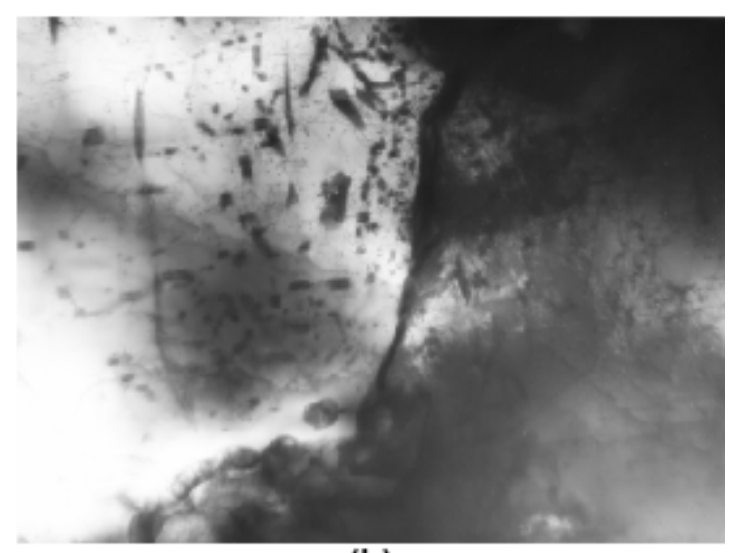

(b)

Figure 10: (a) Scanning and (b) transmission electron microscope image of alloy 2 revealing precipitation of both $\mathrm{MC}$ and $\mathrm{M}_{23} \mathrm{C}_{6}$ near grain boundaries during creep testing at $1800^{\circ} \mathrm{F}$ $\left(982^{\circ} \mathrm{C}\right)$. 

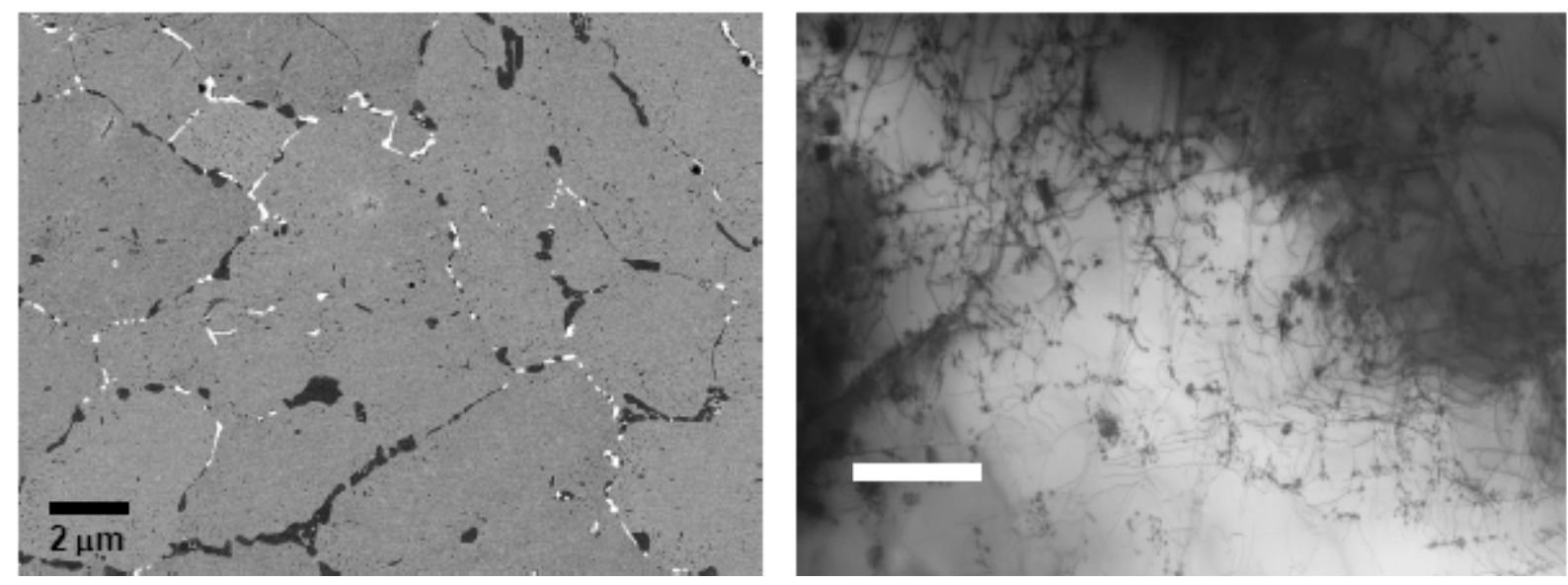

Figure 11: (a) Scanning and (b) transmission electron microscope image of alloy 2 revealing precipitation of uniform $\mathrm{MC}$ and $\mathrm{M}_{23} \mathrm{C}_{6}$ within the grain during creep testing at $1800^{\circ} \mathrm{F}$ $\left(982^{\circ} \mathrm{C}\right)$.
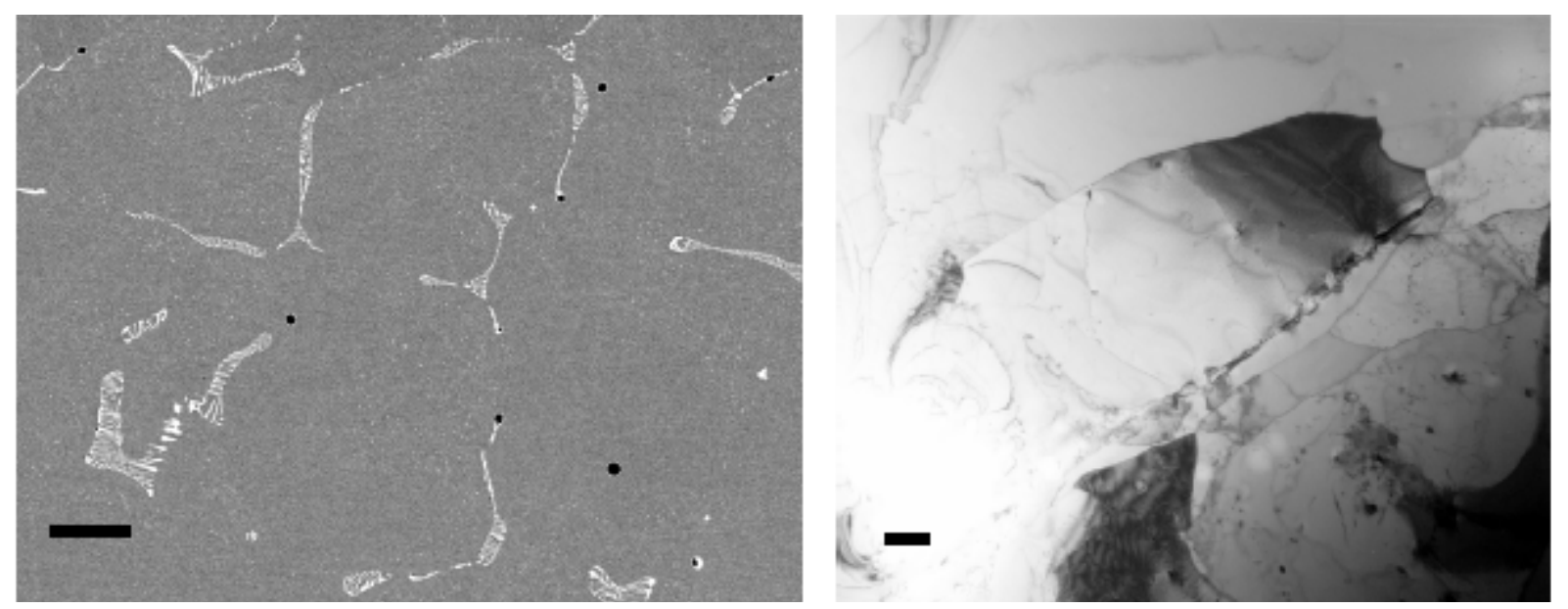

Figure 12: (a) Scanning and (b) transmission electron microscope image of alloy 3 revealing precipitation of only MC near the grain boundaries during creep testing at $1800^{\circ} \mathrm{F}\left(982^{\circ} \mathrm{C}\right)$. 

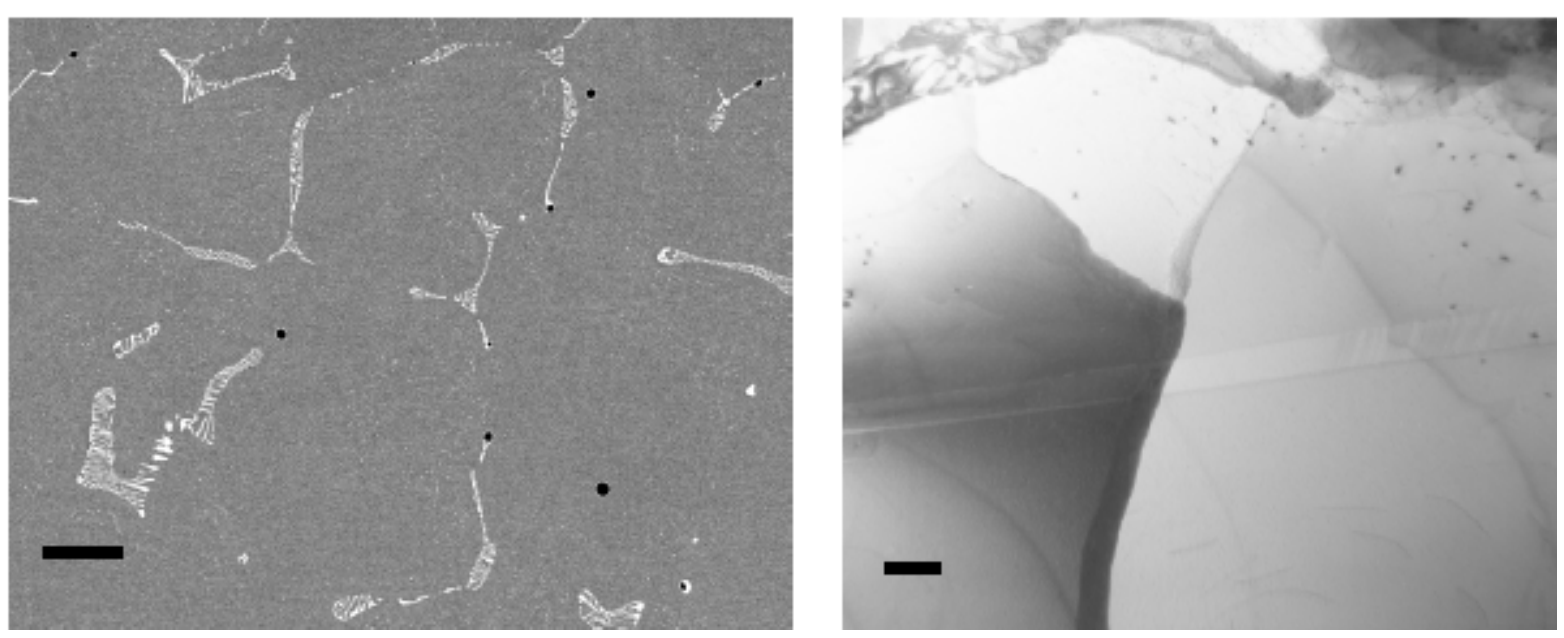

Figure 13: (a) Scanning and (b) transmission electron microscope image of alloy 3 revealing little fine precipitation within the grains during creep testing at $1800^{\circ} \mathrm{F}\left(9^{\circ} 2^{\circ} \mathrm{C}\right)$.

4.3.1.4 Validation of Thermodynamic Calculations using Quantitative Microscopy: As pointed out above, comparison of the prediction obtained from thermodynamic calculations with results from microstructural characterization clearly shows good qualitative agreement. To further evaluate the accuracy of calculations, it was decided to test if good quantitative agreement would be obtained between the observed volume fraction of phases and predicted volume fraction of phases. To enable this comparison, volume fraction of phases in alloys 2 and 3 were obtained by measuring the area fraction of phases in a back-scattered electron image. This was achieved by using the differences in contrast between the darker $\mathrm{M}_{23} \mathrm{C}_{6}$ phase and the brighter MC phase. Regions of the two phases were identified using contrast values appropriate to the phase of interest, and the corresponding area fractions were calculated in the binary image. Figure 4.14 shows an example of images where thresholding of contrast has been used to delineate the matrix and the two carbide phases. The darker $\mathrm{M}_{23} \mathrm{C}_{6}$ phase has been identified and colored blue, while the brighter MC phase is colored yellow.

Table 4.2 shows a comparison between the measured volume fractions of phases obtained using the methodology explained above and the weight fractions of phases obtained from equilibrium thermodynamic calculations. It is assumed that the densities of the phases are comparable for the purpose of these calculations. Note that the comparison between the experimental measurements and equilibrium volume fractions will be valid only if equilibrium is reached at the temperature of interest. Table 4.3 shows a similar comparison between the measured volume fractions and the predictions of Scheil calculations [9-11]. Scheil calculations assume local equilibrium during solidification and will tend to reflect the as-solidified microstructure rather than the equilibrium microstructure that would be obtained after prolonged exposure at a high temperature. Comparison shows that although some discrepancies exist, there is reasonable agreement between measurement and calculations. Particularly relevant is that alloy 3 is predicted to be void of $\mathrm{M}_{23} \mathrm{C}_{6}$, which has been observed to be experimentally valid. Measured $\mathrm{M}_{23} \mathrm{C}_{6}$ contents of alloy 2 are between the values predicted by Scheil and equilibrium calculations. This can be explained on the basis that equilibrium may not have been completely achieved during creep testing at $1800^{\circ} \mathrm{F}\left(982^{\circ} \mathrm{C}\right)$. 


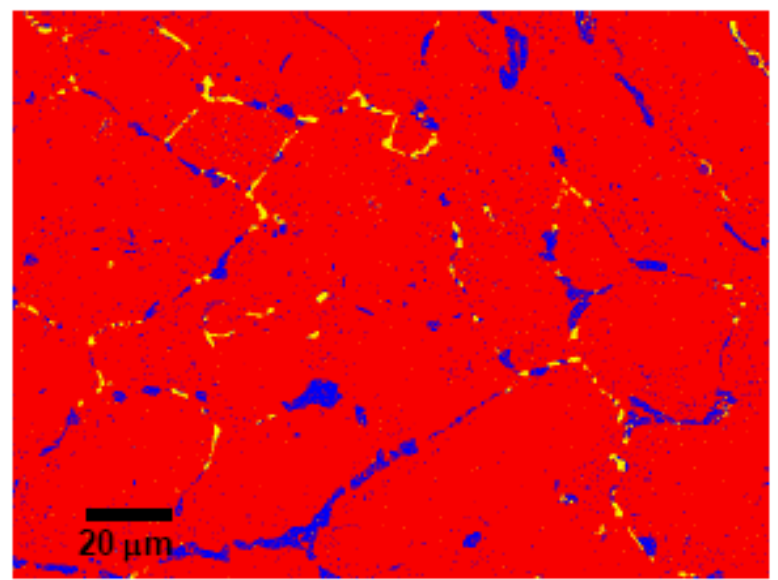

(a)

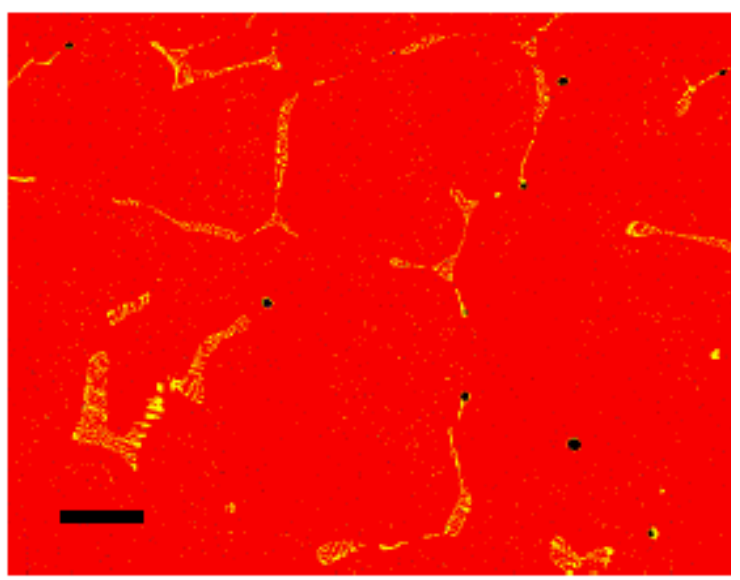

(b)

Figure 4.14: Threshold image showing areas of austenitic matrix (red), $\mathrm{M}_{23} \mathrm{C}_{6}$ (blue), and MC (yellow) in (a) alloy 2 and (b) alloy 3.

Table 4.2. Comparison between Measured Volume Fraction of Phases and Weight Fraction of Phases Predicted using Equilibrium Thermodynamic Calculations at $1800^{\circ} \mathrm{F}\left(982^{\circ} \mathrm{C}\right)$

\begin{tabular}{|c|c|c|c|c|c|c|c|}
\hline \multirow{2}{*}{$\begin{array}{c}\text { Alloy } \\
\text { Designation }\end{array}$} & \multicolumn{2}{|c|}{$\begin{array}{c}\text { Austenite } \\
(\gamma)\end{array}$} & \multicolumn{2}{c|}{$\begin{array}{c}\text { Chromium-rich Carbides } \\
\mathbf{M}_{\mathbf{2} 3} \mathbf{C}_{\mathbf{6}} / \mathbf{M}_{\mathbf{7}} \mathbf{C}_{\mathbf{3}}\end{array}$} & \multicolumn{2}{|c|}{$\begin{array}{c}\text { Niobium-rich Carbides } \\
\text { MC }\end{array}$} & Others \\
\cline { 2 - 8 } & $\begin{array}{c}\text { Predicted } \\
\text { (wt \%) }\end{array}$ & $\begin{array}{c}\text { Average } \\
\text { Measured } \\
\text { (vol \%) }\end{array}$ & $\begin{array}{c}\text { Predicted } \\
\text { (wt \%) }\end{array}$ & $\begin{array}{c}\text { Average } \\
\text { Measured } \\
\text { (vol \%) }\end{array}$ & $\begin{array}{c}\text { Predicted } \\
\text { (wt \%) }\end{array}$ & $\begin{array}{c}\text { Average } \\
\text { Measured } \\
\text { (vol \%) }\end{array}$ & $\begin{array}{c}\text { Predicted } \\
\text { (wt \%) }\end{array}$ \\
\hline Alloy 2 & 93.5 & 95.0 & 5.5 & 4.0 & 1.0 & 1.0 & 0 \\
\hline Alloy 3 & 99.1 & 98.3 & 0 & 0 & 0.9 & 1.7 & 0 \\
\hline
\end{tabular}

Table 4.3. Comparison between Measured Volume Fraction of Phases and Weight Fraction of Phases Predicted using Scheil Calculations

\begin{tabular}{|c|c|c|c|c|c|c|c|}
\hline \multirow{2}{*}{$\begin{array}{c}\text { Alloy } \\
\text { Designation }\end{array}$} & \multicolumn{2}{|c|}{$\begin{array}{c}\text { Austenite } \\
(\gamma)\end{array}$} & \multicolumn{2}{|c|}{$\begin{array}{c}\text { Chromium-rich Carbides } \\
M_{23} C_{6} / M_{7} C_{3}\end{array}$} & \multicolumn{2}{|c|}{$\begin{array}{c}\text { Niobium-rich Carbides } \\
\text { MC }\end{array}$} & \multirow{2}{*}{$\begin{array}{c}\text { Others } \\
\text { Predicted } \\
\text { (wt \%) }\end{array}$} \\
\hline & $\begin{array}{l}\text { Predicted } \\
\text { (wt \%) }\end{array}$ & $\begin{array}{c}\text { Average } \\
\text { Measured } \\
\text { (vol \%) }\end{array}$ & $\begin{array}{l}\text { Predicted } \\
\text { (wt \%) }\end{array}$ & $\begin{array}{c}\text { Average } \\
\text { Measured } \\
\text { (vol \%) }\end{array}$ & $\begin{array}{l}\text { Predicted } \\
\text { (wt \%) }\end{array}$ & $\begin{array}{c}\text { Average } \\
\text { Measured } \\
\text { (vol \%) }\end{array}$ & \\
\hline Alloy 2 & 95.9 & 95.0 & 3.2 & 4.0 & 0.9 & 1.0 & 0 \\
\hline Alloy 3 & 98.8 & 98.3 & 0 & 0 & 0.6 & 1.7 & 0.6 \\
\hline
\end{tabular}

4.3.1.5 Discussion on the Relationship between Microstructure and Creep Properties in Commercial H-Series Alloys: Based on the results presented above, it is evident that there are significant differences in the amount of carbide phases present in alloys 2 and 3 . Considering that alloy 2 has a significantly better creep rupture life at $1800^{\circ} \mathrm{F}\left(982^{\circ} \mathrm{C}\right)$, it can be concluded that carbide phases have a positive role on the creep rupture life of $\mathrm{H}$-Series alloys. Furthermore, it can be observed that alloy 2 has two major types of strengthening carbides, while alloy 3 lacks precipitation of $\mathrm{M}_{23} \mathrm{C}_{6}$. It is hypothesized that the presence of the two carbide phases is desirable when compared to the presence of only one type of carbide.

In summary, based on the results of detailed thermodynamic calculations, and microstructural characterization on selected commercial H-Series alloys, it was concluded that: (1) thermodynamic calculations were reliable in qualitative prediction of microstructure, 
(2) quantitative comparisons between thermodynamic calculations and microstructure show reasonable agreement with occasional discrepancies, and (3) creep properties are better in alloys that contain both $\mathrm{M}_{23} \mathrm{C}_{6}$ and $\mathrm{MC}$ in their microstructure.

Based on the observations on the relationship between the carbides and creep properties, a first generation of new alloys was prepared at ORNL. The newly designed alloys were melted into 25- to 50-lb heats and cast into slab. Test bars from experimental heats were creep-tested at $2200^{\circ} \mathrm{F}\left(1204^{\circ} \mathrm{C}\right)$ with some tests done at lower temperatures; one test was done at $2300^{\circ} \mathrm{F}$ $\left(1260^{\circ} \mathrm{C}\right)$. Further work was carried out to study the relationship between composition, microstructure, and creep properties of some of these alloys as discussed in the following sections.

\subsubsection{Study of Trial ORNL HP Alloys with Different Niobium Contents}

Preliminary study on the effect of alloying elements in existing alloys showed that addition of niobium improved the creep properties of H-Series alloys. Two alloys with different niobium contents were cast in small batches at ORNL to study the effect of niobium additions on HP-type alloys. Compositions of these alloys are shown in Table 4.4

Table 4.4. Composition of Trial HP Alloys with High Niobium Contents

\begin{tabular}{|c|c|c|c|c|c|c|c|c|}
\hline $\begin{array}{c}\text { Alloy } \\
\text { Designation }\end{array}$ & $\mathbf{C}$ & $\mathbf{C r}$ & $\mathbf{N i}$ & $\mathbf{M n}$ & $\mathbf{S i}$ & $\mathbf{N b}$ & $\mathbf{W}$ & $\mathbf{F e}$ \\
\hline HP-1 & 0.4 & 22.7 & 34.6 & 0.8 & 1.5 & 1.0 & 0.1 & Balance \\
\hline HP-2 & 0.4 & 23.0 & 35.2 & 0.8 & 1.5 & 2.1 & 0.1 & Balance \\
\hline
\end{tabular}

Detailed thermodynamic calculations along with microstructural characterization were carried out to study the microstructure in these alloys and to evaluate their effect on the creep properties of these two alloys.

4.3.2.1 Thermodynamic Calculations of ORNL Trial HP Alloy with Different Niobium Contents: Thermodynamic calculations were performed to understand the stability of various phases at equilibrium in HP-1 and HP-2 alloys as a function of temperature, and the results are shown in Figs. 4.15 and 4.16. In addition to austenite, carbides such as $\mathrm{M}_{23} \mathrm{C}_{6}, \mathrm{MC}$, and $\mathrm{M}_{7} \mathrm{C}_{3}$ were predicted to be important over the temperature range of interest, which is consistent with observations from previous experimental studies. Note that relative to HP-2, $\mathrm{M}_{23} \mathrm{C}_{6}$ is predicted to be present in larger fractions in HP-1 along with a smaller amount of MC-type carbides in the temperature range of 1472 to $2012^{\circ} \mathrm{F}\left(800\right.$ to $\left.1100^{\circ} \mathrm{C}\right)$. In contrast, $\mathrm{M}_{23} \mathrm{C}_{6}$ and $\mathrm{MC}$-type carbides are predicted to be present in comparable weight fractions in alloy HP-2 over the same temperature range, indicating a much larger MC-content in alloy HP-2. Thus, it is expected that MC-type carbides will play a significantly larger role in affecting the mechanical properties of alloy HP-2 than that of alloy HP-1. Furthermore, the total carbide content in HP-2 is smaller than that in HP-1, and the effect of these carbide contents on the creep properties was evaluated as shown later. Microstructural characterization was carried out to verify the predictions of thermodynamic calculations. 


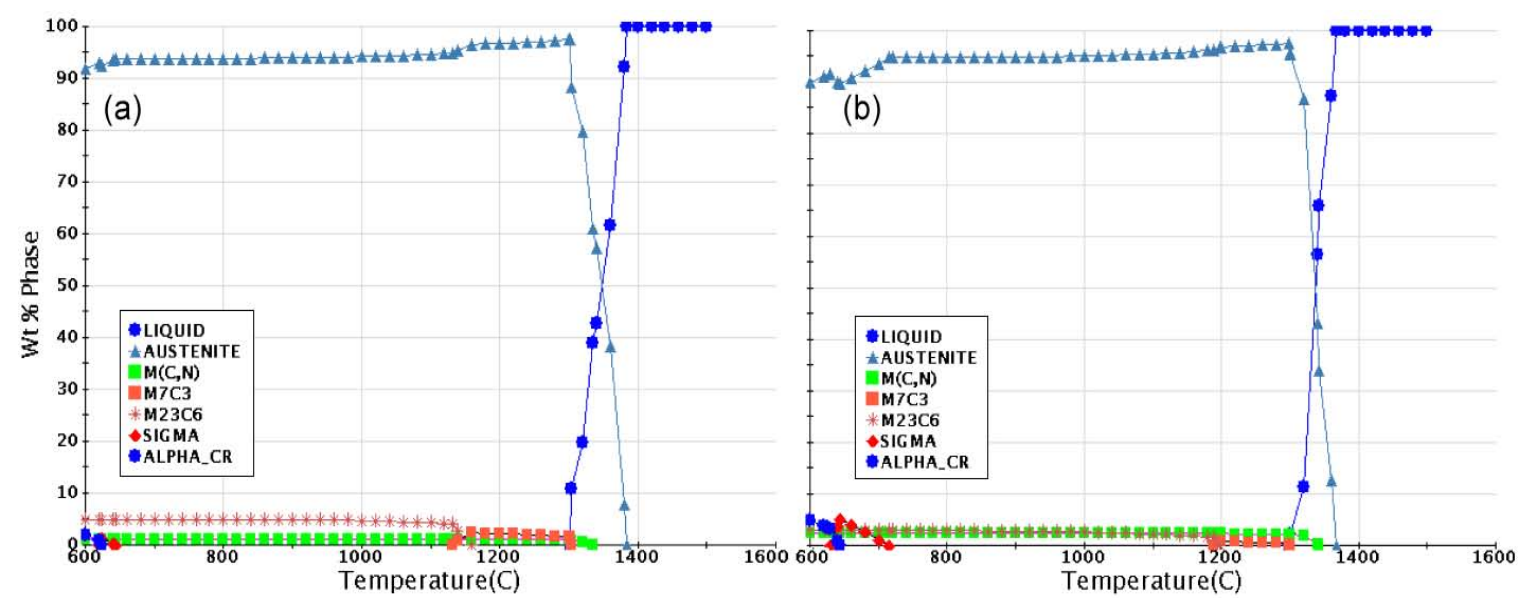

Figure 4.15: Thermodynamic calculations predict differences in carbide precipitation between (a) HP-1 and (b) HP-2.

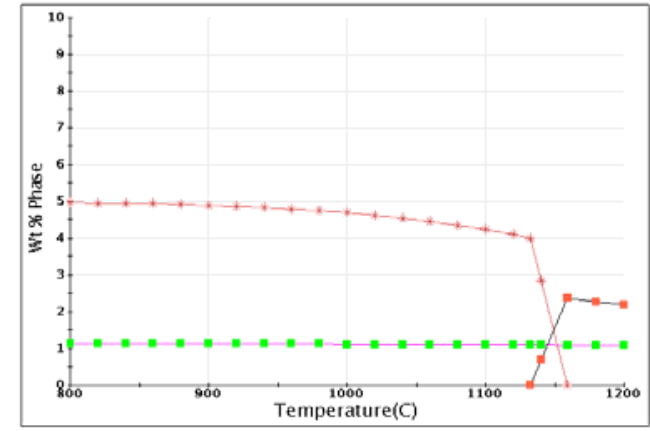

(a)

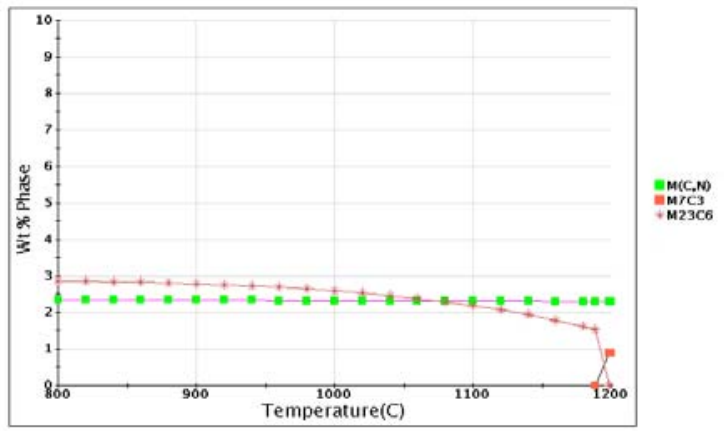

(b)

Figure 4.16: An expanded view of Fig. 4:16 showing the carbide phases and their phase fractions predicted to be present over the temperature range of 1472 to $2192 \mathrm{~F}$ (800 to 1200C) in (a) HP-1 and (b) HP-2. Note the decrease in the amount of $\mathrm{M}_{23} \mathrm{C}_{6}$ and increase in amount of MC in HP-2 when compared to HP-1.

4.3.2.2 Microstructural Characterization of ORNL Trial HP Alloy with Different Niobium Contents in the As-Cast Condition: Figure 4.17 shows a typical backscattered scanning electron micrograph obtained from the as-cast specimen of HP-1 and HP-2. In Fig. 4.17(a), large carbides are observed both along the seams between the colonies of dendrites and in the interdendritic regions. Precipitates appearing brighter than the matrix have been identified using energy-dispersive X-ray spectrometry to be niobium-rich MC-type carbides/carbonitrides, while those appearing dark have been identified to be chromium-rich carbides. Figure 4.17(b) shows the corresponding backscattered electron image from as-cast HP-2 alloy. In contrast to HP-1, Fig. 4.17(b) shows an increase in the amount of the bright MC-type carbides. A similar conclusion can be obtained from comparing the X-ray diffraction patterns from these two alloys shown in Fig. 4.18. 

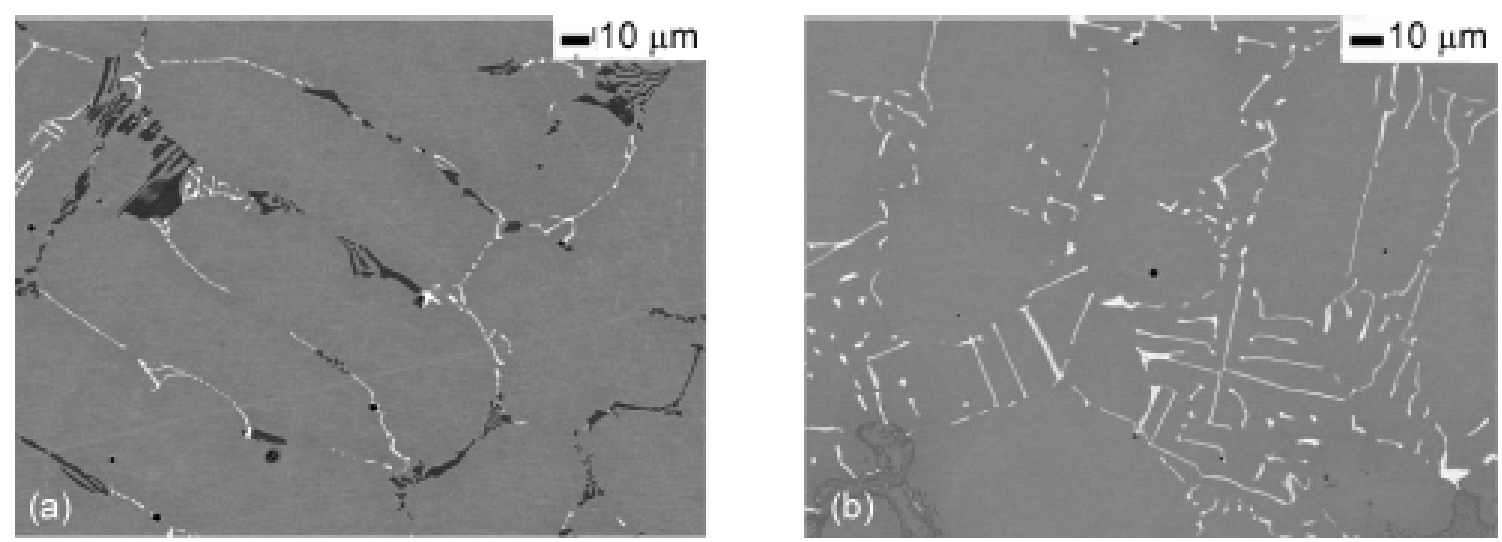

Figure 4.17: Backscattered scanning electron micrograph of (a) as-cast HP-1 and (b) ascast HP-2 showing the presence of both niobium-rich (bright) and chromium-rich carbides (dark) in HP-1 and predominantly niobium-rich carbides in HP-2.
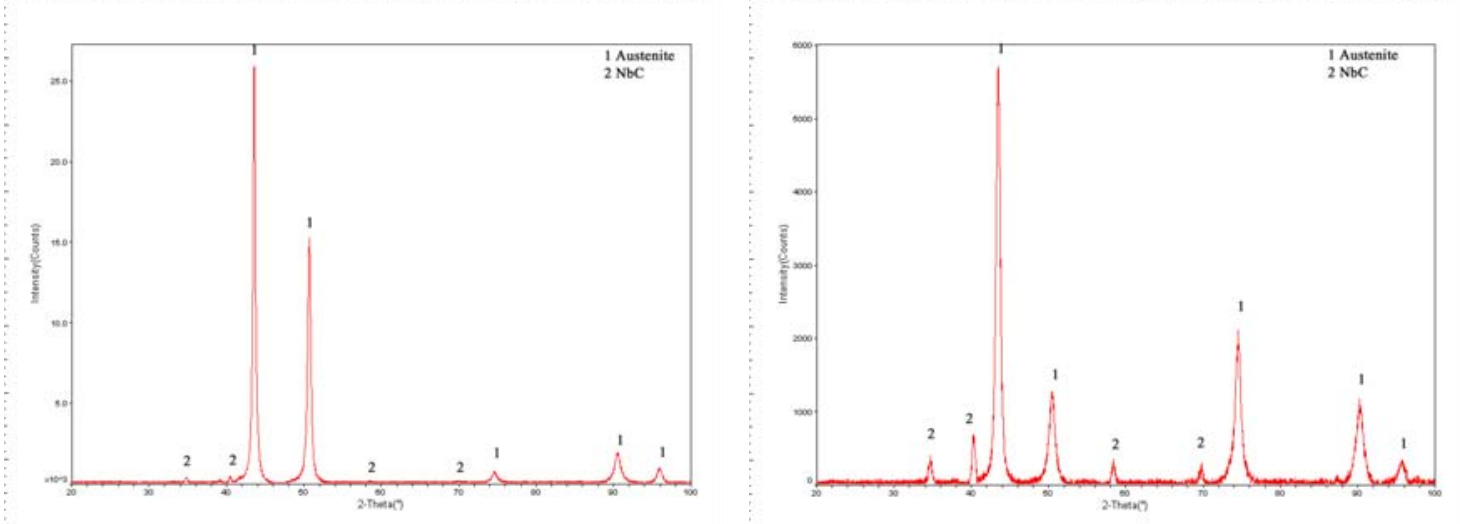

Figure 4.18: $X$-ray diffraction patterns from (a) as-cast HP-1 and (b) as-cast HP-2 showing the presence of austenite in both samples and an increase in the intensity of $\mathrm{NbC}$ peaks in (b).

4.3.2.3 Quantitative Microscopy of ORNL Trial HP Alloy with Different Niobium Contents in the As-Cast Condition: To enable a quantitative comparison of predictions and the observed as-cast microstructure, Scheil calculations were performed for both alloy compositions.

Table 4.5 shows a summary of the comparison between the Scheil prediction for phases present in the solidified alloys and the average values measured from image analysis of backscattered electron images of as-cast specimens. Again, weight fractions have been assumed to be equal to volume fractions. It can be observed that the predictions for HP- 1 are in reasonable agreement with measured values. However, for HP-2, although the effect of increasing the niobiumcontents is qualitatively consistent with an increase in the fraction of MC-carbides, the measured fraction of MC-type carbides is much larger than the predicted values. 
Table 4.5. Comparison between the Phase Contents Predicted using Scheil Calculations and Actual Measured Values in the As-cast Microstructure

\begin{tabular}{|c|c|c|c|c|c|c|c|}
\hline \multirow{2}{*}{$\begin{array}{c}\text { Alloy } \\
\text { Designation }\end{array}$} & \multicolumn{2}{|c|}{$\begin{array}{c}\text { Austenite } \\
(\gamma)\end{array}$} & \multicolumn{2}{c|}{$\begin{array}{c}\text { Chromium-rich Carbides } \\
\mathbf{M}_{\mathbf{2}_{3}} \mathbf{C}_{\mathbf{6}} / \mathbf{M}_{\mathbf{7}} \mathbf{C}_{\mathbf{3}}\end{array}$} & \multicolumn{2}{c|}{$\begin{array}{c}\text { Niobium-rich Carbides } \\
\text { MC }\end{array}$} & Others \\
\cline { 2 - 8 } & $\begin{array}{c}\text { Predicted } \\
\text { (wt \%) }\end{array}$ & $\begin{array}{c}\text { Average } \\
\text { Measured } \\
\text { (vol \%) }\end{array}$ & $\begin{array}{c}\text { Predicted } \\
\text { (wt \%) }\end{array}$ & $\begin{array}{c}\text { Average } \\
\text { Measured } \\
\text { (vol \%) }\end{array}$ & $\begin{array}{c}\text { Predicted } \\
\text { (wt \%) }\end{array}$ & $\begin{array}{c}\text { Average } \\
\text { Measured } \\
\text { (vol \%) }\end{array}$ & $\begin{array}{c}\text { Predicted } \\
\text { (wt \%) }\end{array}$ \\
\hline HP-1 & 96.6 & 95.1 & 2.5 & 3.7 & 1.0 & 1.2 & 0 \\
\hline HP-2 & 96.0 & 95.0 & 1.7 & 0.7 & 2.1 & 4.3 & 0.3 \\
\hline
\end{tabular}

Comparison of the microstructure observed in the as-cast state with the Scheil calculations shows that the thermodynamic calculations are qualitatively consistent with the observed microstructure of HP-1 and HP-2 alloys. For example, the amounts of chromium-rich carbides are predicted to be more than the amount of MC-carbides in HP-1, which has been verified with evaluation of microstructure. In contrast, the amount of MC- carbides has been predicted to be larger than $\mathrm{M}_{23} \mathrm{C}_{6}$ carbides in HP-2 and is also consistent with the observed microstructure. However, the observed microstructure shows a much larger amount of MC carbides than what is predicted, and hence is the discrepancy observed between the observed microstructure and the calculations. Again, it can be concluded that thermodynamic calculations have been qualitatively correct but may be quantitatively different from the observed microstructure.

4.3.2.4 Creep Properties of Trial HP Alloys with Different Niobium Contents: Figure 4.19 shows the results of creep testing of HP- 1 and HP-2 at a stress of $4 \mathrm{ksi}$ at $1800^{\circ} \mathrm{F}\left(982^{\circ} \mathrm{C}\right)$ and 2 and $2.4 \mathrm{ksi}$ at $2000^{\circ} \mathrm{F}\left(1093^{\circ} \mathrm{C}\right)$. Results clearly show that HP-1 has improved creep properties when compared to HP-2. It was the goal of the microstructure analysis to understand the reason for the improved properties in HP-1.

\subsubsection{Microstructural Characterization of ORNL Trial HP Alloy with Different Niobium} Contents after Creep Testing at $1800^{\circ} \mathrm{F}\left(9^{\circ} 2^{\circ} \mathrm{C}\right)$ : Microstructural changes occur when the ascast structure is exposed to high temperatures during creep testing. It was important to evaluate these microstructural changes to relate it to the improved properties of HP-1. To understand this evolution and to evaluate its effect, a quantitative study of the phase fractions was carried out on samples that were tested at $1800^{\circ} \mathrm{F}\left(982^{\circ} \mathrm{C}\right)$. Figure 4.20 (a) shows a backscattered electron micrograph from HP-1 that was exposed to $1800^{\circ} \mathrm{F}\left(982^{\circ} \mathrm{C}\right)$ for $762 \mathrm{~h}$ (time to failure). Some breakdown of the as-cast microstructure is observed along with an increase in the globular nature of the phases. Figure 4.20(b) shows the corresponding micrograph obtained from HP-2, but after $608 \mathrm{~h}$ of exposure (time to failure). Comparison with the as-cast microstructure again shows some spheroidization of the phases. However, qualitatively, the microstructure was similar to that observed in the as-cast condition. Thus, it was necessary to evaluate the effect of the high-temperature exposure on the amounts of $\mathrm{M}_{23} \mathrm{C}_{6}$ and $\mathrm{MC}$ in the two alloys, and the results of the evaluation are shown below. 


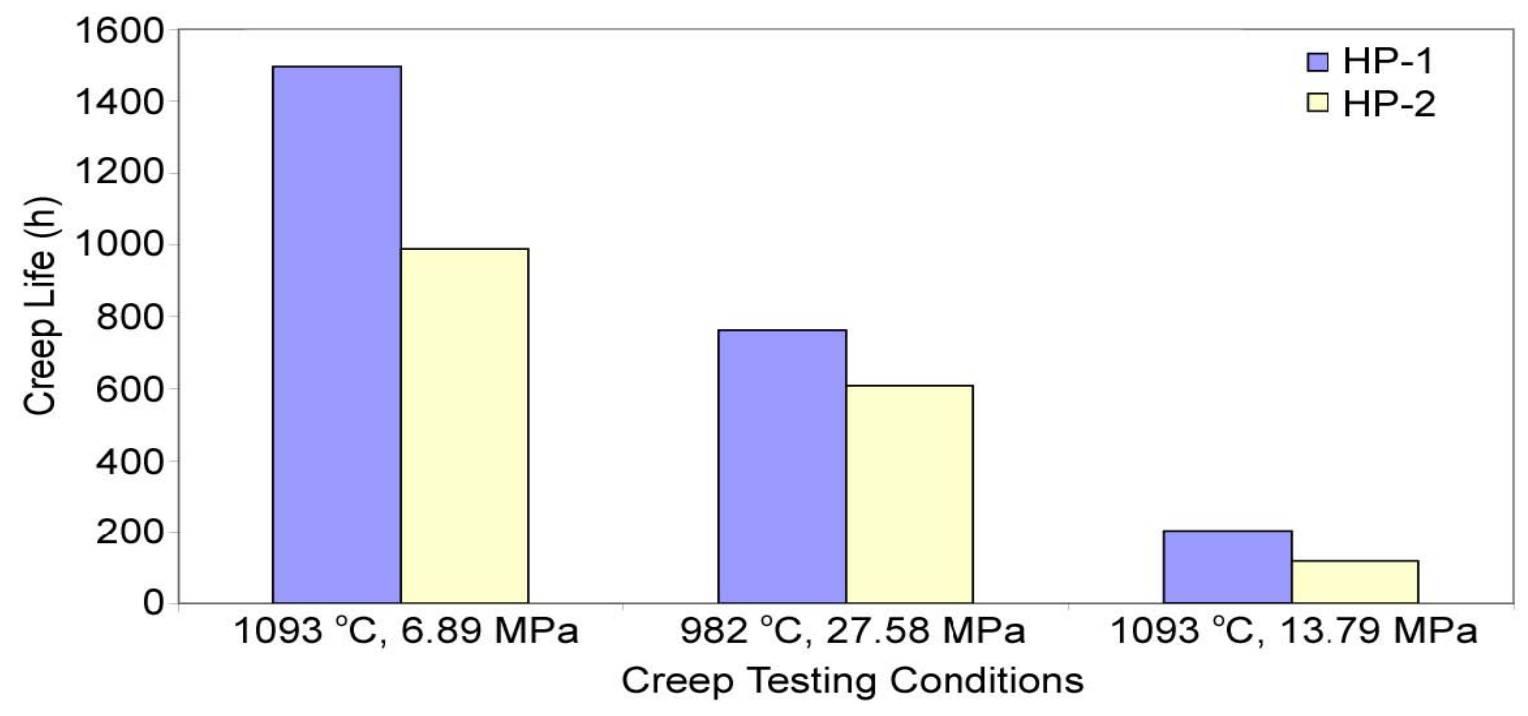

Figure 4.19: Results of creep testing at different temperatures and stress levels showing that HP-1 has better creep properties than HP-2.
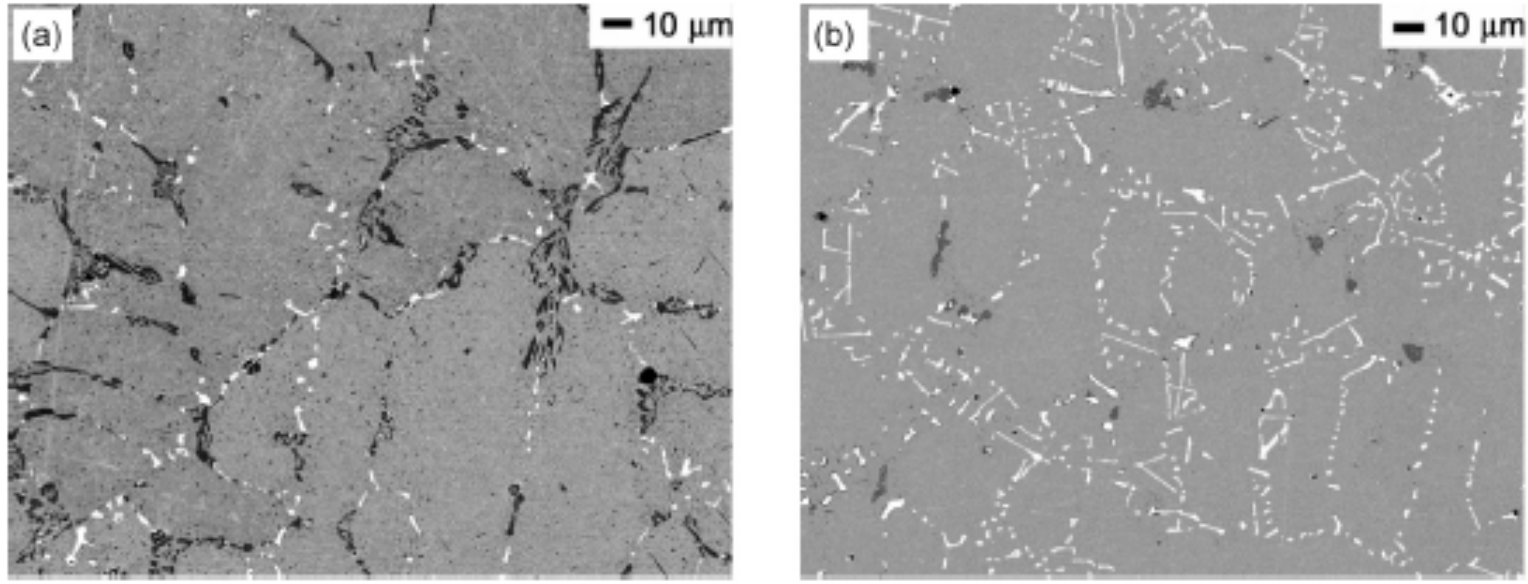

Figure 4.20: Backscattered scanning electron micrograph obtained from (a) HP-1 and (b) HP-2 after creep failure at $1800^{\circ} \mathrm{F}\left(982^{\circ} \mathrm{C}\right)$.

\subsubsection{Quantitative Microscopy of ORNL Trial HP Alloy with Different Niobium Contents} after Creep Testing at $\mathbf{1 8 0 0}^{\circ} \mathbf{F}\left(\mathbf{9 8 2}^{\circ} \mathrm{C}\right)$ : Table 4.6 shows a comparison between the observed phase fractions in HP-1 and HP-2 with that predicted by equilibrium thermodynamic calculations. Although region-to-region variations were prevalent, good quantitative agreement is observed between the predictions and average measurements for HP-1. In the case of HP-2, although good qualitative agreement between the predictions and the observed microstructure is observed, quantitative measurements show a larger amount of MC-type carbides and a smaller amount of $\mathrm{M}_{23} \mathrm{C}_{6}$ than that predicted by thermodynamic calculations. It is likely that the carbon 
is tied up in the stable MC-phase due to its precipitation under nonequilibrium conditions prevailing during solidification, thus limiting further precipitation of $\mathrm{M}_{23} \mathrm{C}_{6}$ during exposure to high temperatures.

Table 4.6. Comparison between the Phase Contents Predicted using Equilibrium Calculations and Actual Measured Values in the Microstructure Observed in the Failed Creep Specimens

\begin{tabular}{|c|c|c|c|c|c|c|}
\hline \multirow{2}{*}{$\begin{array}{c}\text { Alloy } \\
\text { Designation }\end{array}$} & \multicolumn{2}{|c|}{$\begin{array}{c}\text { Austenite } \\
(\gamma)\end{array}$} & \multicolumn{2}{c|}{$\begin{array}{c}\text { Chromium-rich Carbides } \\
\mathbf{M}_{\mathbf{2}} \mathbf{C}_{\mathbf{6}}\end{array}$} & \multicolumn{2}{c|}{$\begin{array}{c}\text { Niobium-rich Carbides } \\
\mathbf{M}(\mathbf{C}, \mathbf{N})\end{array}$} \\
\cline { 2 - 7 } & $\begin{array}{c}\text { Predicted } \\
\text { (wt \%) }\end{array}$ & $\begin{array}{c}\text { Average } \\
\text { Measured } \\
\text { (vol \%) }\end{array}$ & $\begin{array}{c}\text { Predicted } \\
\text { (wt \%) }\end{array}$ & $\begin{array}{c}\text { Average } \\
\text { Measured } \\
\text { (vol \%) }\end{array}$ & $\begin{array}{c}\text { Predicted } \\
\text { (wt \%) }\end{array}$ & $\begin{array}{c}\text { Average } \\
\text { Measured } \\
\text { (vol \%) }\end{array}$ \\
\hline HP-1 & 94.1 & 94.2 & 4.7 & 4.8 & 1.1 & 1.1 \\
\hline HP-2 & 95.0 & 95.2 & 2.7 & 0.8 & 2.3 & 4.0 \\
\hline
\end{tabular}

Table 4.7 shows a comparison of the volume fractions of the various carbides observed after creep testing with those observed in the as-cast structure. From the table, it can be inferred that the volume fraction of $\mathrm{M}_{23} \mathrm{C}_{6}$ has increased in both alloys after exposure to $1800^{\circ} \mathrm{F}\left(982^{\circ} \mathrm{C}\right)$, with the increase in HP-1 being much larger than that observed in HP-2. Correlation of the creep properties with the relative phase fractions of $\mathrm{M}_{23} \mathrm{C}_{6}$ and $\mathrm{MC}$ clearly shows that $\mathrm{M}_{23} \mathrm{C}_{6}$ plays an important role in improving the creep properties of these alloys. This observation is consistent with a previous study that showed that some $\mathrm{M}_{23} \mathrm{C}_{6}$ is essential for improving creep properties of H-Series alloys. The use of thermodynamic calculations offers the possibility of obtaining quantitative relationships between precipitation and coarsening of various phases, and the creep properties.

Table 4.7. Change in the Measured Volume Fractions of Chromium-rich and Niobium-rich Carbides after Creep Testing at $1800^{\circ} \mathrm{F}\left(982^{\circ} \mathrm{C}\right)$

\begin{tabular}{|c|c|c|c|}
\hline $\begin{array}{c}\text { Alloy } \\
\text { Designation }\end{array}$ & $\begin{array}{c}\text { Change in Measured Vol } \\
\% \text { of Chromium-rich } \\
\text { Carbides } \mathrm{M}_{23} \mathrm{C}_{6} \text { during } \\
\text { Creep Testing }\end{array}$ & $\begin{array}{l}\text { Change in Measured Vol } \\
\text { \% of Niobium-rich } \\
\text { Carbides } M(C, N) \text { during } \\
\text { Creep Testing }\end{array}$ & $\begin{array}{c}\text { Creep Rupture } \\
\text { Life } \\
\text { (h) } 1800^{\circ} \mathrm{F}\left(982^{\circ} \mathrm{C}\right) \text {, } \\
4 \mathrm{ksi}\end{array}$ \\
\hline HP-1 & 1.01 & -0.2 & 762 \\
\hline HP-2 & 0.1 & -0.3 & 608 \\
\hline
\end{tabular}

As can be seen from Table 4.7 above, the alloy with a significant precipitation of $\mathrm{M}_{23} \mathrm{C}_{6}$ at the temperature of creep testing reveals improved creep properties. Similar conclusions can be obtained by the study of creep properties and microstructural evolution occurring at $2000^{\circ} \mathrm{F}$ $\left(1093^{\circ} \mathrm{C}\right)$ in the above alloys. Figure 4.21 shows calculated amounts of $\mathrm{M}_{23} \mathrm{C}_{6}$ and $\mathrm{MC}$ carbides present in the alloys at equilibrium, after solidification, and the extent of precipitation occurring during exposure to the temperature of creep tests, respectively. Figure 4.22 shows equivalent data for MC-type carbides. It can be observed from these figures that the creep properties of the alloys correlate better with the precipitation of $\mathrm{M}_{23} \mathrm{C}_{6}$ than with that of $\mathrm{MC}$, illustrating that precipitation of this carbide is essential for improved creep resistance. 


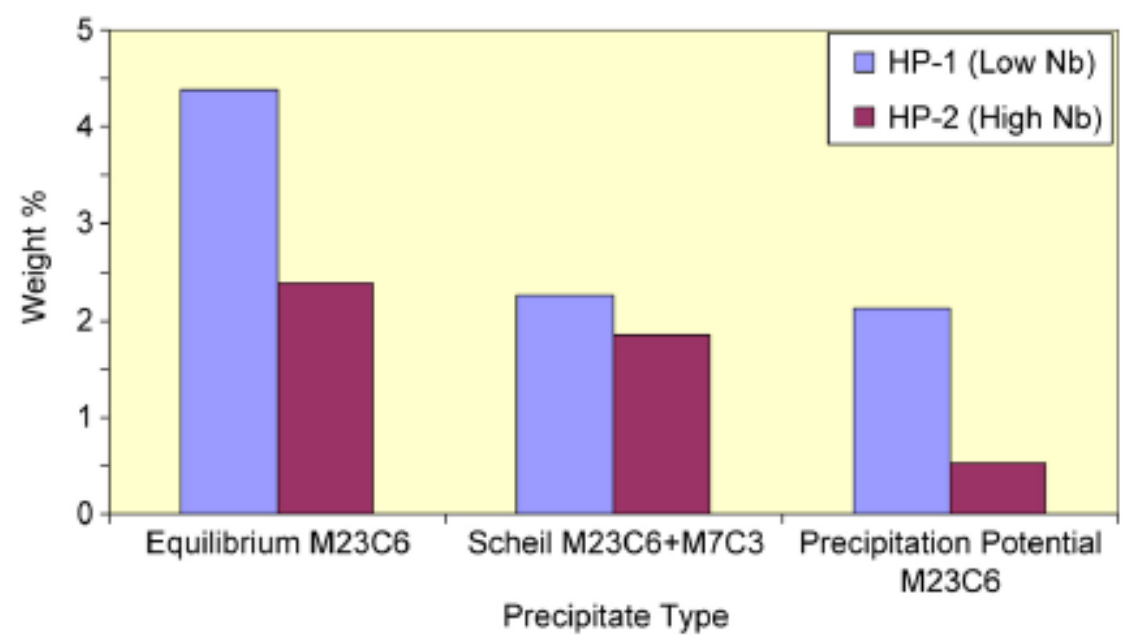

Figure 4.21: Calculated amounts of precipitation of $\mathrm{M}_{23} \mathrm{C}_{6}$ at Equilibrium during Solidification and Exposure to Creep Testing Temperature of $2000^{\circ} \mathrm{F}\left(1093^{\circ} \mathrm{C}\right)$.

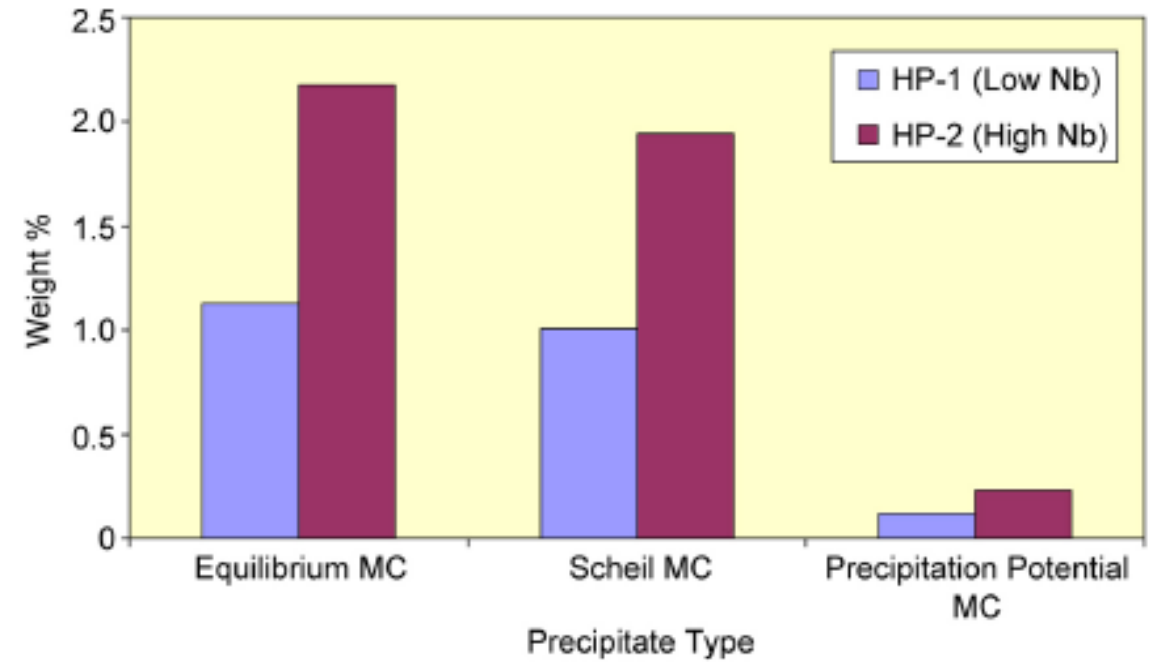

Figure 4.22: Calculated amounts of precipitation of $\mathrm{MC}$ at equilibrium during solidification and exposure to creep testing temperature of $2000^{\circ} \mathrm{F}\left(1093^{\circ} \mathrm{C}\right)$.

Based on the above discussion, it was concluded that: (1) a larger amount of carbide typically results in improved creep properties, and (2) the presence of both $\mathrm{M}_{23} \mathrm{C}_{6}$ and $\mathrm{MC}$ carbides would be beneficial for high-temperature creep properties.

These results are consistent with the observations made during the study of existing commercial H-Series alloys. Hence in the second phase of the work, baseline alloy compositions were modified using thermodynamic calculations to (1) maximize the amount of carbide phases, (2) maximize the amount of carbide phases that precipitate during creep testing, (3) generate a microstructure that would have both $\mathrm{M}_{23} \mathrm{C}_{6}$ and $\mathrm{MC}$ phases stable at the temperature of interest, and (4) reduce the amount of deleterious topologically closed packed phases such as sigma. 


\subsection{Development and Study of New Advanced Alloys}

\subsubsection{Methodology of Development of New Alloys}

The methodology used for the development of new alloys was to consider certain reference compositions of HP and HK alloys. Using these compositions as a starting point, the effect of addition of alloying elements on the stabilities of $\mathrm{M}_{23} \mathrm{C}_{6}$ and $\mathrm{MC}$ were calculated using thermodynamic models. Sufficient alloying element additions were used to stabilize strengthening phases at the required temperature [for example, $2200^{\circ} \mathrm{F}\left(1204^{\circ} \mathrm{C}\right)$ ] as indicated by results of the thermodynamic calculations, while minimizing the formation of deleterious topologically closed packed phases at low temperatures. The focus of studies was on high temperatures because the aim of the work was to increase the operating temperature of alloys. The following shows an example of this methodology.

Figure 4.23(a) shows thermodynamic predictions for phase equilibria in an HP-11 alloy with poor creep performance at $2200^{\circ} \mathrm{F}\left(1204^{\circ} \mathrm{C}\right.$ ) (creep rupture life of about $14 \mathrm{~h}$ at a stress of 500 psi) [see Fig. 4.23(b)]. As can be noticed from this figure, $\mathrm{M}_{23} \mathrm{C}_{6}$ carbides are predicted to be stable only up to about $2100^{\circ} \mathrm{F}\left(1149^{\circ} \mathrm{C}\right)$ and are replaced by $\mathrm{M}_{7} \mathrm{C}_{3}$ carbides above this temperature. The approach adopted in this work was to add alloying elements to extend the range of stability of $\mathrm{M}_{23} \mathrm{C}_{6}$ to higher temperatures.

Figures 4.24(a) and (b) show the effect of the addition of varying levels of titanium, one of the commonly used alloying elements, on the stabilities of $\mathrm{M}_{23} \mathrm{C}_{6}$ and $\mathrm{MC}$ in HP-11. As increasing levels of titanium are added, the $\mathrm{M}_{23} \mathrm{C}_{6}$ content in the alloy decreases, while correspondingly, the $\mathrm{MC}$ content increases. The highest temperature at which $\mathrm{M}_{23} \mathrm{C}_{6}$ remains stable increases slightly with the addition of titanium. Figures 4.25(a) and (b) show the effect of the addition of varying levels of tungsten on the stabilities of the two carbides. With increasing levels of tungsten, the highest temperature of stability of $\mathrm{M}_{23} \mathrm{C}_{6}$ increases significantly along with a small increase in the weight percent of the carbide phase. Tungsten has very little effect on the MC phase as seen from Fig. 4.25(b). Thus, if the goal were to increase the amount of MC, addition of titanium would be desirable as an alloying element. Addition of tungsten would be important to increase the amount of $\mathrm{M}_{23} \mathrm{C}_{6}$ and to increase its temperature range of stability.

\subsubsection{Thermodynamic Calculations and Creep Properties of New HP-type Alloys}

Using a computational modeling approach, the addition of alloying $\mathrm{Mo}, \mathrm{Nb}, \mathrm{Ti}$, and $\mathrm{W}$ to $\mathrm{HP}-11$ was proposed, and a new generation of HP- type alloys were designed and prepared at ORNL. Figures 4.26 to 4.29 show the thermodynamic stabilities of the carbide phases and the corresponding creep properties at $2200^{\circ} \mathrm{F}\left(1204^{\circ} \mathrm{C}\right), 500$ psi of alloys HP-7, HP-14R1, HP-15, and HP-16. As can be noticed from Figs. 4.27(a), 4.28(a), and 4.29(a), the addition of alloying elements increases the highest temperature at which $\mathrm{M}_{23} \mathrm{C}_{6}$ is calculated to be stable. 

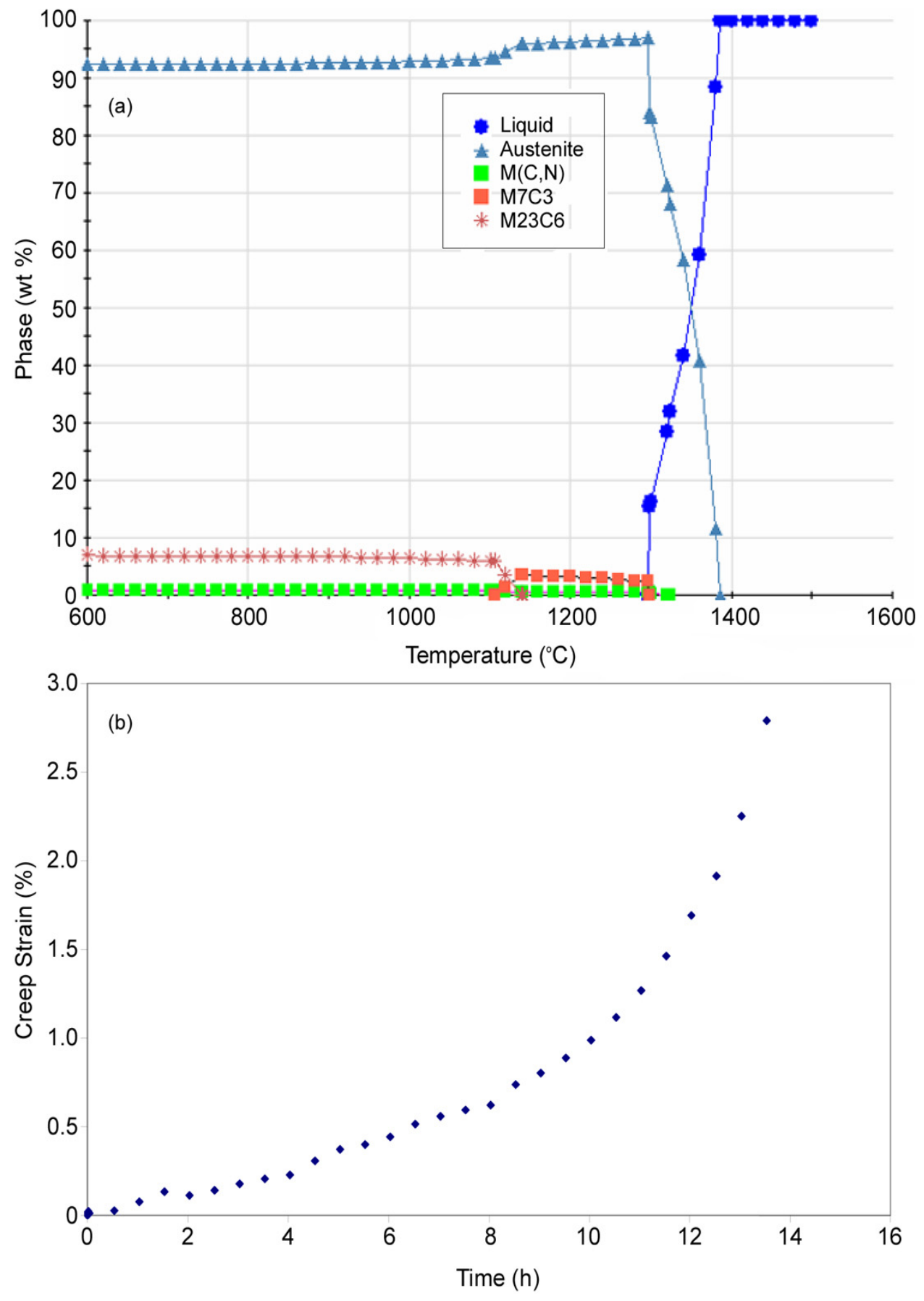

Figure 4.23: (a) Thermodynamic calculations for HP-11 and (b) creep strain as a function of time obtained during testing at $2200^{\circ} \mathrm{F}\left(1204^{\circ} \mathrm{C}\right)$ and 500 psi. Failure occurred after $14 \mathrm{~h}$. 


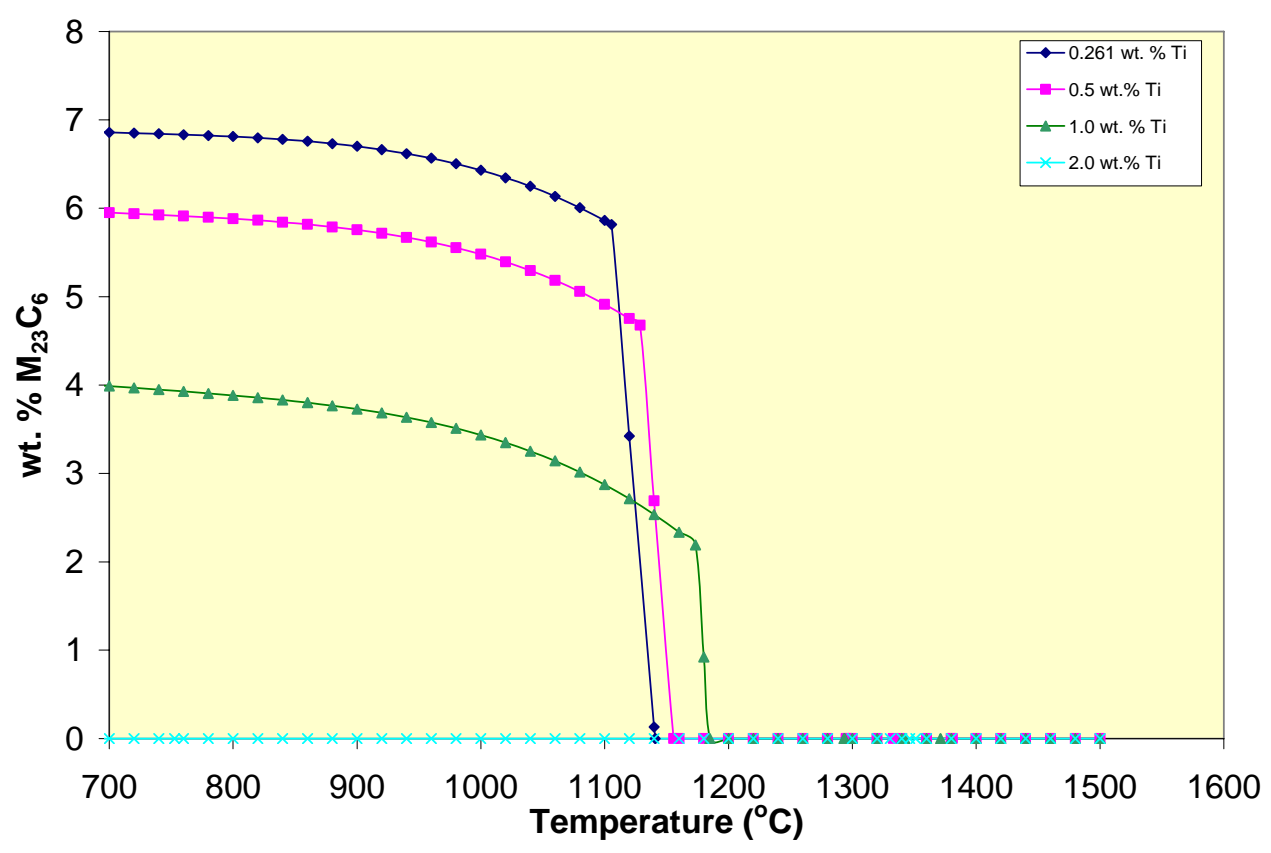

(a)

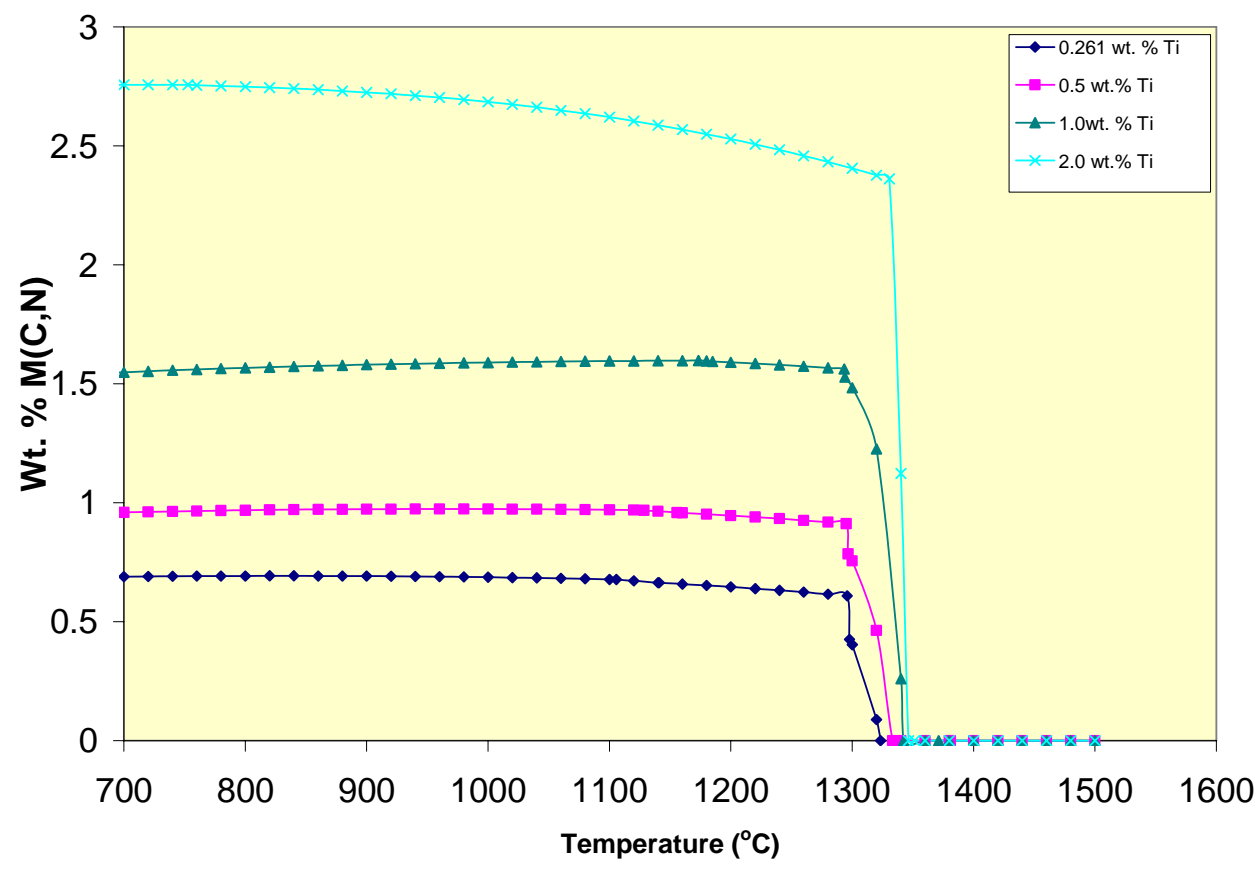

(b)

Figure 4.24: Thermodynamic calculations showing the effect of titanium additions on the stabilities of $\mathrm{M}_{23} \mathrm{C}_{6}$ and $\mathrm{MC}$. 


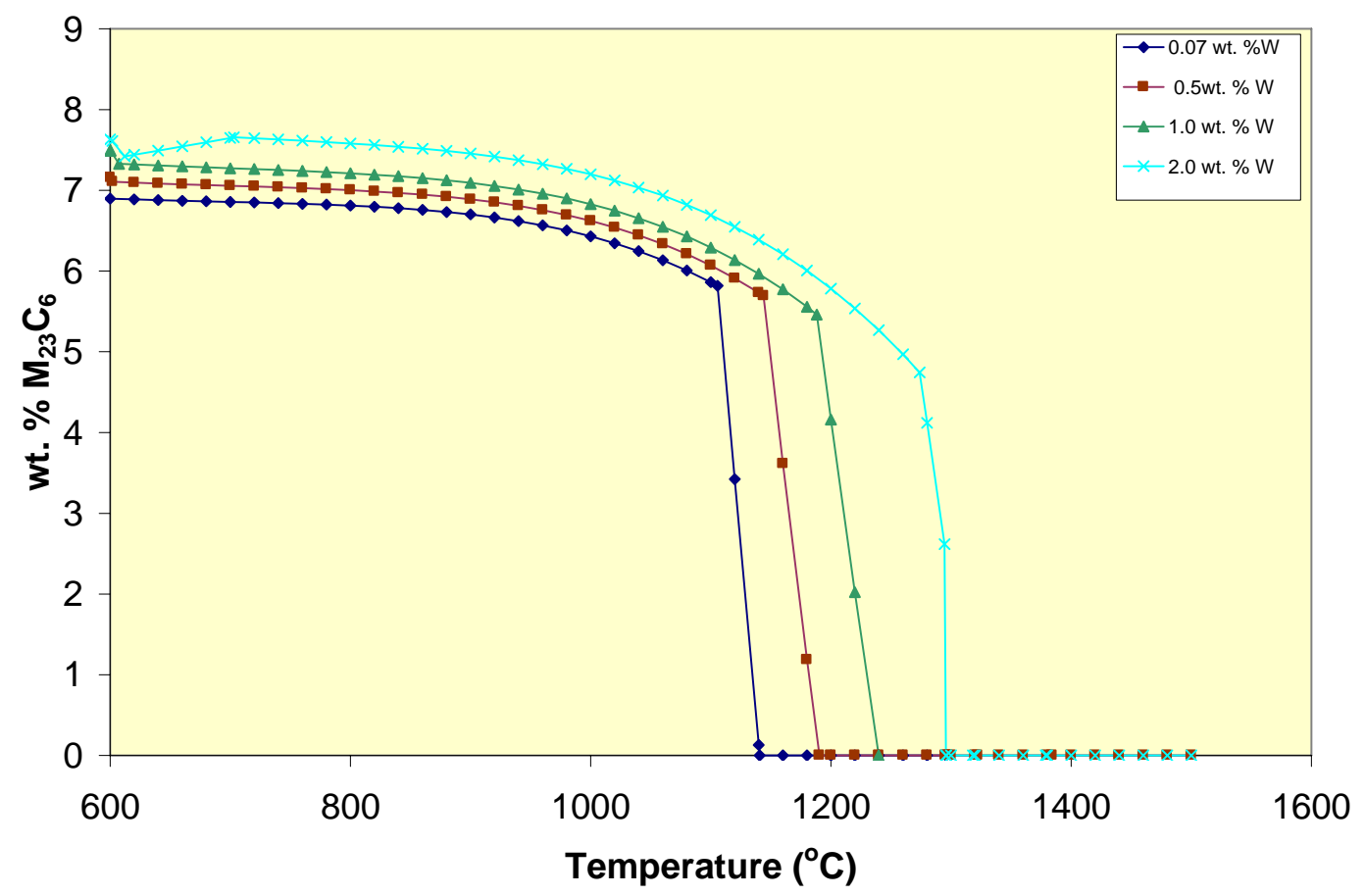

(a)

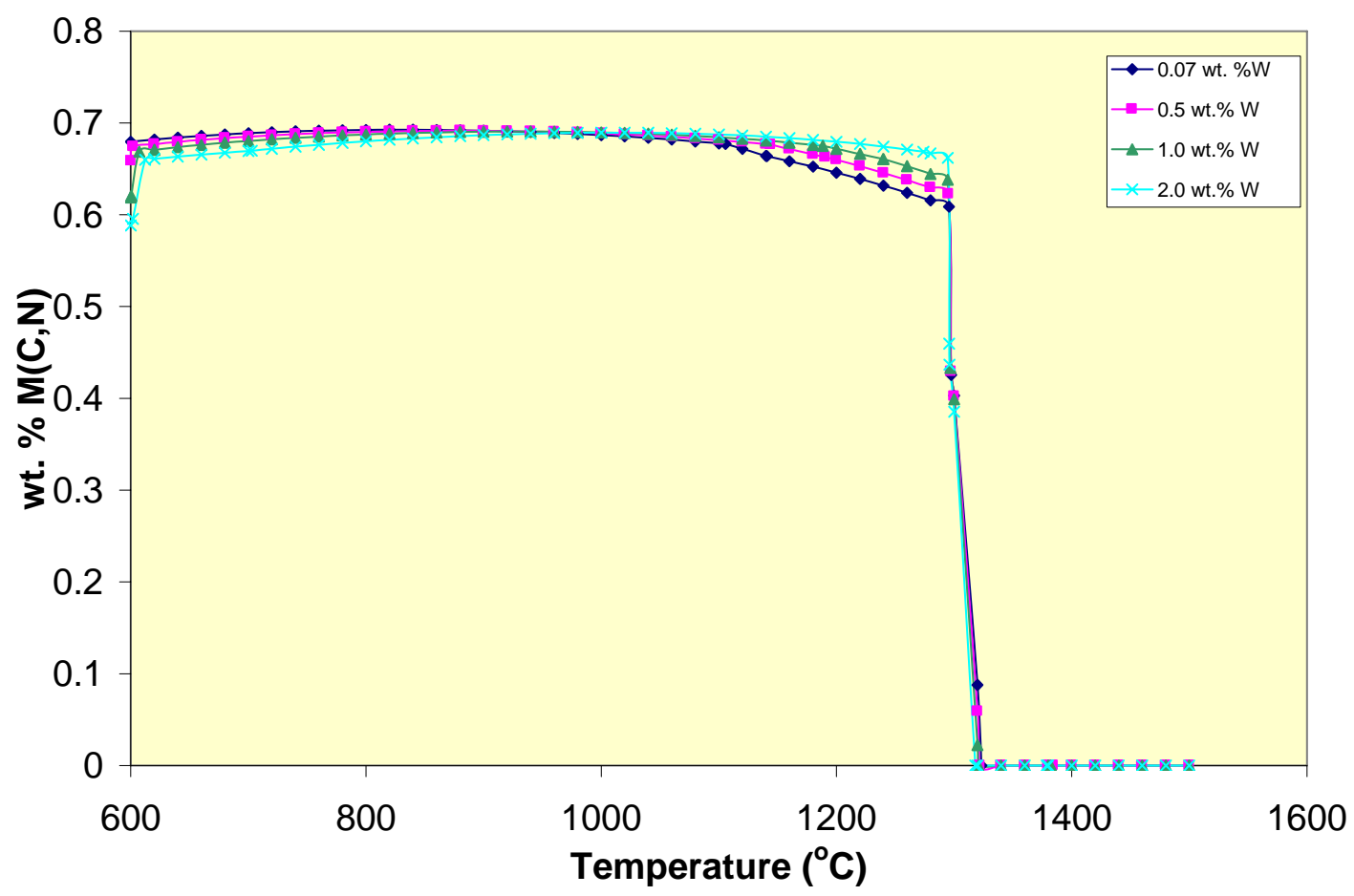

(b)

Figure 4.25: Thermodynamic calculations showing the effect of tungsten addition on the stabilities of $\mathrm{M}_{23} \mathrm{C}_{6}$ and $\mathrm{MC}$. 


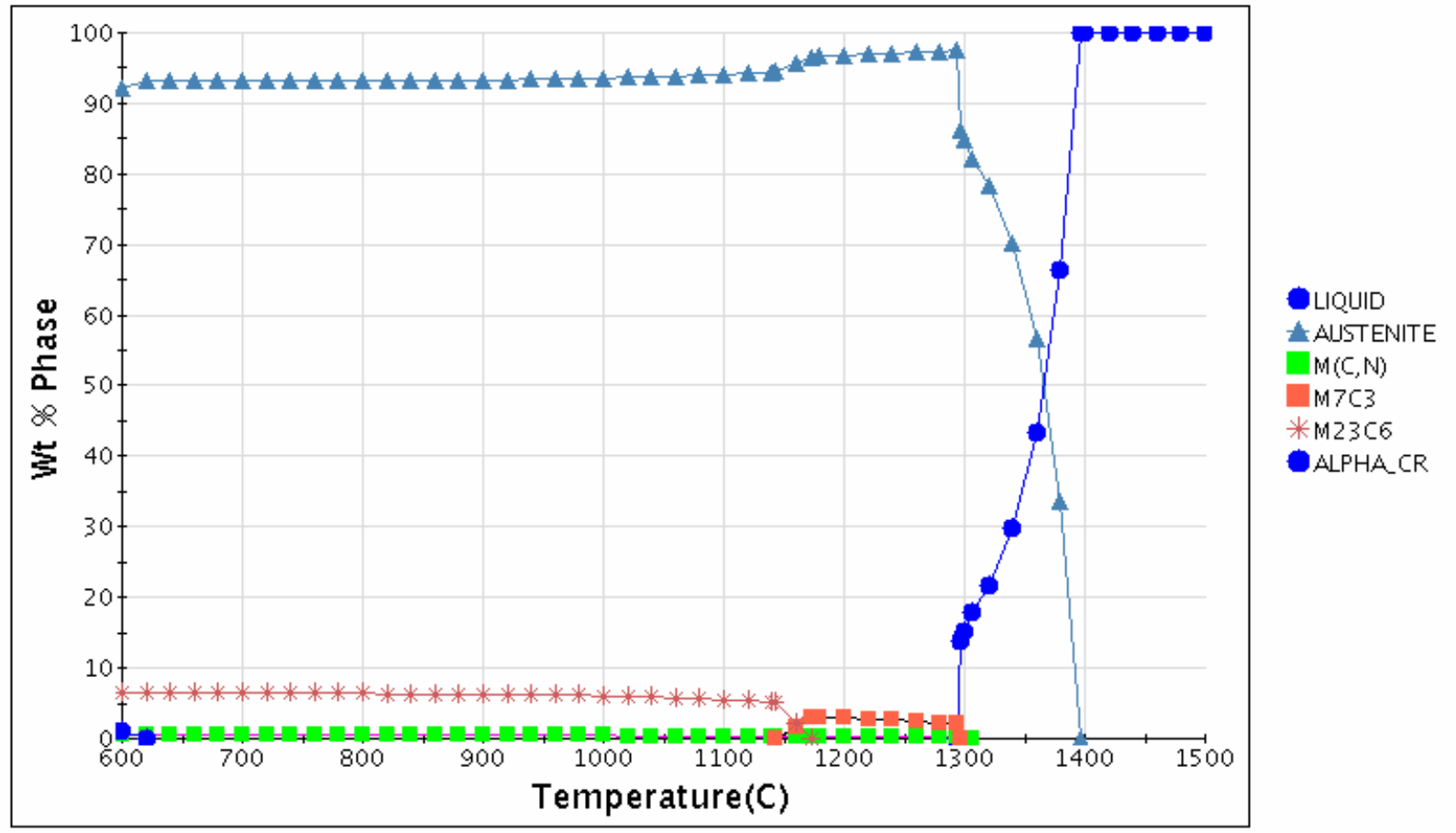

(a)

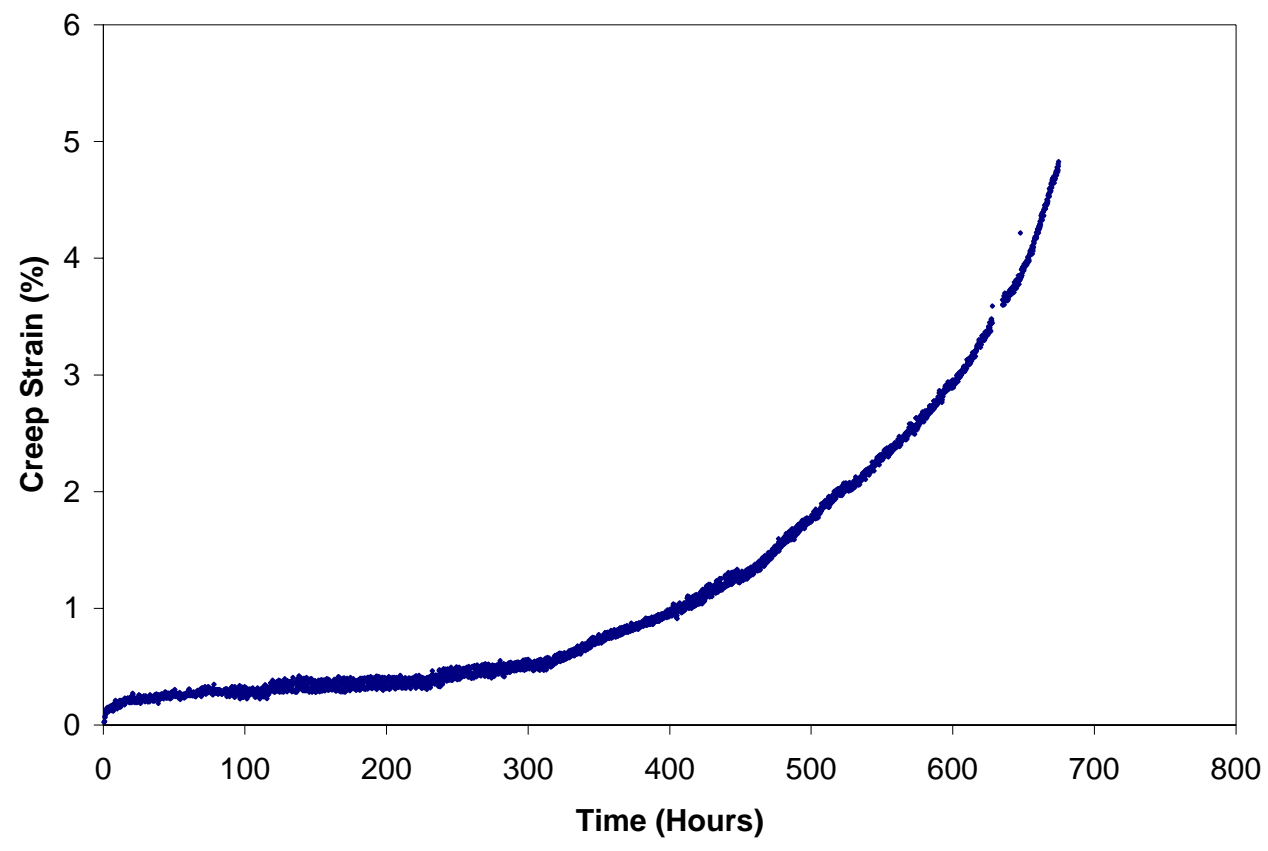

(b)

Figure 4.26: (a) Thermodynamic calculations for HP-7 and (b) creep strain as a function of time obtained during testing at $2200^{\circ} \mathrm{F}\left(1204^{\circ} \mathrm{C}\right)$ and $500 \mathrm{psi}$. Failure occurred after $675 \mathrm{~h}$. 


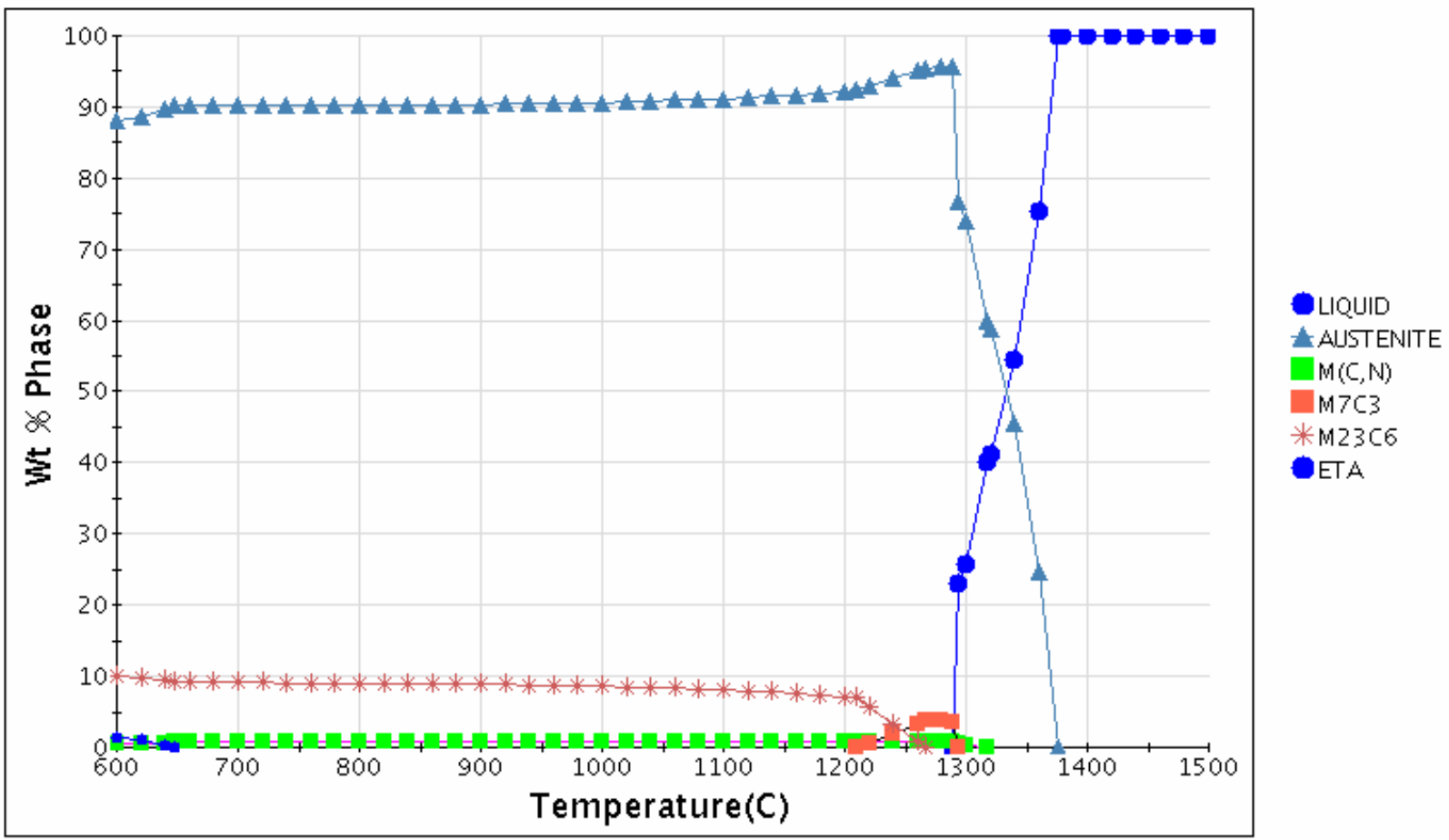

(a)

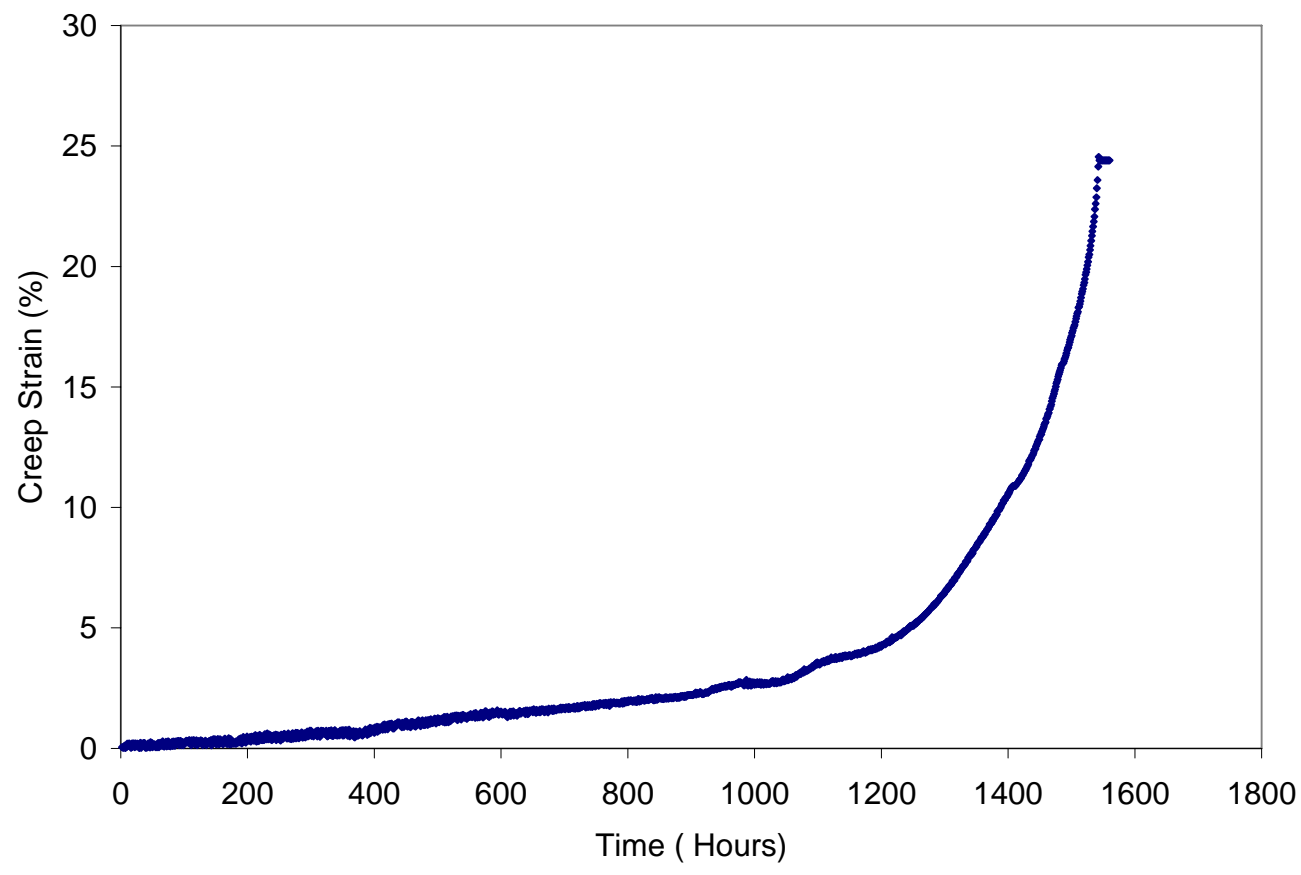

(b)

Figure 4.27: (a) Thermodynamic calculations for HP-14R1 and (b) creep strain as a function of time obtained during testing at $2200^{\circ} \mathrm{F}\left(1204^{\circ} \mathrm{C}\right)$ and 500 psi. Failure occurred after $1558 \mathrm{~h}$. 


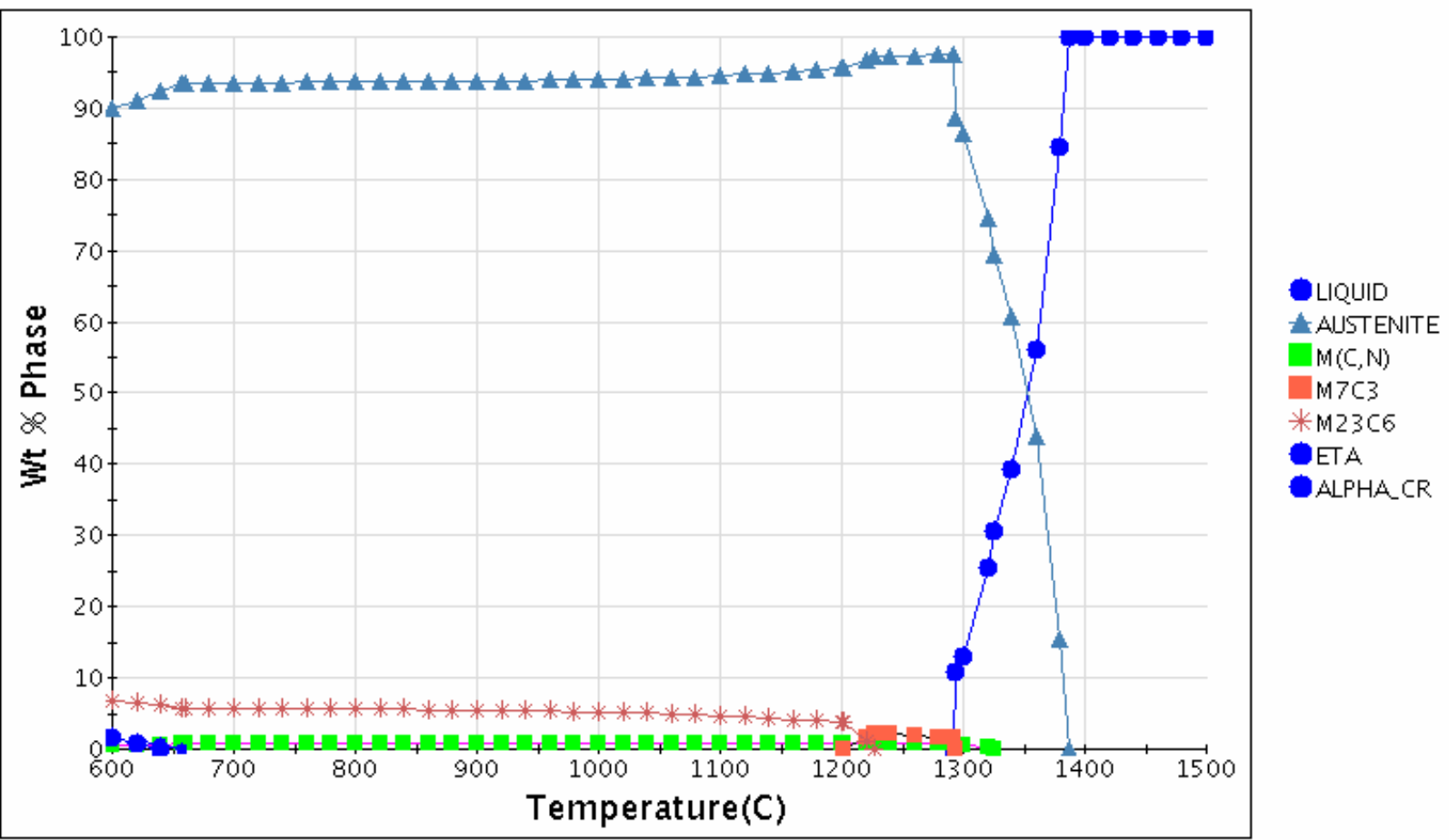

(a)

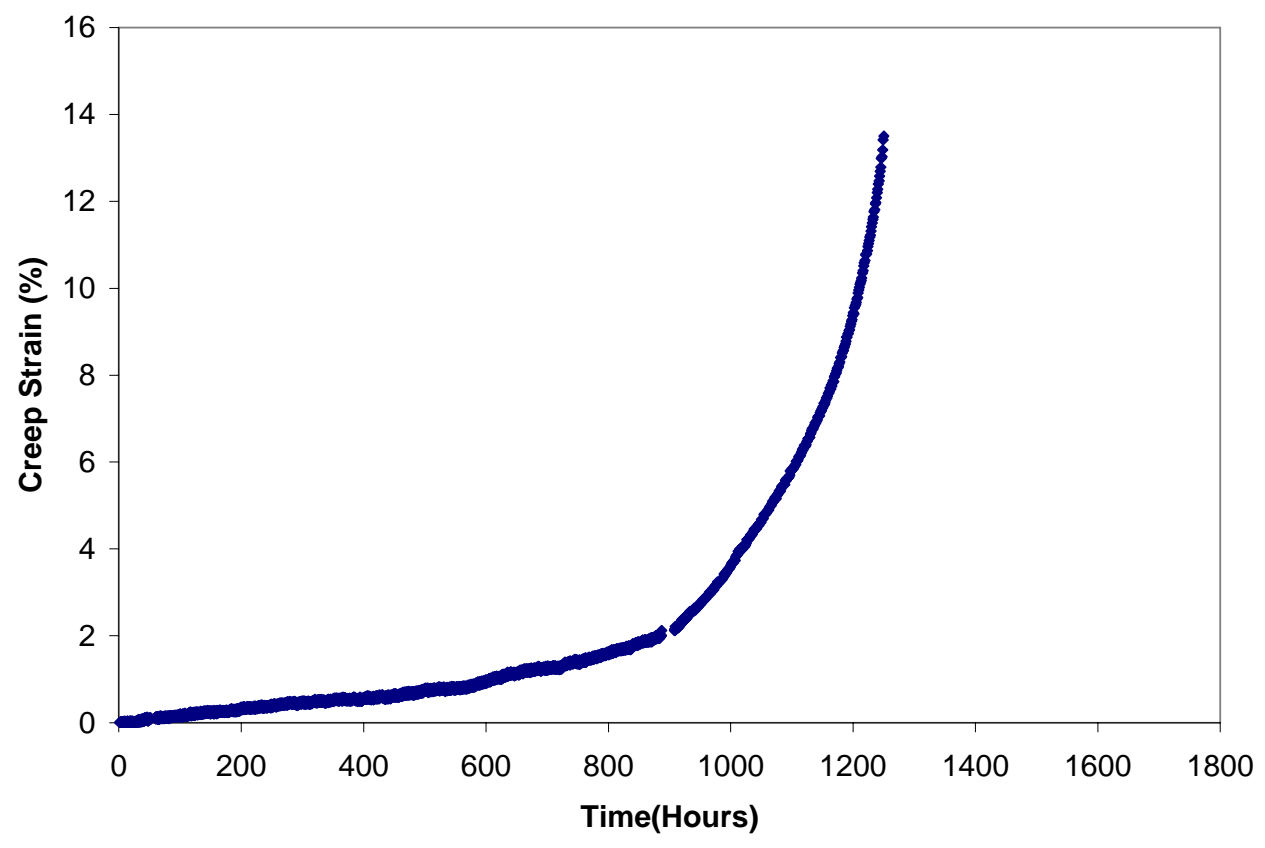

(b)

Figure 4.28: (a) Thermodynamic calculations for HP-15 and (b) creep strain as a function of time obtained during testing at $2200^{\circ} \mathrm{F}\left(\mathbf{1 2 0 4}^{\circ} \mathrm{C}\right)$ and $500 \mathrm{psi}$. Failure occurred after $1251 \mathrm{~h}$. 


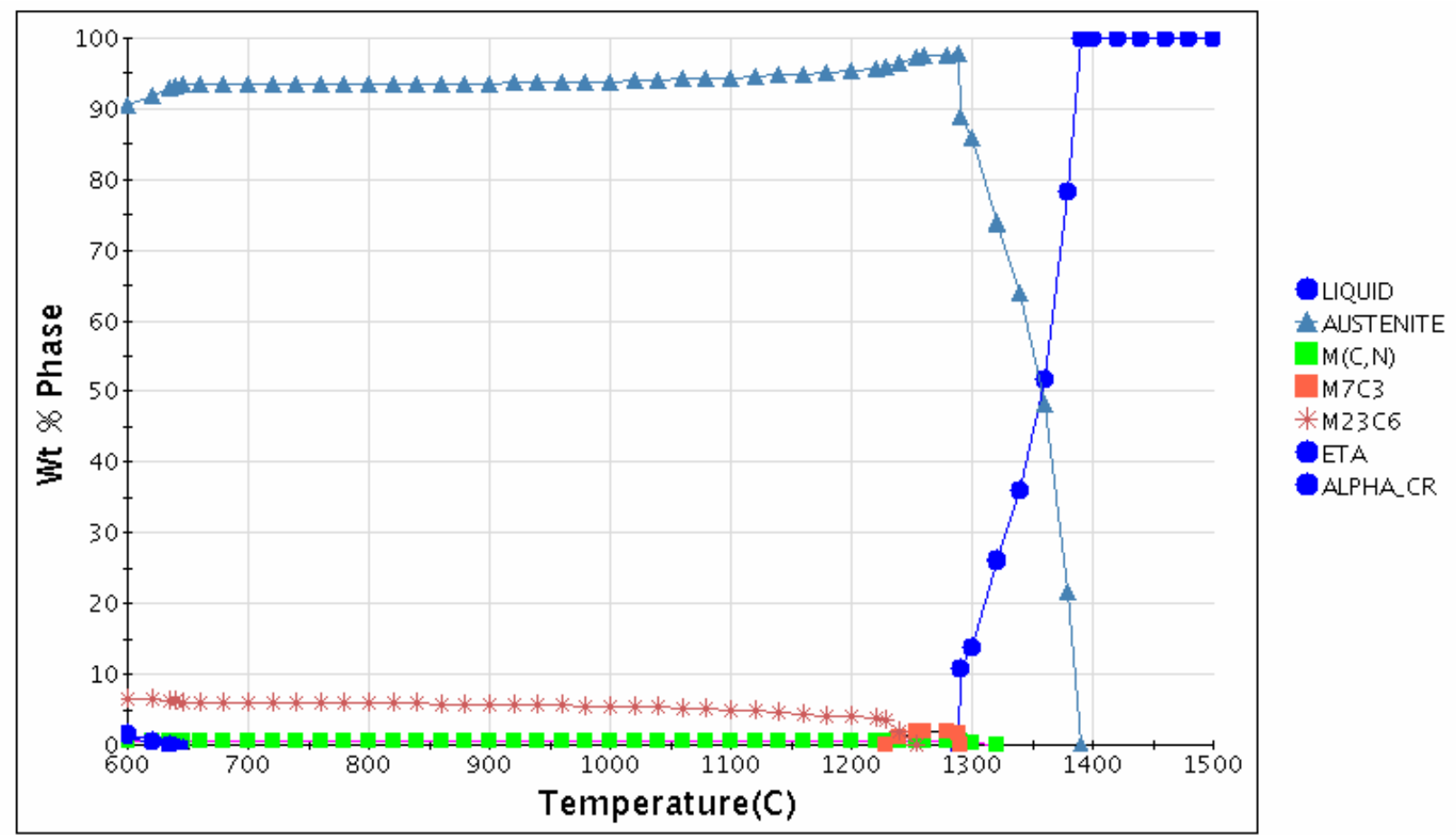

(a)

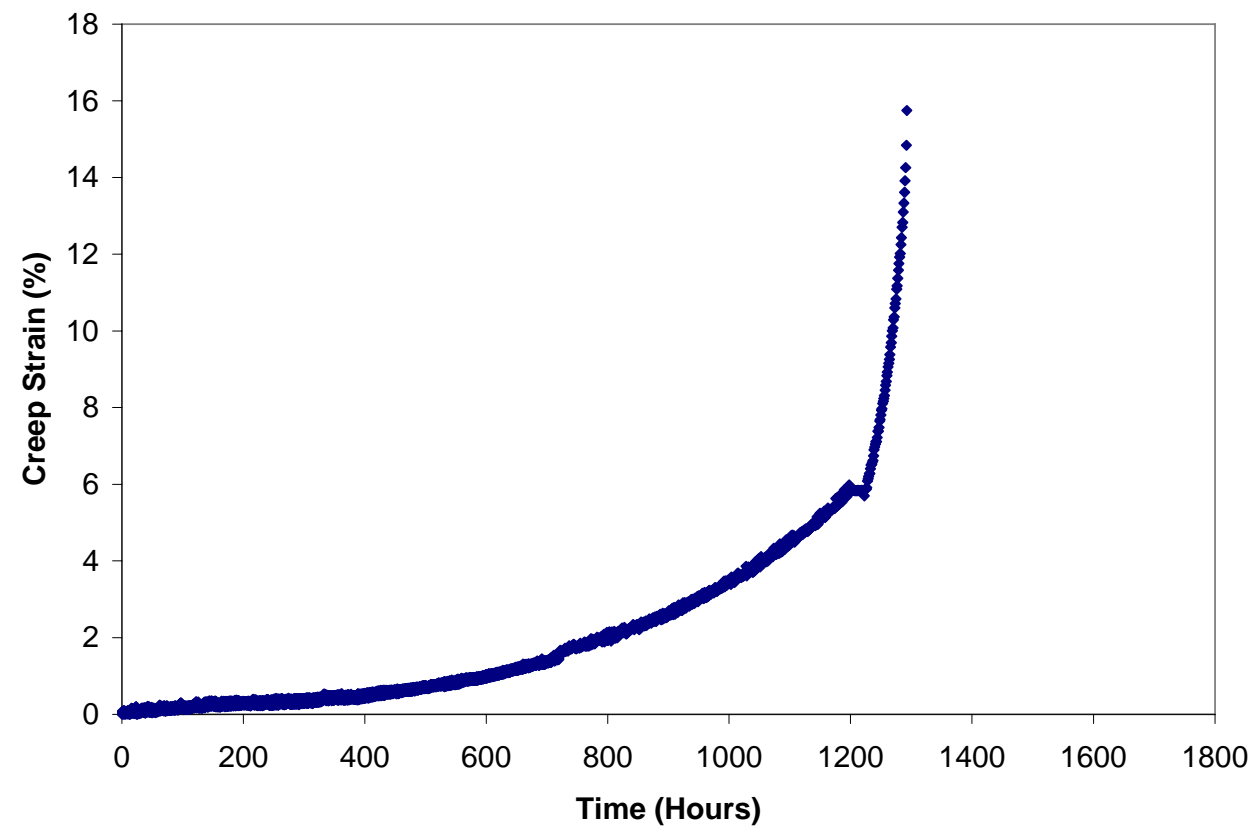

(b)

Figure 4.29: (a) Thermodynamic calculations for HP-16 and (b) creep strain as a function of time obtained during testing at $2200^{\circ} \mathrm{F}\left(1204^{\circ} \mathrm{C}\right)$ and 500 psi. Failure occurred after $1293 \mathrm{~h}$. 


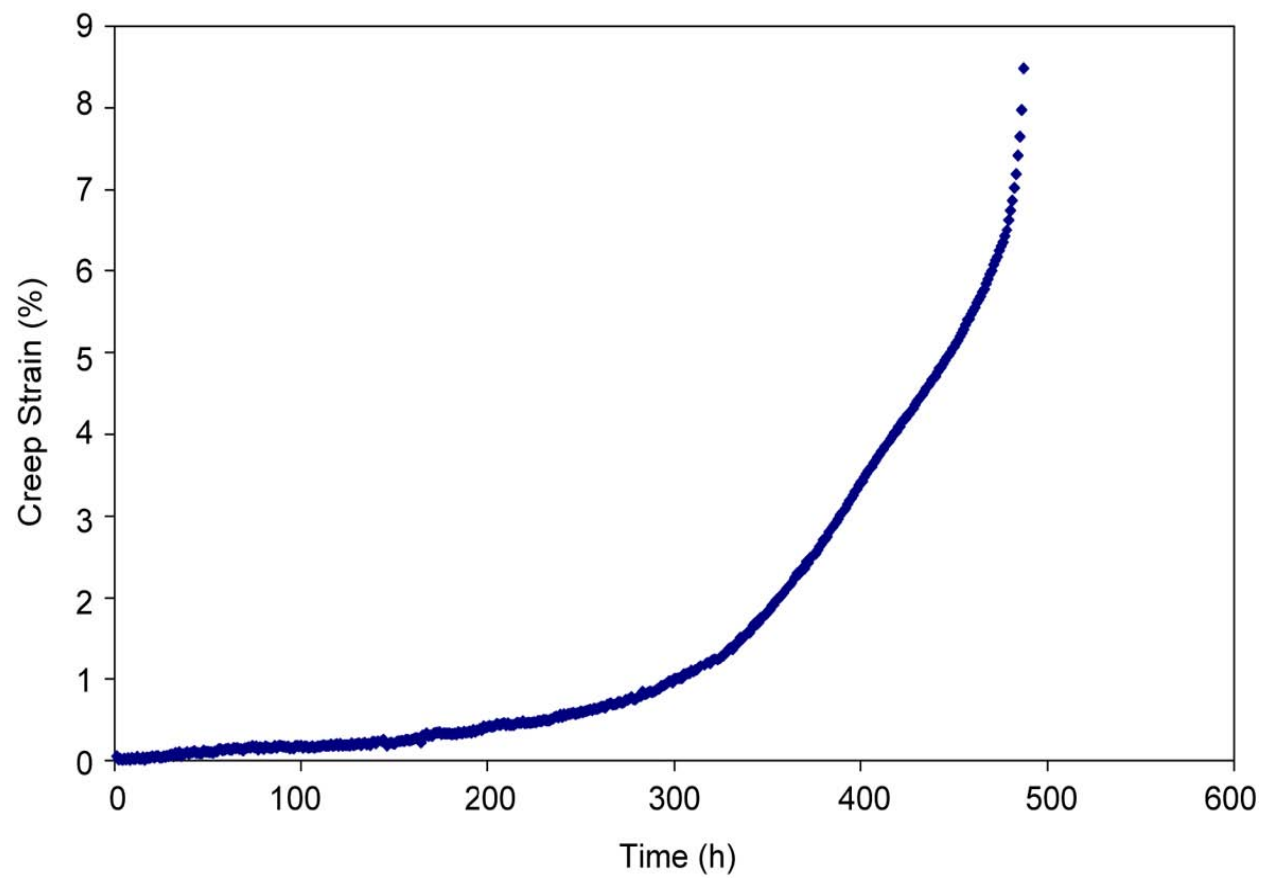

Figure 4.30: Creep strain as a function of time obtained for alloy Supertherm ${ }^{\mathrm{TM}}$ during testing at $2200^{\circ} \mathrm{F}\left(\mathbf{1 2 0 4}^{\circ} \mathrm{C}\right)$ and $500 \mathrm{psi}$. Time to rupture was $477 \mathrm{~h}$.

Figures 4.30 and 4.31 show the creep properties of commonly used commercial HP alloys Supertherm and S-22H. Figure 4.32 shows a comparison of the creep properties at $2200^{\circ} \mathrm{F}$ $\left(1204^{\circ} \mathrm{C}\right)$ and 500 psi of certain ORNL alloys with commercially available alloys. From this figure, it can be seen that alloys HP-7, HP-14R1, HP-15, and HP-16 show improved creep properties. Table 4.8 shows a summary of all alloys tested in the program and conditions of testing. As seen from this table, other alloys developed in this work also show creep properties better than existing alloys under other testing conditions.

\subsubsection{Thermodynamic Calculations and Creep Properties of New HK-type Alloys}

An approach similar to that used for the development of new HP alloys was used for the development of new HK alloys. Figure 4.33(a) shows the results of thermodynamic calculations, and 4.33(b) shows the creep curve obtained from an HK-3 alloy developed at ORNL. Figure 4.34 compares the creep rupture life of two HK alloys developed at ORNL with a commercially available HP-type alloy. The properties of the two HK alloys are better than an HP alloy at the test temperature of $2200^{\circ} \mathrm{F}\left(1204^{\circ} \mathrm{C}\right)$.

\subsubsection{Application of New Alloys in Industrial Use}

Radiant burner tube assemblies of the newly developed HP grades were produced by Duraloy and installed at Nucor Steel. Figure 4.35 shows a typical radiant tube assembly. Tubes have operated successfully for more than a year. Based on this experience, Nucor has ordered additional radiant burner tube assemblies. 


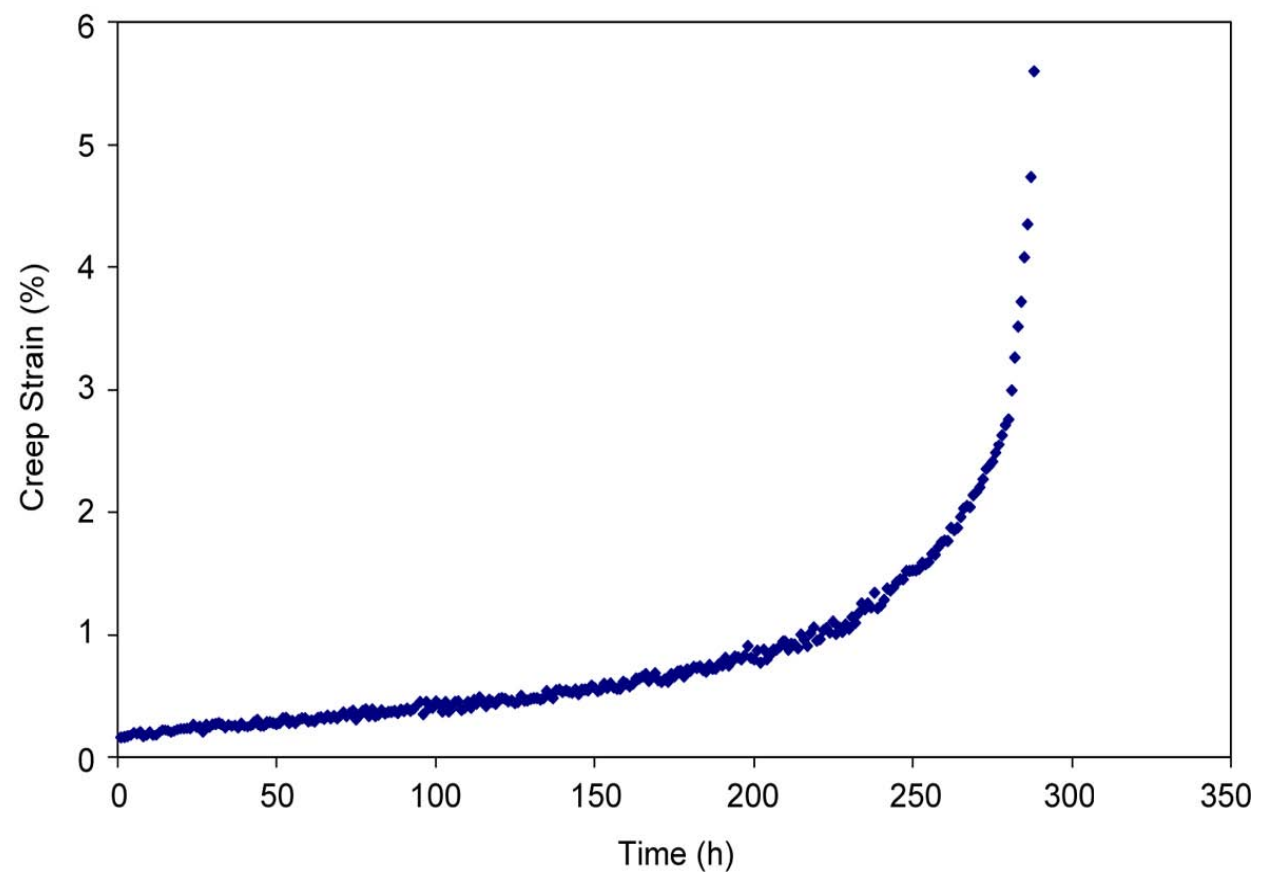

Figure 4.31: Creep strain as a function of time obtained for alloy S-22H during testing at $\mathbf{2 2 0 0}^{\circ} \mathbf{F}\left(\mathbf{1 2 0 4}^{\circ} \mathbf{C}\right)$ and $500 \mathrm{psi}$. Time to rupture was $289 \mathrm{~h}$.

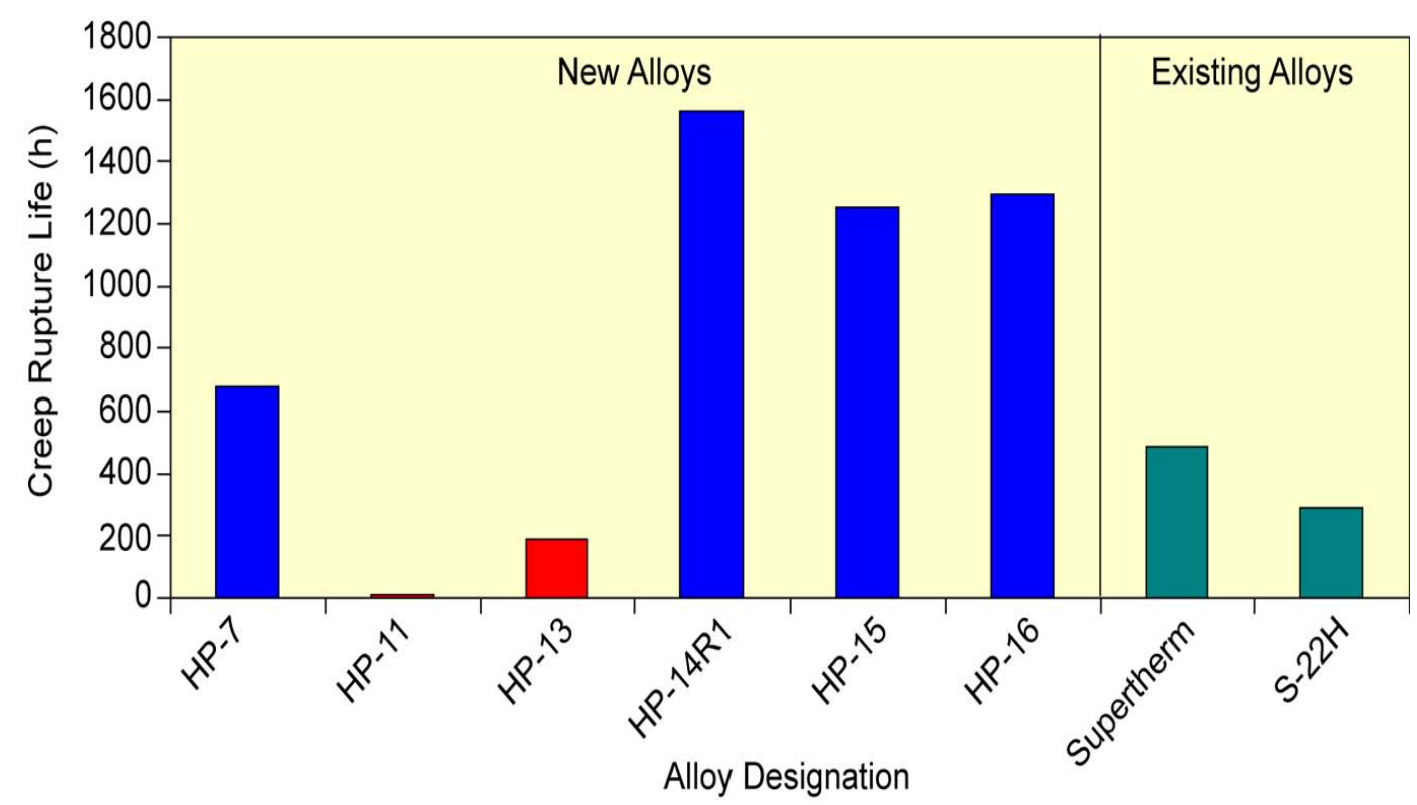

Figure 4.32: Additions of alloying elements to HP-11 results in new alloys with improved creep rupture life at $2200^{\circ} \mathrm{F}\left(\mathbf{1 2 0 4}^{\circ} \mathrm{C}\right)$ and $500 \mathrm{psi}$. Times to rupture of some of the new alloys are better than existing alloys. 
Table 4.8. Summary of Alloys Tested, Creep Testing Conditions, and Time to Rupture Under Different Testing Conditions

\begin{tabular}{|c|c|c|c|c|c|c|}
\hline $\begin{array}{c}\text { Alloy } \\
\text { Designation }\end{array}$ & $\begin{array}{c}1800^{\circ} \mathrm{F}, \\
4 \mathrm{ksi}\end{array}$ & $\begin{array}{c}2000^{\circ} \mathrm{F} \\
1 \mathrm{ksi}\end{array}$ & $\begin{array}{c}2000^{\circ} \mathrm{F} \\
2000 \text { psi }\end{array}$ & $\begin{array}{c}2000^{\circ} \mathrm{F} \\
2400 \mathrm{psi}\end{array}$ & $\begin{array}{c}2100^{\circ} \mathrm{F} \\
1 \mathrm{ksi}\end{array}$ & $\begin{array}{l}2200^{\circ} \mathrm{F} \\
100 \mathrm{ksi}\end{array}$ \\
\hline HP-1 & 762 & 1496 & 204 & 63 & --- & 274 \\
\hline HP-2 & 608 & 825 & 118 & 58 & $\begin{array}{ll}-- \\
--\end{array}$ & 233 \\
\hline HP-3 & 746 & --- & 404 & --- & --- & --- \\
\hline HP-4 & 984 & --- & 291 & --- & --- & --- \\
\hline HP-5 & 650 & $\begin{array}{l}-- \\
\end{array}$ & 401 & $\begin{array}{l}-- \\
\end{array}$ & --- & $\begin{array}{l}-- \\
\end{array}$ \\
\hline HP-6 & 979 & --- & 584 & --- & --- & 450 \\
\hline HP-7 & 1497 & --- & 1401 & --- & --- & 675 \\
\hline HP-10 & 770 & --- & --- & --- & 427 & 388 \\
\hline HP-11 & 922 & --- & 546 & -- & --- & 14 \\
\hline HP-12 & --- & --- & 20 & --- & --- & 5 \\
\hline HP-13 & 67 & --- & 43 & --- & --- & 189 \\
\hline HP-14 & --- & --- & 207 & --- & --- & --- \\
\hline HP-14R1 & 576 & $\begin{array}{l}-- \\
\end{array}$ & --- & $\begin{array}{l}-- \\
\end{array}$ & --- & 1558 \\
\hline HP-14R2 & --- & --- & 130 & --- & --- & --- \\
\hline HP-15 & 102 & --- & 139 & --- & --- & 1251 \\
\hline HP-16 & --- & --- & 338 & -- & --- & 1293 \\
\hline HP-16C & 585 & --- & --- & --- & --- & 477 \\
\hline Supertherm $^{\mathrm{TM}}$ & 971 & --- & --- & --- & --- & 488 \\
\hline MORE 2 & --- & --- & --- & --- & --- & 3147 \\
\hline $\mathrm{S}-22 \mathrm{H}$ & --- & --- & --- & --- & --- & 289 \\
\hline HK-3 & --- & --- & 460 & --- & --- & 831 \\
\hline HK-4 & 327 & --- & 196 & --- & --- & 526 \\
\hline HK-6 & --- & --- & 509 & --- & --- & 267 \\
\hline
\end{tabular}




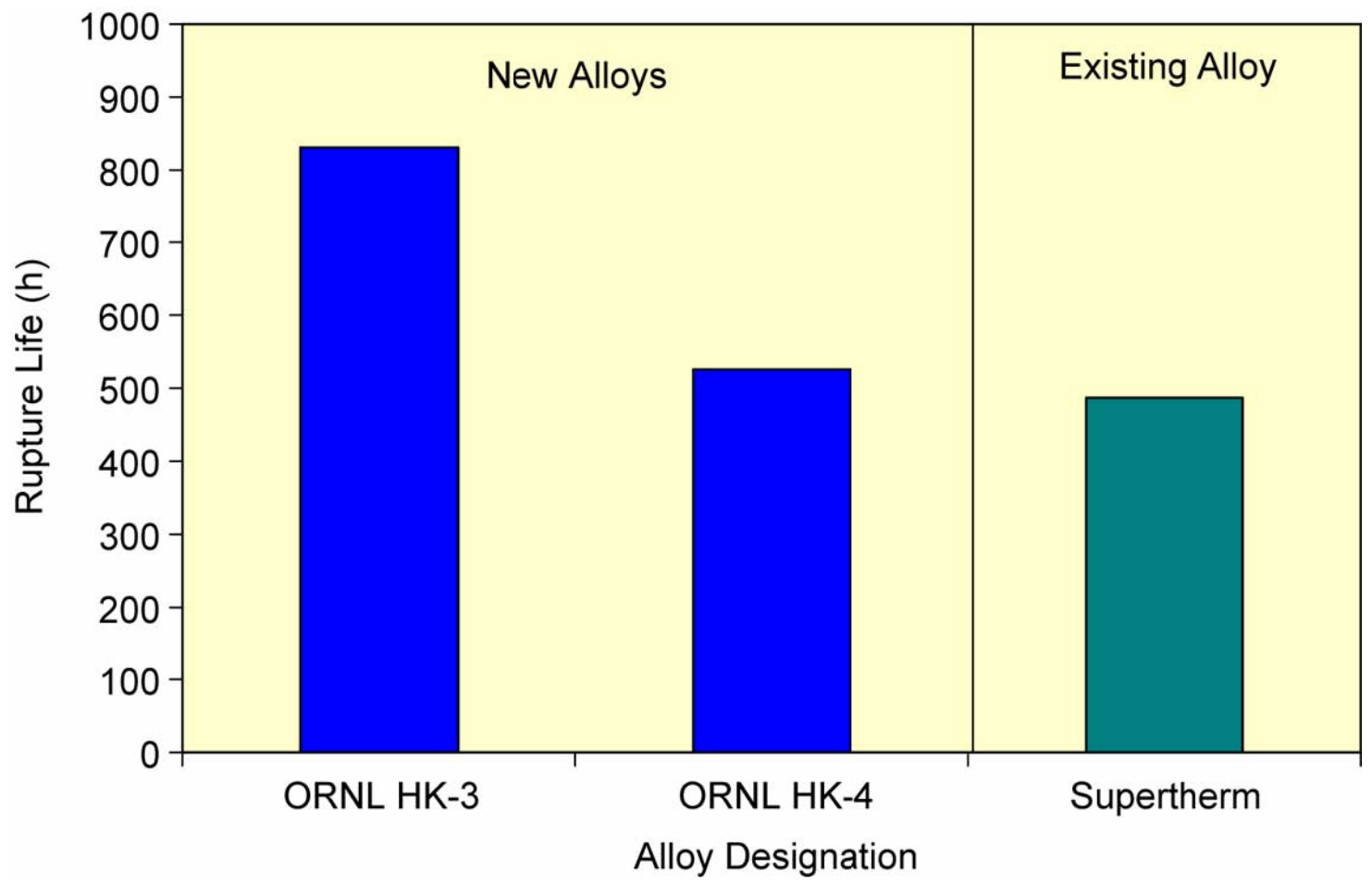

Figure 4.33: (a) Thermodynamic calculations for HK-3 and (b) creep strain as a function of time obtained during testing at $2200^{\circ} \mathrm{F}\left(1204^{\circ} \mathrm{C}\right)$ and $500 \mathrm{psi}$.

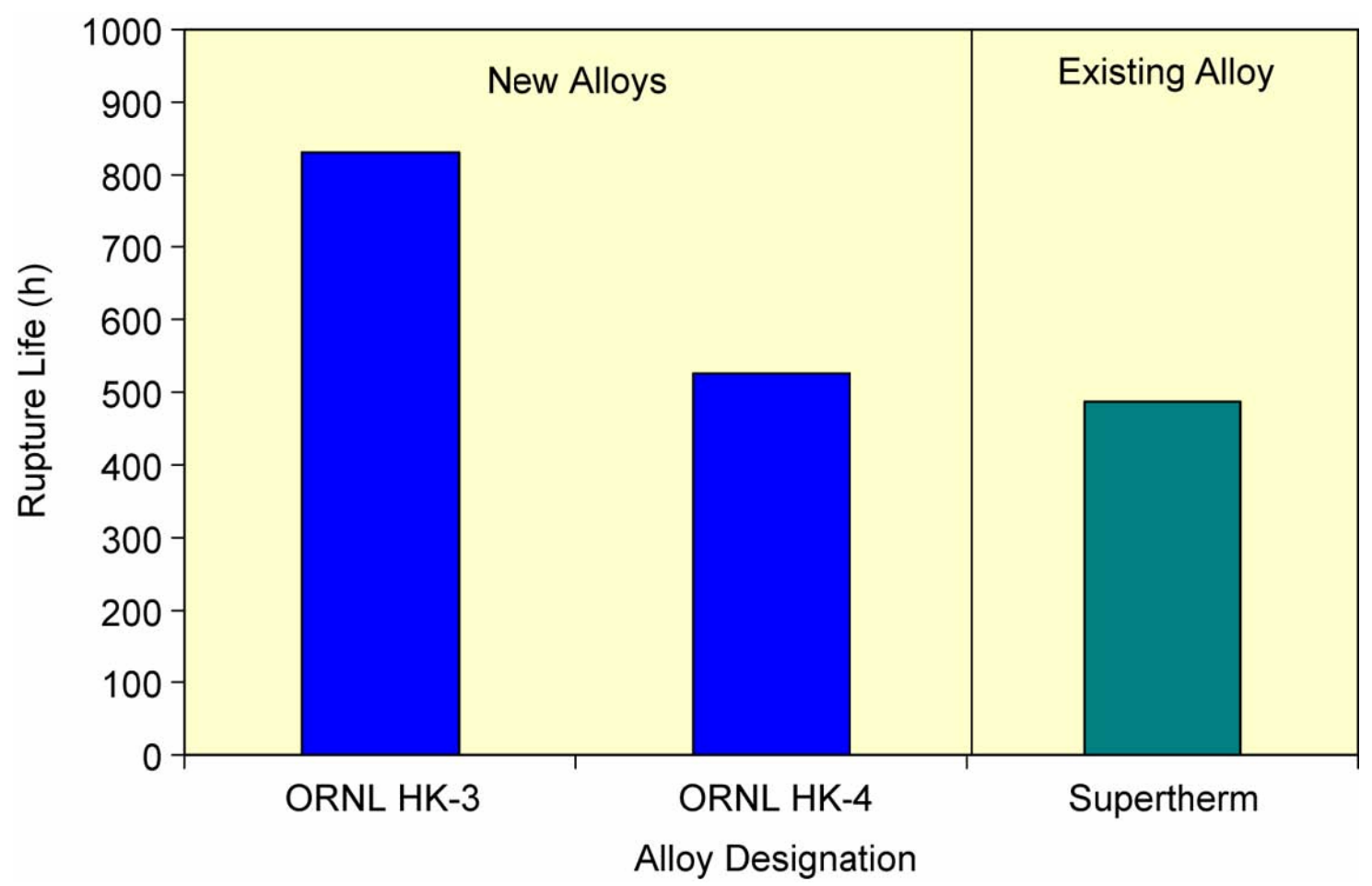

Figure 4.34: New HK alloys with improved creep rupture life at $2200^{\circ} \mathrm{F}\left(1204^{\circ} \mathrm{C}\right)$ and 500 psi and are comparable to Supertherm ${ }^{\mathrm{TM}}$, a commercial HP-type alloy. 


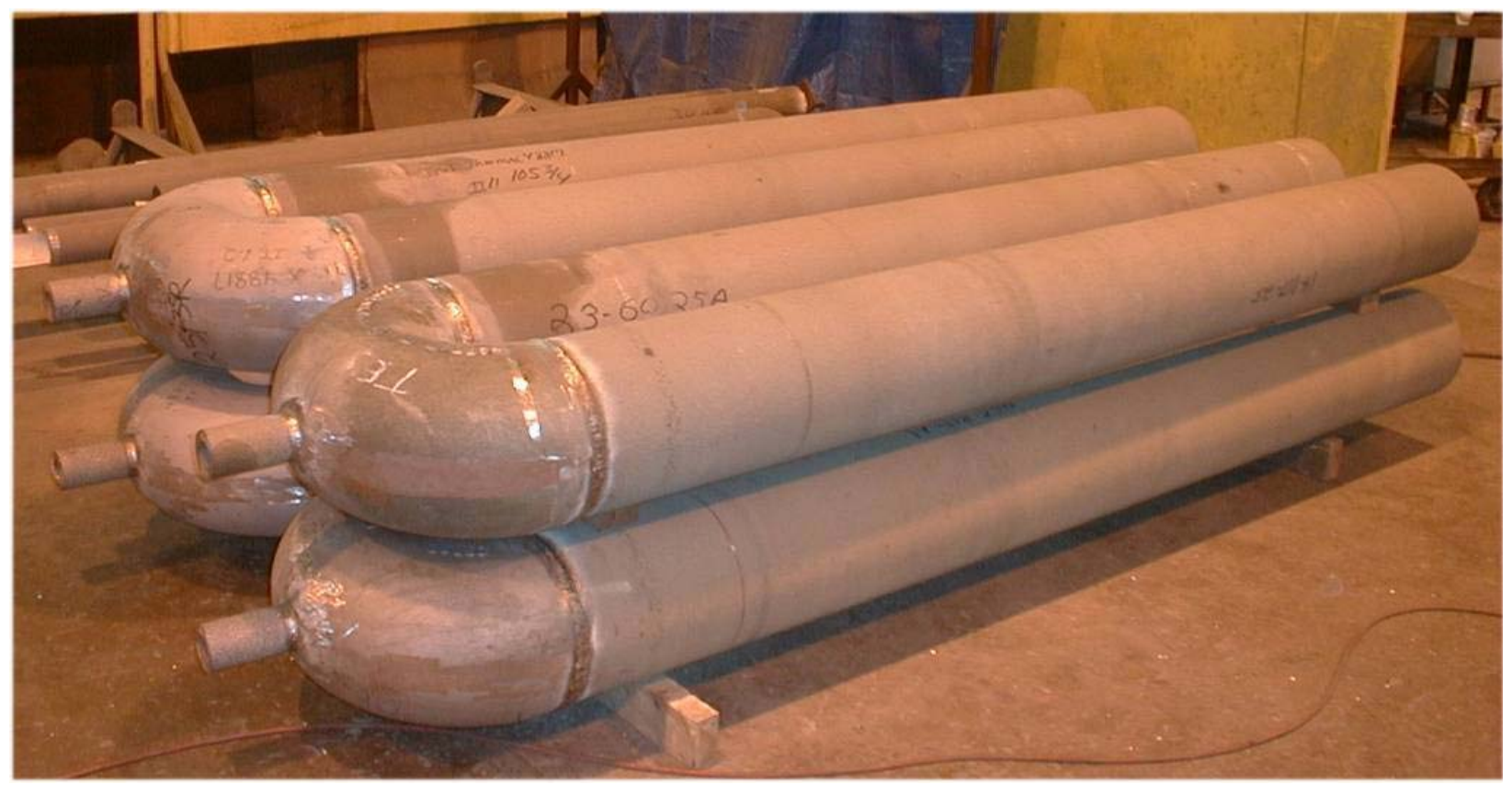

Figure 4.35: Typical radiant-tube assembly fabricated using newly developed HP alloys.

\subsection{Accomplishments}

This project accomplished the technical, technology transfer, and commercialization goals as described below.

\subsubsection{Technical Goals}

There were two major goals for this project: (1) increase the creep strength of current $\mathrm{HK}$ and $\mathrm{HP}$ steels by $50 \%$, and (2) increase the upper use temperature limit by 86 to $140^{\circ} \mathrm{F}$ (30 to $60^{\circ} \mathrm{C}$ ). Both of the goals were met during this project.

The HK alloy that met the project goal has been designated by Duraloy as TMA® 4701. Its nominal composition consists of Fe-25Ni-25Cr-0.7Mn-1.5Si-0.6C-0.2Mo-0.5W-0.3Nb. The HP alloy that met the project goal has been designated by Duraloy as TMA ${ }^{\circledR}$ 6301. Its nominal composition consists of Fe-34Ni-23Cr-1Mn-0.7Si-0.4C-0.5Mo-0.1W-0.3Nb.

\subsubsection{Technology Transfer}

The make-up of the project led by Duraloy, an alloy and component producer, made the technology transfer process easier. Many of the users were partners on the project and became familiar with the new technology through review meetings and visits to their plants by the Duraloy staff. It is through these efforts that Nucor Steel has been testing the radiant burner tube assemblies of the newly developed HP steel in their plant. Many of the mini-steel mills have shown great interest in using the new steels in their steel reheating furnaces. 
Two patent applications were filed. Duraloy will practice the patents for their core business and will license the technology for other applications. Some initial licensing inquiries have already been received.

The technology transfer of the results from this project is considered a success.

\subsubsection{Publications and Patents}

Publications and presentations from this project are listed below, and their full version is included in Appendix A of this report.

1. G. Muralidharan, N. D. Evans, K. C. Liu, J. G. Hemrick, M. L. Santella, P. J. Maziasz, and R. I. Pankiw, "Effect of Precipitation on Creep Properties of Certain Cast H-Series Austenitic Stainless Steels,” Proceedings of Materials Science \& Technology 2004, p. 651-661.

2. G. Muralidharan, N. D. Evans, K. C. Liu, J. G. Hemrick, M. L. Santella, P. J. Maziasz, and R. I. Pankiw, "Development of Stronger and More Reliable Cast Austenitic Stainless Steels (HSeries) Based on a Scientific Design Methodology,” Materials Science \& Technology 2004, 2004 ASM Materials Solutions Conference and Exposition, Columbus, Ohio, October 18-20, 2004.

3. G. Muralidharan, N. D. Evans, K. C. Liu, J. G. Hemrick, M. L. Santella, P. J. Maziasz, V. K. Sikka, and R. I. Pankiw, "Precipitation and its Effect of on the Creep Properties of certain Cast H-Series Austenitic Stainless Steels," to be published in the proceedings of the conference on Solid-Solid Phase Transformations in Inorganic Materials 2005, May 29-June 3, 2005, Phoenix, Arizona.

4. EERE/EDER FY05 Critical Milestone Outcome, G. Muralidharan and V. K. Sikka, quarterly progress report for April 1-June 20, 2005.

In addition to publications and presentations, the following two patent disclosures were made from this project:

1. G. Muralidharan, V. K. Sikka, P. J. Maziasz, and R. I. Pankiw, "Low-Cost, Cast, HeatResistant Austenitic Stainless Steel Compositions having Improved High-Temperature Creep Properties,” ID 1445C, S-105,041, submitted to USPO on August 27, 2004.

2. G. Muralidharan, V. K. Sikka, P. J. Maziasz, and R. I. Pankiw, "Cast Heat-Resistant Austenitic Stainless Steels with Improved High Temperature Creep Properties and Balanced Alloying Element Additions (Rev. 1)," ID 1300001544, S-105-146, submitted to UT/Battelle in April 2005.

\subsubsection{Commercialization}

The progress made toward the commercialization included the following:

1. A data sheet comparing creep properties of newly developed HK and HP grades with currently used alloys was prepared and sent to the industrial users of HK and HP grade steels.

2. Radiant burner tube assemblies of the newly developed HP grades were produced and installed at Nucor Steel. The tubes have operated successfully for nearly 10 months. Based on 
this experience, Nucor has ordered additional radiant burner tube assemblies.

3. Based on the data sheet, Nucor plants in Indiana and Alabama have shown strong interest in installing uncooled rolls in their thin slab reheating furnaces to replace water-cooled rolls. Similar interest has been shown by Steel Dynamics. A proposal requesting DOE funding for uncooled roll application for the new HP grades was submitted to DOE-ITP during October 2005.

4. Air Products has shown a strong interest in using the new high-strength HP grade in furnace tubes for its hydrogen cracking furnace.

5. Discussions are under way with additional customers for many other applications.

Because Duraloy is a commercial producer of HK and HP grades, it is relatively easy for the company to introduce the newly developed steels to customers as higher performance materials.

It should be noted that the newly developed grades of HK and HP are no more expensive than the standard grades. Furthermore, they have strength and creep properties exceeding Supertherm $^{\mathrm{TM}}$, but are free of expensive cobalt additions. In addition, the weldability of the newly developed grades is similar to that of the currently used grades.

\subsection{Summary and Conclusions}

\subsubsection{Summary}

The research and development work was conducted by a team consisting of Duraloy Technologies, ISG, The Timken Company, Energy Industries of Ohio, Harper International, IPSCO, Nucor Steel, and ORNL.

This project focused on developing and utilizing a computational method for identifying new cast austenitic steel compositions with 50\% higher creep strength and their upper use temperature extended by 86 to $140^{\circ} \mathrm{F}$ ( 30 to $60^{\circ} \mathrm{C}$ ) as compared to commonly used grades $\mathrm{HK}$ and HP. The computational method used thermodynamic modeling that allowed the prediction of volume percent of phases and their stability as a function of temperature. The predicted volume percent of phases was validated by using detailed microstructural analysis. The creep rupture strength data for a range of alloys was correlated with the phase volume percent. These correlations were used as a guide to design new alloy compositions to meet the project goals of higher strength and increasing the upper use temperature. The computational method was able to help design new alloys using lower cost elements.

The newly designed alloys were melted into 25- to 50-lb heats and cast into slab. Test bars from experimental heats were creep-tested at $2200^{\circ} \mathrm{F}\left(1204^{\circ} \mathrm{C}\right)$ with some tests done at lower temperatures; one test was done at $2300^{\circ} \mathrm{F}\left(1260^{\circ} \mathrm{C}\right)$. The experimental alloys that met the project objective were melted in large quantities at Duraloy Technologies, Inc., and cast into tubes. The cast tubes were fabricated into radiant burner tube assemblies, which have been in testing at Nucor Steel for nearly 12 months.

The new alloy compositions have been introduced to steel and chemical industries for other applications, including uncooled rolls for steel reheating furnaces and tubes for steam hydrogen cracking furnaces. Two patent applications were prepared on the new compositions. 


\subsubsection{Conclusions}

The computational model developed during this project provides the opportunity not only to design HK and HP steel compositions that meet the strength and upper use temperature requirements of industry but also to select lower cost alloying elements that produce less or none of the embrittling phases during application. The results of the project can give the United States a new lead in producing higher strength $\mathrm{H}$-Series stainless steels with very significant savings of energy and associated cost savings.

The following are the important conclusions from this project:

1. Developed a computational method for designing high-strength low-cost versions of cast austenitic stainless steels of standard grades known as HK and HP steels.

2. Validated computational method for phase prediction in the HK and HP steels by microstructural analysis.

3. Used validated computational method to develop new compositions of HK and HP steels. Two patents have been filed to cover the newly developed compositions.

4. Validated creep data on newly designed compositions of both HK and HP steels at test temperature of $2200^{\circ} \mathrm{F}\left(1204^{\circ} \mathrm{C}\right)$ and stress of 500 psi.

5. Melted designed alloys with validated creep performance and cast into tubes at Duraloy.

6. Fabricated new HP alloy tubes into radiant burner tubes, which have been nearly a 10-month operation at Nucor Steel.

7. Ensured that project has met the proposed goals of extending the upper use temperature by 86 to $140^{\circ} \mathrm{F}$ (30 to $60^{\circ} \mathrm{C}$ ).

8. Established that energy savings for application identified to date have been shown to be 15.6 trillion Btu/year by 2015 to 2020. Higher energy savings will result as new applications are implemented.

9. Projected that the outcome from the proposed program has given the United States a new lead in higher strength H-Series stainless steels with very significant savings of energy and associated cost savings.

\subsubsection{Commercialization Aspects (Plans, Status, Barriers)}

The commercialization plans for this project included the following:

1. Being a material and component supplier, it is easy for Duraloy to introduce a new higher strength version of the alloy.

2. Several potential users of the cast austenitic stainless steels are partners in the project and, thus, have been briefed on the new advances made during this project. This creates a user demand for these higher strength materials. For example, two Nucor Steel plants and Steel Dynamics are requesting the use of new materials as uncooled rolls in steel reheating furnaces.

3. User partners have already stepped up in installing radiant burner tubes from the new alloys in their production plant. They have operated successfully for nearly 10 months. Such success will encourage other companies to use new materials for their applications.

4. Broad-based information dissemination on these alloys was planned by presenting papers at 
national technical meetings. Three papers were presented at national technical meetings.

5. A comparative data sheet for customer information has been prepared. More data are needed to prepare a comprehensive data sheet.

\subsubsection{Barriers}

The following are the barriers for a broad-based acceptance for new grades:

1. More creep data are needed over a broader test temperature range. This project only focused on data at $2200^{\circ} \mathrm{F}\left(1204^{\circ} \mathrm{C}\right)$.

2. Creep data are needed for test times exceeding 10,000 h. Data in this project only reached test times of approximately $2000 \mathrm{~h}$.

3. Although the new grades weld similar to standard grades, in order to take full advantage of higher base metal strength, additional development is needed in weld filler wire compositions with strength matching the base metal.

\subsection{Recommendations}

This project accomplished all of the planned goals. However, the following steps were recommended to take further advantage of this project:

1. Creep data are the limiting factors in use of these steel materials for very high-temperature industrial applications. These data are needed in the test temperature range of 1650 to $2200^{\circ} \mathrm{F}$ (900 to $1204^{\circ} \mathrm{C}$ ) and for test times exceeding $10,000 \mathrm{~h}$ and for three to five different heats of a specified composition.

2. This project has developed the higher strength versions of HK and HP steels. However, they will still be welded by the lower-strength-version weld filler wire. The computational approach developed for base metal in this project should also be extended to develop new weld filler compositions that match or exceed the strengths of the base metal compositions.

3. For some high-risk applications, such as replacing water-cooled rolls with uncooled rolls, there is a need for DOE funding to minimize the use risk. However, if successful, this application has the potential for the most energy savings.

4. No corrosion data were developed for newly developed steels in this project. There is a great need to generate data in oxidizing, carburizing, and sulfidizing environments as part of a database/knowledge base effort.

\section{Subject Inventions}

1. G. Muralidharan, V. K. Sikka, P. J. Maziasz, and R. I. Pankiw, "Low-Cost, Cast, HeatResistant Austenitic Stainless Steel Compositions having Improved High-Temperature Creep Properties,” ID 1445C, S-105,041, submitted to USPO on August 27, 2004.

2. G. Muralidharan, V. K. Sikka, P. J. Maziasz, and R. I. Pankiw, "Cast Heat-Resistant Austenitic Stainless Steels with Improved High Temperature Creep Properties and Balanced Alloying Element Additions (Rev. 1),” ID 1300001544, S-105-146, submitted to UT/Battelle in April 2005. 


\section{Commercialization Possibilities}

The progress made toward the commercialization included the following:

1. A data sheet comparing creep properties of newly developed HK and HP grades with currently used alloys was prepared and sent to the industrial users of HK and HP grades.

2. Radiant burner tube assemblies of the newly developed HP grades were produced and installed at Nucor Steel. The tubes have operated successfully for nearly 12 months. Based on this experience, Nucor has ordered additional radiant burner tube assemblies.

3. Based on the data sheet, Nucor plants in Indiana and Alabama have shown strong interest in installing uncooled rolls in their thin slab reheating furnaces to replace water-cooled rolls. Similar interest has been shown by Steel Dynamics. A proposal requesting DOE funding for uncooled roll application for the new HP grades was submitted to DOE-ITP during October 2005.

4. Air Products has shown a strong interest in using the new high-strength HP grade as furnace tubes for their hydrogen cracking furnace.

5. Discussions are under way with other customers for many other applications.

Being a commercial producer of HK and HP grades, it is relatively easy for Duraloy to introduce the newly developed grades to our customers as higher performance materials.

It should be noted that the newly developed grades of HK and HP are no more expensive than the standard grades. Furthermore, they have strength and creep properties exceeding Supertherm ${ }^{\mathrm{TM}}$, but are free of expensive cobalt additions. In addition, the weldability of the newly developed grades is similar to that of the currently used grades.

\section{Plan for Future Collaboration}

Implementation is planned for the newly developed alloys (HK and HP) in several industries including steel, chemical, and heat treating.

\section{Conclusions}

The computational model developed during this project provides the opportunity not only to design HK and HP steel compositions that meet the strength and upper use temperature requirements of industry but also to select lower cost alloying elements that produce less or none of the embrittling phases during application. The results of the project can give the United States a new lead in producing higher strength $\mathrm{H}$-Series stainless steels with very significant savings of energy and associated cost savings.

The following are the important conclusions from this project:

1. Developed a computational method for designing high-strength low-cost versions of cast austenitic stainless steels of standard grades known as HK and HP steels.

2. Validated computational method for phase prediction in the HK and HP steels by microstructural analysis. 
3. Used validated computational method to develop new compositions of HK and HP steels. Two patents have been filed to cover the newly developed compositions.

4. Validated creep data on newly designed compositions of both HK and HP steels at test temperature of $2200^{\circ} \mathrm{F}\left(1204^{\circ} \mathrm{C}\right)$ and stress of $500 \mathrm{psi}$.

5. Melted designed alloys with validated creep performance and cast into tubes at Duraloy.

6. Fabricated new HP alloy tubes into radiant burner tubes, which have been nearly a 10-month operation at Nucor Steel.

7. Ensured that project has met the proposed goals of extending the upper use temperature by 86 to $140^{\circ} \mathrm{F}$ (30 to $60^{\circ} \mathrm{C}$ ).

8. Established that energy savings for application identified to date have been shown to be 15.6 trillion Btu/year by 2015 to 2020. Higher energy savings will result as new applications are implemented.

9. Projected that the outcome from the proposed program has given the United States a new lead in higher strength H-Series stainless steels with very significant savings of energy and associated cost savings.

\section{References}

1. P. J. Maziasz, "Developing an Austenitic Stainless Steel for Improved Performance in Advanced Fossil Power Facilities,” Journal of Metals, 41, 14-20 (July 1989).

2. P. J. Maziasz, "Microstructural Stability and Control for Improved Irradiation Resistance and for High-Temperature Strength of Austenitic Stainless Steels," pp. 116-161 in MiCon '86: Optimization of Processing, Properties and Service Performance Through Microstructural Control, ASTM STP 979, eds. B. L. Bramfitt, R. L. Benn, C. R. Brinkman, and G. F. Vander Voort, Am. Soc. For Testing and Materials, Philadelphia, Pennsylvania (1988).

3. R. W. Swindeman and P. J. Maziasz, "The Mechanical and Microstructural Stability of Austenitic Stainless Steels Strengthened by MC-Forming Elements,” pp. 33-42 in Creep: Characterization, Damage and Life Assessment, ASM International, Materials Park, Ohio (1992).

4. R. W. Swindeman and P. J. Maziasz, "The Effect of MC Forming Additions and 10\% Cold Work on the High Temperature Strength of 20Cr-30Ni-Fe Alloys,” pp. 251-259 in HeatResistant Materials, eds. K. Natesan and D. J. Tillack, ASM International, Materials Park, Ohio (1991).

5. M. A. Harper, G. D. Smith, P. J. Maziasz, and R. W. Swindeman, "Selecting and Developing Advanced Alloys for Creep-Resistance for Microturbine Recuperator Applications," paper published in Proceedings of ASME Turbo Expo 2001, June 4-7, 2001, New Orleans, Louisiana.

6. P. J. Maziasz, R. W. Swindeman, M. T. Kiser, C. W. Siebenaler, and M. E. Frary, "Development of Low-Cost Austenitic Stainless Diesel Engine Components with Enhanced High-Temperature Reliability," DOE Office of Transportation Technology Heavy Vehicle Propulsion Materials Program Quarterly Progress Report, for Period Ending March 31, 2001.

7. Q. Chen and B. Sundman, “TQ-1 Thermodynamic Calculation Interface: Programmers' Guide and Examples,” Thermo-Calc AB, 1999. 
8. A. Jansson and B. Sundman, "Simulation of Solidification of Light Alloys using a Thermodynamic Database (1997)." In A. Jansson Phase Diagram Evaluation and Applications in Light Metal Alloys, KTH Ph.D. Dissertation. C. H. Gulliver, J. Inst. Metals, 9, 120 (1913).

9. N. Saunders, "Phase Diagram Calculations for Commercial Al-Alloys," $5^{\text {th }}$ Intl. Conf. on AlAlloys, Grenoble, France, 1996.

10. B. Sundman, B. Jansson, and M. Schalin, "Thermodynamic Calculations Made Easy,” J. Phase Equilibria, 573-562 (1993).

11. E. Scheil, E. Metallkde, 34, 70 1942).

12. Email communication with john Hoffman of Air Products and Chemicals, Inc. and Don Voke of Duraloy Technologies, Inc., dated October 25, 2005.

13. "Today's Hydrogen Production Industry," http://www.fe.doe.gov/programs/fuels/ hydrogen/current technology.html.

14. Energy and Environmental Profile, prepared for ORNL and U.S. Department of Energy, Industrial Technologies Program by Energetics, Inc., October 2003.

15. G. Muralidharan, N. D. Evans, K. C. Liu, J. G. Hemrick, M. L. Santella, P. J. Maziasz, and R. I. Pankiw, "Effect of Precipitation on Creep Properties of Certain Cast H-Series Austenitic Stainless Steels,” Proceedings of Materials Science \& Technology 2004, pp. 651661.

16. G. Muralidharan, N. D. Evans, K. C. Liu, J. G. Hemrick, M. L. Santella, P. J. Maziasz, V. K. Sikka, and R. I. Pankiw, "Precipitation and Its Effect on the Creep Properties of Certain Cast H-Series Austenitic Stainless Steels," to be published in the proceedings of the conference on Solid-Solid Phase Transformations in Inorganic Materials 2005, May 29-June 3, 2005, Phoenix, Arizona. 


\section{DISTRIBUTION}

Vinod K. Sikka, ORNL, Bldg. 4508, MS 6083

G. Muralidharan, ORNL, Bldg. 4508, MS 6083

Philip J. Maziasz, ORNL, Bldg. 4500S, MS 6115

Roman I. Pankiw, Duraloy Technologies, Inc., 120 Bridge Street, Scottdale, PA 15683-0081

Ashok Choudhury, ORNL, Bldg. 4500N, MS 6196

Ronald Ott, ORNL, Bldg. 4508, MS 6083

Sharon M. Robinson, ORNL, Bldg. 4500N, MS 6181

Steven J. Zinkle, ORNL, Bldg. 4500S, MS 6132

Sarah A. Dillich, U.S. Department of Energy, Industrial Technologies Program, EE-2F, 1000 Independence Avenue S.W., Washington, DC 20585

Mary H. Rawlins, DOE ORNL Site Office, Bldg. 4500N, MS 6269

Office of Scientific and Technical Information, P.O. Box 62, Oak Ridge, TN 37831 